\title{
Systematic Review \\ Motor Evoked Potential Warning Criteria in Supratentorial Surgery: A Scoping Review
}

\author{
Evridiki Asimakidou ${ }^{1}$, Pablo Alvarez Abut ${ }^{1,2}$, Andreas Raabe ${ }^{1}$ and Kathleen Seidel ${ }^{1, *}$ (i) \\ 1 Department of Neurosurgery, Inselspital, Bern University Hospital, 3010 Bern, Switzerland; \\ evridiki.asimakidou@students.unibe.ch (E.A.); pabloalvarezabut@gmail.com (P.A.A.); \\ Andreas.Raabe@insel.ch (A.R.) \\ 2 Department of Neurosurgery, Clínica 25 de Mayo, 7600 Mar del Plata, Argentina \\ * Correspondence: kathleen.seidel@insel.ch
}

check for updates

Citation: Asimakidou, E.; Abut, P.A.;

Raabe, A.; Seidel, K. Motor Evoked

Potential Warning Criteria in

Supratentorial Surgery: A Scoping

Review. Cancers 2021, 13, 2803.

https: / / doi.org/10.3390/

cancers13112803

Academic Editor: Shinji Kawabata

Received: 29 April 2021

Accepted: 31 May 2021

Published: 4 June 2021

Publisher's Note: MDPI stays neutral with regard to jurisdictional claims in published maps and institutional affiliations.

Copyright: (C) 2021 by the authors. Licensee MDPI, Basel, Switzerland. This article is an open access article distributed under the terms and conditions of the Creative Commons Attribution (CC BY) license (https:// creativecommons.org/licenses/by/ $4.0 /)$.
Simple Summary: Motor evoked potential (MEP) alarm criteria may have an important impact on the preservation of motor function in supratentorial neurosurgical procedures. However, no consensus exists regarding the optimal cut-off values and interpretation of MEP signal changes. In addition, their performance as diagnostic and surrogate biomarkers has not been adequately investigated. The existing clinical studies that utilized alarm criteria are heterogeneous, rendering quantitative evidence synthesis problematic. In this study, we sought to summarize the pertinent literature using an emerging synthesis methodology, namely a scoping review. The objective was to assess the extent and range of available evidence, identifying research gaps, clarifying concepts, and providing insights for further research. Due to the heterogeneity of studies, we applied a descriptive approach, in particular by visualizing instead of pooling the data. A comprehensive overview of MEP warning criteria has not been provided yet, and therefore, our study should pave the way for future research.

Abstract: During intraoperative monitoring of motor evoked potentials (MEP), heterogeneity across studies in terms of study populations, intraoperative settings, applied warning criteria, and outcome reporting exists. A scoping review of MEP warning criteria in supratentorial surgery was conducted in accordance with the Preferred Reporting Items for Systematic reviews and Meta-Analyses extension for Scoping Reviews (PRISMA-ScR). Sixty-eight studies fulfilled the eligibility criteria. The most commonly used alarm criteria were MEP signal loss, which was always a major warning sign, followed by amplitude reduction and threshold elevation. Irreversible MEP alterations were associated with a higher number of transient and persisting motor deficits compared with the reversible changes. In almost all studies, specificity and Negative Predictive Value (NPV) were high, while in most of them, sensitivity and Positive Predictive Value (PPV) were rather low or modest. Thus, the absence of an irreversible alteration may reassure the neurosurgeon that the patient will not suffer a motor deficit in the short-term and long-term follow-up. Further, MEPs perform well as surrogate markers, and reversible MEP deteriorations after successful intervention indicate motor function preservation postoperatively. However, in future studies, a consensus regarding the definitions of MEP alteration, critical duration of alterations, and outcome reporting should be determined.

Keywords: motor evoked potential; warning criteria; glioma surgery; aneurysm clipping; motor deficit; intraoperative monitoring; intraoperative neurophysiology

\section{Introduction}

During supratentorial surgery, risk stratification and intraoperative guidance of the surgical strategy depend on various tools. Intraoperative monitoring of motor evoked potentials (MEPs) enables real-time assessment of functional integrity of motor pathways and has become a valuable adjunct in neurosurgical procedures [1,2]. Minimizing the risk 
of disabling motor deficits is the main factor during surgery in eloquent motor areas. At the same time, this constitutes the major challenge for the neurosurgeon, who aims to achieve the best possible surgical outcome, such as the maximal extent of tumor removal, without compromising the patient's functional status.

Classical, intraoperative stimulation for MEP can be delivered through scalp electrodes (transcranial electrical stimulation, TES) or directly over the exposed motor cortex via strip electrodes (direct cortical stimulation, DCS). The responses are recorded from the target muscles (muscle MEPs) or (less frequent) with epidural electrodes (D wave) [3,4]. Intraoperative recording of muscle MEPs requires trains of stimuli to overcome the aesthetic inhibition of the lower motor neuron excitability by temporal and spatial summation of the excitatory postsynaptic potentials [5]. Stimulating scalp montages are derived from the 10/20 international system. Scalp stimulating arrays are placed at measured sites over the motor cortex to allow hemispheric stimulation $(\mathrm{C} 3 / \mathrm{Cz}-1$ and $C 4 / \mathrm{Cz}-1)$ or interhemispheric stimulation $(\mathrm{C} 3 / \mathrm{C} 4, \mathrm{C} 4 / \mathrm{C} 3, \mathrm{C} 1 / \mathrm{C} 2$, and $\mathrm{C} 2 / \mathrm{C} 1)$ [6]. As classical stimulation intensity is applied slightly above the motor threshold, responses of several muscles can be recorded at the same time. Direct cortical and subcortical stimuli might be applied focal on the primary motor cortex or at the trajectory of the corticospinal tract (CST) and thus, elicit MEP in a few muscles of one anatomical territory $[7,8]$.

Intraoperative MEP signal changes may result from an acutely disturbed nerve action potential conduction along the corticospinal axons because of compression, traction, ischemia, or mechanical injury [9]. However, MEP alterations may also be confounded by non-surgical factors. MEPs exhibit trial-to-trial variability and are susceptible to the effect of volatile anesthetic agents, neuromuscular blockade, systemic factors like hypotension and hypothermia, and focal factors like nerve conduction failure because of malpositioning [9]. Provided that non-surgical causes are excluded, MEP alterations should urge the surgical team to intervene or to stop in time while the impending neurological injury is still reversible.

Warning criteria represent a priori defined parameters. Optimally, they should alert the surgical team, and they prompt the implementation of corrective measures. Obviously, a false-negative reassurance will miss the neurological injury; however, a false-positive alarm may also indirectly harm the patient by stopping the surgery too early. The most common proposed MEP alarm criteria include the disappearance of MEP signal, amplitude reduction, threshold elevation, and morphology simplification [9-11]. Additional discussed warning criteria include latency increase [12,13], decrease in the Area Under the Curve (AUC) [14], and increase in potential width [15]. Further, different criteria are recommended for supratentorial surgery, compared to the brainstem, skull base, and spinal surgery [9]. Moreover, the magnitude of MEP change regarded as alarming varies substantially across neurosurgical centers and sometimes depends on previous institutional experience [16-19]. It becomes apparent that there is no consensus on the interpretation of MEP signal alterations and the selected cut-off values are often empirically derived [20,21].

The diagnostic accuracy of MEPs in supratentorial surgery for temporary and permanent postoperative motor deficits has not been adequately investigated, and the existing evidence provides controversial results [22,23]. Drawing overall conclusions is fraught with difficulty, as there is significant heterogeneity across primary studies in terms of methodological approach and reporting of outcomes. In light of all these considerations, we conducted a scoping review of MEP warning criteria in supratentorial neurosurgical procedures, including tumor, vascular, and epilepsy surgery. The objective was to assess the extent, range, and nature of primary studies that utilized intraoperative MEP warning criteria, summarize their findings within the context of postoperative motor outcomes, identify research gaps and provide implications for future research. Subsequently, we intended to perform a diagnostic accuracy analysis of MEPs as well as a correlation analysis between postoperative motor deficits and recovery of an intraoperative MEP alteration after successful interventions to investigate the value of MEPs as a surrogate marker. 


\section{Materials and Methods}

The scoping review was conducted in accordance with the Preferred Reporting Items for Systematic reviews and Meta-Analyses extension for Scoping Reviews (PRISMAScR) [24] and was based on the methodological framework suggested by Arksey and O'Malley and refined by Levac et al. $[25,26]$.

\subsection{Search Strategy}

The literature research was done by two independent researchers using the electronic databases PubMed (MEDLINE), Embase, Scopus, CINAHL, and the Cochrane Library. The included research articles ranged from the beginning of the databases until April 2021. There was no restriction on language. A detailed description of search terms and techniques is provided in Appendix A. The reference lists of retrieved articles and the sets of similar articles suggested by the database were screened in order to identify additional relevant citations. Additionally, the grey literature databases Open Grey, NTIS, British Library Direct Plus, York's CRD, and Mednar were also searched.

\subsection{Eligibility Criteria}

Studies eligible for inclusion were all types of primary clinical studies, in which at least one MEP warning criterion was used intraoperatively in anesthetized patients during supratentorial surgery, including intrinsic brain tumors, metastases, aneurysms, vascular malformations, and other brain lesions, that are targets for epilepsy surgery. The utilized warning criteria had to be preoperatively (a priori) defined, and the authors had to report postoperative motor outcome data in conjunction with the intraoperative presence or absence of MEP alterations. MEPs had to be elicited by electrical stimulation and not transcranial magnetic stimulation. Our goal was to analyze MEP monitoring alarm criteria, but if D-wave recording or subcortical mapping were used as supplementary factors for warning signs, we included these aspects as well. However, we did not include studies solely with D-wave monitoring or mapping warning criteria without continuous muscle MEP monitoring. Studies with awake patients, infratentorial and spinal cord lesions were not included in our analysis unless the outcomes for asleep patients with supratentorial lesions were clearly described in a subgroup. In this case, only the data for supratentorial operations for anesthetized patients were extracted for further analysis. Studies with aneurysms located in arteries of the posterior circulation were included because the primary outcome of interest was the postoperative motor outcome and not ischemia.

\subsection{Study Selection}

The study selection was performed by two independent authors. Each author screened the titles and abstracts of all retrieved articles, defined a subset of relevant studies, and after full-text review, selected the eligible studies. The results of their individual search were compared, and a final list of eligible records was created. Some disagreements were resolved through discussion. If multiple publications from the same authors or overlapping study populations from the same institution were identified, the most recent paper was taken into consideration. The reason why specific articles did not meet the inclusion criteria can be found in Appendix B.

\subsection{Data Extraction}

From each included study, the following data were extracted: authors, year of publication, study design, country, number of patients with MEP data, stimulation technique (transcranial electrical stimulation (TES), direct cortical stimulation (DCS), subcortical stimulation), and stimulation parameters, recorded muscles, MEP warning criterion/criteria, interventions in case of a warning sign, number of reversible and irreversible intraoperative MEP changes and number of patients with postoperative motor deficit immediately after surgery as well as during short-term and long-term follow-up. A pilot test of the 
data extraction protocol was initially performed with five citations and was afterward implemented for all included studies.

\subsection{Data Analysis and Synthesis of Results}

The extracted data were charted in tables with special emphasis on the number of patients with reversible or irreversible MEP changes who developed a postoperative motor deficit. A $2 \times 2$ contingency table was constructed for each study providing sufficient information to identify the true positive (TP), false positive (FP), false negative (FN), and true negative (TN) results. Subsequently, we performed a Diagnostic Test Accuracy (DTA) analysis of MEPs for postoperative motor deficits. Sensitivity, specificity, Positive Predictive Value (PPV), and Negative Predictive Value (NPV) were calculated using the RevMan calculator in the Review Manager software (RevMan, version 5.4) from the Cochrane Collaboration [27]. The forest plots displaying sensitivity, specificity, and the corresponding 95\% Confidence Interval (CI) were generated for each study with the same software [27]. In order to visualize the values of diagnostic accuracy measures across all studies, heatmaps were constructed using MATLAB (version R2020b). The DTA analysis was divided into four sub-analyses and more specifically in the analysis of early-transient motor deficit (reported by authors as motor deficit immediately after surgery or at the day of the operation or resolved before the day of discharge), transient motor deficit (reported by authors as temporary or transient or present at discharge or short-term motor deficit), permanent motor deficit (reported by authors as permanent or persistent or long-term motor deficit) and all motor deficits regardless of the postoperative duration of the impairment. Given the differences in outcome reporting among the studies, this descriptive approach was deemed more appropriate than the use of the common cut-off time of 3 months to distinguish transient from permanent deficits. A postoperative motor deficit was defined as any new motor deficit or deterioration of an already compromised motor function with a decrease of $\geq 0.5$ points on the Medical Research Council Scale (MRCS) or an increase of $\geq 0.5$ points on the Modified Rankin Scale (mRS). In all sub-analyses, irreversible MEP changes according to the utilized warning criterion that did not recover until the end of the operation were considered as positive results, whereas reversible MEP changes and absence of MEP changes were considered as negative results. Detailed definitions for the DTA analysis are provided in Table S1. The DTA sub-analyses were performed separately for different stimulation modalities and warning criteria if it was possible to retrieve the relevant data from a primary study. Monitoring and mapping criteria were analyzed both separately and in combination, if applicable. We did not pool the data and did not undertake a meta-analysis of the results because of the heterogeneity in study populations, anesthetic regimens, stimulation techniques and parameters, recorded muscles, and utilized MEP warning criteria.

In addition to the DTA analysis, we carried out an analysis of the correlation between intraoperative MEP alterations that were reversed after successful intervention and new postoperative motor deficits. We sought to investigate the direction of association between these two variables in order to assess the significance of MEPs as surrogate endpoints. The calculations were performed based on the formulas and the methodology described by Holdefer et al. [28]. A $3 \times 2$ summary table was constructed for each study, and the proportion of reversible MEP changes after intraoperative intervention triggered by MEP warning criteria as well as the proportion of new motor deficits associated with MEP alterations were defined. All new motor deficits were included regardless of the postoperative duration. The correlation analysis was performed in $\mathrm{R}$ (version 4.0.2, R-project.org). The normality of the data was checked with a Shapiro-Wilk test, and Spearman's rank correlation coefficients with corresponding $p$-values were computed. The plots were constructed using the R package ggplot2. Case reports were not included in the DTA analysis or in the correlation analysis. 


\section{Results}

A total of 662 records were identified from the literature research. In particular, we extracted 540 references from electronic databases (204 from PubMed, 224 from Scopus, 63 from Embase, 25 from CINAHL, three from Cochrane Library, and 21 from grey literature databases), while the reference lists provided 122 additional citations. The titles were screened for relevance to our research question and for duplicate records. After exclusion of irrelevant or dual records, 281 abstracts were further screened, and subsequently, the fulltexts of 208 articles were reviewed. Finally, 68 studies (31 studies for tumors and other brain lesions, two for epilepsy surgery, 28 for aneurysm clipping, five for endovascular aneurysm procedures, and two case reports) fulfilled the eligibility criteria and were included in our review. All of them were published in peer-reviewed journals, and no record from grey literature databases met the inclusion criteria. Figure 1 depicts the flow chart with the different phases of study selection.

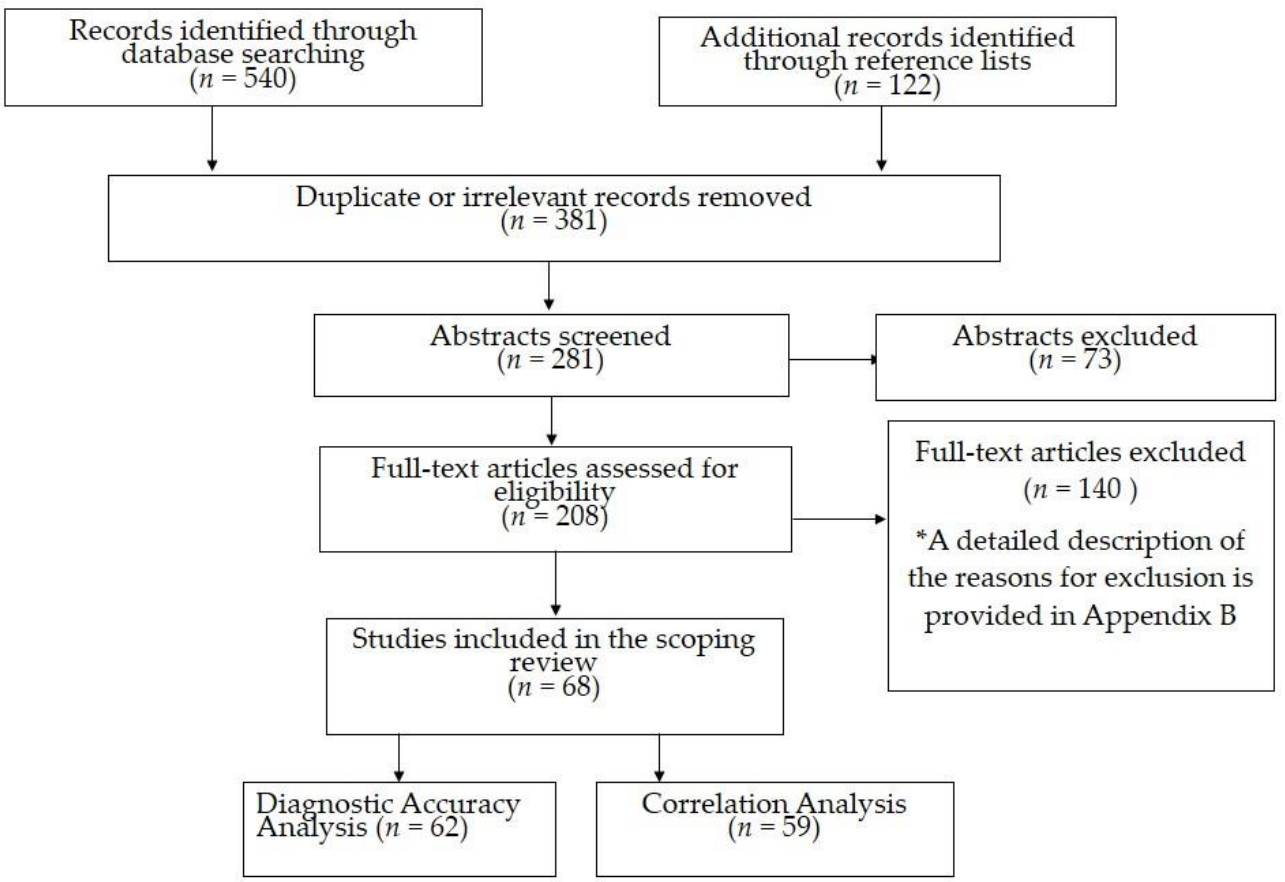

Figure 1. Flow diagram for study selection.

The included studies were 30 prospective and 28 retrospective case series, two case series with both prospective and retrospective design, six case series with unclear study design, and two case reports. The largest portion of evidence for tumors and other brain lesions was derived from Europe (especially Germany), whereas the main body of literature for aneurysm surgery consisted of studies from Asia (especially Japan, Korea, and China). An overview of MEP warning criteria utilized in supratentorial surgery and a summary of transient and permanent postoperative motor deficits in correlation with reversible and irreversible alarming MEP alterations for tumor surgery is provided in Table 1 . The equivalent for vascular surgery can be found in Table 2. In all studies, MEP signal loss was considered a major warning sign. Additional information about the pathology of treated lesions, stimulation parameters, recorded muscles, and interventions following the appearance of warning criteria is provided in Table S2 in the Supplementary Material. 


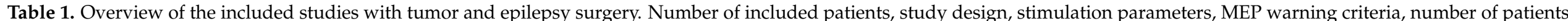

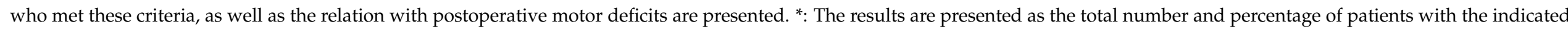

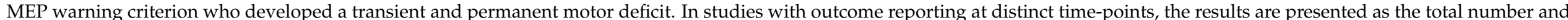

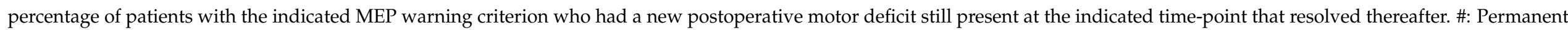
motor deficit in $13 / 25=$ not assessable. Transient motor deficit in $1 / 25=$ not assessable. (The absence of cases with a deficit is indicated by the symbol "-").

\begin{tabular}{|c|c|c|c|c|c|c|c|}
\hline \multirow{2}{*}{ Authors } & \multirow{2}{*}{ No. of Patients } & \multirow{2}{*}{$\begin{array}{l}\text { Study Design/ } \\
\text { Country }\end{array}$} & \multirow[t]{2}{*}{ STT } & \multirow[t]{2}{*}{ Warning Criterion } & \multirow[t]{2}{*}{ MEP Changes } & \multicolumn{2}{|c|}{$\begin{array}{c}\text { Postoperative Motor Deficit in Relation to } \\
\text { MEP Change }\end{array}$} \\
\hline & & & & & & Transient* & Permanent * \\
\hline & & & & & \multicolumn{3}{|c|}{ TUMORS AND OTHER BRAIN LESIONS } \\
\hline \multirow{2}{*}{$\begin{array}{l}\text { Giampiccolo et al. (2021) } \\
\text { [29] }\end{array}$} & \multirow{2}{*}{125} & \multirow{2}{*}{$\begin{array}{l}\text { Retrospective } \\
\text { Italy }\end{array}$} & \multirow{2}{*}{ DCS } & \multirow[b]{2}{*}{$\mathrm{AR}>50 \%$} & $\begin{array}{c}\text { Upper Limbs } \\
\text { AR/loss }(n=26)\end{array}$ & $\begin{array}{l}2 \mathrm{~d}: 3 / 26(11.5 \%) \\
5 \mathrm{~d}: 6 / 26(23 \%)\end{array}$ & $10 / 26(38.5 \%)$ \\
\hline & & & & & $\begin{array}{c}\text { Lower Limbs } \\
\text { AR/loss }(n=14)\end{array}$ & $\begin{array}{l}2 \mathrm{~d}: 2 / 14(14.3 \%) \\
5 \mathrm{~d}: 3 / 14(21.4 \%)\end{array}$ & $3 / 14(21.4 \%)$ \\
\hline \multirow{2}{*}{$\begin{array}{c}\text { Gogos et al. (2020) } \\
\text { [30] }\end{array}$} & \multirow{2}{*}{58} & \multirow{2}{*}{$\begin{array}{l}\text { Prospective } \\
\text { USA }\end{array}$} & \multirow{2}{*}{$\begin{array}{l}\text { DCS } \\
\text { TES } \\
\text { ScS }\end{array}$} & \multirow{2}{*}{$\begin{array}{l}\mathrm{AR}>20 \% \\
\mathrm{MT} \leq 5 \mathrm{~mA}\end{array}$} & $\operatorname{IRR}$ AR $(n=6)$ & $2 / 6(33.3 \%)$ & $1 / 6(16.6 \%)$ \\
\hline & & & & & $\mathrm{MT} \leq 5 \mathrm{~mA}(n=18)$ & $2 / 18(11.1 \%)$ & $1 / 18(5.5 \%)$ \\
\hline \multirow{2}{*}{$\begin{array}{c}\text { Mammadk-hanli et al. } \\
\text { (2020) } \\
\text { [31] }\end{array}$} & \multirow{2}{*}{145} & \multirow{2}{*}{$\begin{array}{l}\text { Retrospective } \\
\text { Turkey }\end{array}$} & \multirow{2}{*}{ DCS } & \multirow{2}{*}{$\begin{array}{l}\mathrm{AR}>50 \% \\
\mathrm{LTI}>10 \%\end{array}$} & REV changes $(n=7)$ & \multicolumn{2}{|c|}{$\begin{array}{c}4 / 7(57.1 \%), \text { not specified if transient or } \\
\text { permanent }\end{array}$} \\
\hline & & & & & IRR changes $(n=14)$ & \multicolumn{2}{|c|}{$\begin{array}{c}14 / 14(100 \%), \text { not specified if transient or } \\
\text { permanent }\end{array}$} \\
\hline $\begin{array}{l}\text { Seidel et al. (2020) } \\
\text { [32] }\end{array}$ & 182 & $\begin{array}{l}\text { Prospective } \\
\text { Switzerland }\end{array}$ & $\begin{array}{l}\text { DCS } \\
\text { ScS }\end{array}$ & $\mathrm{THI} \geq 4 \mathrm{~mA} \mathrm{MT} \leq 3 \mathrm{~mA}$ & $\mathrm{MT} \leq 3 \mathrm{~mA}(n=58)$ & $\begin{array}{c}24 \mathrm{~h}: 13 / 58(22.4 \%) \\
\text { discharge: } \\
14 / 58(24.1 \%)\end{array}$ & $3 / 58(5.1 \%)$ \\
\hline \multirow{4}{*}{$\begin{array}{l}\text { Abboud et al. (2019) } \\
{[33]}\end{array}$} & \multirow{4}{*}{126} & \multirow{4}{*}{$\begin{array}{l}\text { Prospective } \\
\text { Germany }\end{array}$} & \multirow{4}{*}{ TES } & \multirow{4}{*}{$\begin{array}{l}\mathrm{AR}>50 \% \\
\mathrm{THI}>20 \% \mathrm{i}\end{array}$} & $\operatorname{REV} \operatorname{AR}(n=2)$ & - & - \\
\hline & & & & & $\operatorname{IRR} \operatorname{AR}(n=36)$ & $\begin{array}{c}24 \text { h: } 6 / 36(16.7 \%) \\
\text { discharge: } 6 / 36(16.7 \%)\end{array}$ & $8 / 36(22.2 \%)$ \\
\hline & & & & & REV THI $(n=9)$ & - & - \\
\hline & & & & & IRR THI $(n=25)$ & $\begin{array}{c}24 \text { h: } 7 / 25(28.0 \%) \\
\text { discharge: } 7 / 25(28.0 \%)\end{array}$ & $8 / 25(32.0 \%)$ \\
\hline \multirow{2}{*}{$\begin{array}{l}\text { Majchrzak et al. (2018) } \\
\text { [34] }\end{array}$} & \multirow{2}{*}{35} & Prospective & & & $\operatorname{REV} \operatorname{AR}(n=7)$ & $6 / 7(85.7 \%)$ & $1 / 7(14.3 \%)$ \\
\hline & & Poland & TES & AR $>50 \%$ & IRR AR $(n=11)$ & $1 / 11(9.1 \%)$ & $10 / 11(90.9 \%)$ \\
\hline
\end{tabular}


Table 1. Cont.

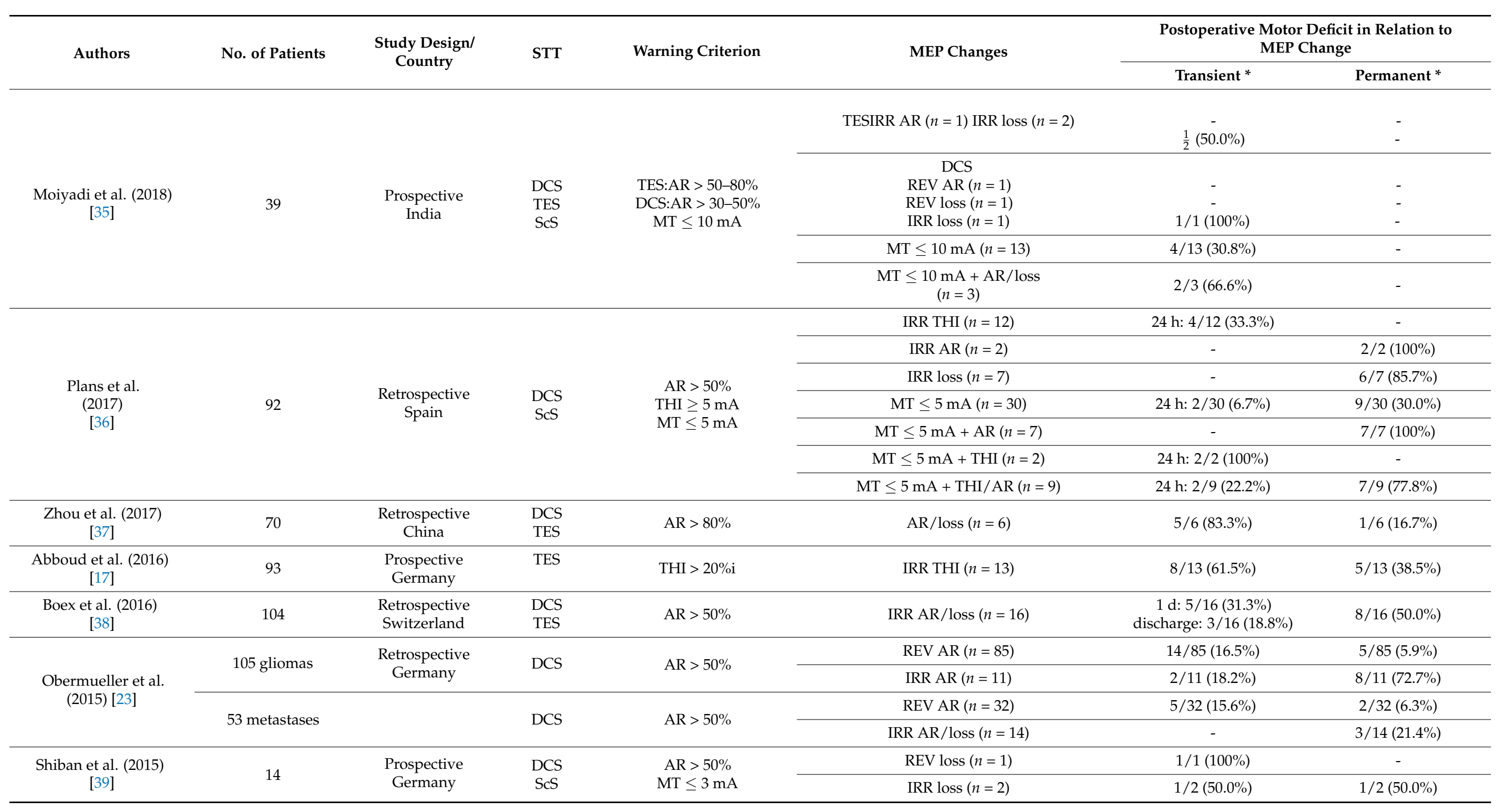


Table 1. Cont.

\begin{tabular}{|c|c|c|c|c|c|c|c|}
\hline \multirow{2}{*}{ Authors } & \multirow{2}{*}{ No. of Patients } & \multirow{2}{*}{$\begin{array}{l}\text { Study Design/ } \\
\text { Country }\end{array}$} & \multirow{2}{*}{ STT } & \multirow[t]{2}{*}{ Warning Criterion } & \multirow[t]{2}{*}{ MEP Changes } & \multicolumn{2}{|c|}{$\begin{array}{l}\text { Postoperative Motor Deficit in Relation to } \\
\text { MEP Change }\end{array}$} \\
\hline & & & & & & Transient * & Permanent * \\
\hline $\begin{array}{l}\text { Lee et al. } \\
(2014) \\
{[40]}\end{array}$ & 84 & $\begin{array}{l}\text { Retrospective } \\
\text { Korea }\end{array}$ & TES & $\begin{array}{l}\mathrm{AR}>50 \% \\
\mathrm{LTI}>10 \%\end{array}$ & IRR AR $(n=7)$ & - & $3 / 7(42.9 \%)$ \\
\hline \multirow{2}{*}{$\begin{array}{l}\text { Gempt et al. (2013) } \\
\text { [41] }\end{array}$} & \multirow{2}{*}{70} & \multirow{2}{*}{$\begin{array}{c}\text { Prospective } \\
\text { Germany }\end{array}$} & \multirow{2}{*}{ DCS } & \multirow{2}{*}{$\mathrm{AR}>50 \%$} & $\operatorname{REV} \operatorname{AR}(n=8)$ & $2 / 8(25.0 \%)$ & $2 / 8(25.0 \%)$ \\
\hline & & & & & $\operatorname{IRR}$ AR $(n=13)$ & $5 / 13(38.5 \%)$ & $8 / 13(61.5 \%)$ \\
\hline \multirow{2}{*}{$\begin{array}{l}\text { Ostrý et al. } \\
\text { (2013) } \\
\text { [42] }\end{array}$} & \multirow[t]{2}{*}{25} & \multirow{2}{*}{$\begin{array}{c}\text { Prospective } \\
\text { Czech Republic }\end{array}$} & \multirow{2}{*}{$\begin{array}{l}\text { DCS } \\
\text { ScS }\end{array}$} & \multirow{2}{*}{$\begin{array}{l}\mathrm{THI} \geq 2 \mathrm{~mA} \\
\mathrm{MT} \leq 5 \mathrm{~mA}\end{array}$} & $\mathrm{MT} \leq 5 \mathrm{~mA}(n=10)$ & $3 / 10(30.0 \%)$ & $1 / 10(10 \%)$ \\
\hline & & & & & $\mathrm{MT} \leq 5 \mathrm{~mA}+$ MEP alteration $(n=2)$ & $2 / 2(100 \%)$ & - \\
\hline \multirow{2}{*}{$\begin{array}{c}\text { Pastor et al. (2013) } \\
\text { [43] }\end{array}$} & \multirow{2}{*}{30} & \multirow{2}{*}{$\begin{array}{l}\text { Prospective } \\
\text { Spain }\end{array}$} & \multirow{2}{*}{$\begin{array}{l}\text { DCS } \\
\text { TES }\end{array}$} & \multirow{2}{*}{$\begin{array}{l}\text { AR }>50 \% \\
\mathrm{LTI}>10 \%\end{array}$} & TES $(n=16)$ & $1 \mathrm{w}: 4 / 16(25.0 \%)$ & $3 / 16(18.8 \%)$ \\
\hline & & & & & $\operatorname{DCS}(n=2)$ & - & - \\
\hline \multirow{4}{*}{$\begin{array}{l}\text { Seidel et al. (2013) } \\
\text { [8] }\end{array}$} & \multirow{4}{*}{100} & \multirow{4}{*}{$\begin{array}{l}\text { Prospective } \\
\text { Switzerland }\end{array}$} & \multirow{4}{*}{$\begin{array}{l}\text { DCS } \\
\text { ScS }\end{array}$} & \multirow{4}{*}{$\begin{array}{l}\mathrm{THI} \geq 4 \mathrm{~mA} \\
\mathrm{MT} \leq 3 \mathrm{~mA}\end{array}$} & $\mathrm{THI} \leq 15 \mathrm{~min} /$ unspecific changes $(n=18)$ & $\begin{array}{c}24 \text { h: 5/18 (27.8\%) } \\
\text { Discharge: } 2 / 18(11.1 \%)\end{array}$ & - \\
\hline & & & & & $\begin{array}{c}\text { THI } \geq 15 \min \\
(n=8)\end{array}$ & $\begin{array}{c}24 \text { h: } 2 / 8(25.0 \%) \\
\text { Discharge: } 3 / 8(37.5 \%)\end{array}$ & $2 / 8(25.0 \%)$ \\
\hline & & & & & $\mathrm{MT} \leq 3 \mathrm{~mA}(n=25)$ & $\begin{array}{c}24 \text { h: } 4 / 25(16.0 \%) \\
\text { Discharge: } 2 / 25(8.0 \%)\end{array}$ & $2 / 25(8.0 \%)$ \\
\hline & & & & & $\mathrm{MT} \leq 3 \mathrm{~mA}+\mathrm{THI} \underset{(n=5)}{\geq 15 \mathrm{~min} / \text { Loss } \geq 15 \mathrm{~min}}$ & $\begin{array}{c}24 \text { h: } 1 / 5(20.0 \%) \\
\text { Discharge: } 2 / 5(40.0 \%)\end{array}$ & $2 / 5(40.0 \%)$ \\
\hline \multirow{2}{*}{$\begin{array}{l}\text { Sakurada et al. (2012) } \\
\text { [44] }\end{array}$} & \multirow{2}{*}{30} & \multirow{2}{*}{$\begin{array}{l}\text { Retrospective } \\
\text { Japan }\end{array}$} & \multirow{2}{*}{ DCS } & \multirow{2}{*}{$\mathrm{AR}>50 \%$} & $\operatorname{REV} \operatorname{AR}(n=2)$ & $1 / 2(50.0 \%)$ & - \\
\hline & & & & & $\operatorname{IRR} \operatorname{AR}(n=2)$ & - & $2 / 2(100 \%)$ \\
\hline $\begin{array}{l}\text { Senft et al. (2012) } \\
{[45]}\end{array}$ & 54 & $\begin{array}{l}\text { Retrospective } \\
\text { Germany }\end{array}$ & TESDCS & $\begin{array}{c}\mathrm{AR}>50 \% \\
\mathrm{THI} \geq 20 \mathrm{~mA} \\
\text { (TES) } \\
\text { THI } \geq 3 \mathrm{~mA} \\
\text { (DCS) }\end{array}$ & $\begin{array}{c}\text { MEP alterations }(n=7: \\
2 \text { THI, } 1 \text { AR, } 1 \text { loss, } 3 \text { N/A) }\end{array}$ & $4 / 7(57.1 \%)$ & $2 / 7(28.6 \%)$ \\
\hline $\begin{array}{l}\text { Hatiboglu et al. (2010) } \\
{[46]}\end{array}$ & 16 & $\begin{array}{l}\text { Retrospective } \\
\text { USA }\end{array}$ & DCS & MEP loss & Loss $(n=4)$ & $1 / 4(25.0 \%)$ & $2 / 4(50.0 \%)$ \\
\hline
\end{tabular}


Table 1. Cont.

\begin{tabular}{|c|c|c|c|c|c|c|c|}
\hline \multirow{2}{*}{ Authors } & \multirow{2}{*}{ No. of Patients } & \multirow{2}{*}{$\begin{array}{l}\text { Study Design/ } \\
\text { Country }\end{array}$} & \multirow{2}{*}{ STT } & \multirow{2}{*}{ Warning Criterion } & \multirow{2}{*}{ MEP Changes } & \multicolumn{2}{|c|}{$\begin{array}{l}\text { Postoperative Motor Deficit in Relation to } \\
\text { MEP Change }\end{array}$} \\
\hline & & & & & & Transient * & Permanent ${ }^{*}$ \\
\hline \multirow{3}{*}{$\begin{array}{l}\text { Ichikawa et al. } \\
\text { (2010) [47] }\end{array}$} & \multirow{3}{*}{21} & \multirow{3}{*}{$\begin{array}{l}\text { Retrospective } \\
\text { Japan }\end{array}$} & \multirow{3}{*}{ DCS } & \multirow{3}{*}{$\mathrm{AR}>50 \%$} & $\operatorname{REV}$ AR $(n=3)$ & $1 / 3(33.3 \%)$ & - \\
\hline & & & & & REV loss $(n=1)$ & $1 / 1(100 \%)$ & - \\
\hline & & & & & IRR loss $(n=1)$ & - & $1 / 1(100 \%)$ \\
\hline \multirow{6}{*}{$\begin{array}{l}\text { Szelényi et al. (2010) \# } \\
\text { [48] }\end{array}$} & \multirow{6}{*}{25} & \multirow{6}{*}{$\begin{array}{l}\text { Prospective } \\
\text { Germany }\end{array}$} & \multirow{6}{*}{ TES } & \multirow{6}{*}{$\begin{array}{c}\mathrm{AR}>50 \% \\
\mathrm{THI}>20 \mathrm{~mA} \text { or }>100 \mathrm{~V}\end{array}$} & $\operatorname{REV} \operatorname{AR}(n=3)$ & - & - \\
\hline & & & & & $\operatorname{IRR}$ AR $(n=2)$ & $2 / 2(100 \%)$ & - \\
\hline & & & & & REV loss $(n=6)$ & $2 / 6(33.3 \%)$ & $2 / 6(33.3 \%)$ \\
\hline & & & & & IRR loss $(n=5)$ & $2 / 5(40.0 \%)$ & $2 / 5(40.0 \%)$ \\
\hline & & & & & REV THI $(n=3)$ & - & - \\
\hline & & & & & IRR THI $(n=8)$ & $2 / 8(25.0 \%)$ & $3 / 8(37.5 \%)$ \\
\hline $\begin{array}{c}\text { Kombos et al. (2009) } \\
\text { [49] }\end{array}$ & 15 & $\begin{array}{l}\text { Prospective } \\
\text { Germany }\end{array}$ & TESScS & $\begin{array}{r}\mathrm{AR}>80 \% \\
\mathrm{LTI}>30 \% \\
\mathrm{MT} \leq 3 \mathrm{~mA}\end{array}$ & $\begin{array}{l}\text { REV AR + LTI } \\
\quad(n=5)\end{array}$ & $2 / 5(40.0 \%)$ & - \\
\hline \multirow{3}{*}{$\begin{array}{l}\text { Neuloh et al. (2009) } \\
\text { [50] }\end{array}$} & \multirow{3}{*}{191} & \multirow{3}{*}{$\begin{array}{l}\text { Prospective } \\
\text { Germany }\end{array}$} & \multirow{3}{*}{$\begin{array}{l}\text { DCS } \\
\text { TES }\end{array}$} & \multirow{3}{*}{$\mathrm{AR}>50 \%$} & REV AR $(n=50)$ & $19 / 50(38.0 \%)$ & $1 / 50(2.0 \%)$ \\
\hline & & & & & IRR AR $(n=26)$ & $11 / 26(42.3 \%)$ & $5 / 26(19.2 \%)$ \\
\hline & & & & & IRR loss $(n=7)$ & $1 / 7(14.3 \%)$ & $6 / 7(85.7 \%)$ \\
\hline \multirow{3}{*}{$\begin{array}{c}\text { Neuloh et al. (2007) } \\
\text { [51] }\end{array}$} & \multirow{3}{*}{88} & \multirow{3}{*}{$\begin{array}{l}\text { Prospective } \\
\text { Germany }\end{array}$} & \multirow{3}{*}{$\begin{array}{l}\text { DCS } \\
\text { TES }\end{array}$} & \multirow{3}{*}{$\mathrm{AR}>50 \%$} & REV AR/loss $(n=26)$ & $12 / 26(46.2 \%)$ & - \\
\hline & & & & & IRR AR $(n=8)$ & $7 / 8(87.5 \%)$ & $1 / 8(12.5 \%)$ \\
\hline & & & & & IRR loss $(n=7)$ & - & $7 / 7(100 \%)$ \\
\hline \multirow{2}{*}{$\begin{array}{l}\text { Suess et al. (2006) } \\
\text { [15] }\end{array}$} & \multirow{2}{*}{232} & \multirow{2}{*}{$\begin{array}{l}\text { Unclear } \\
\text { Germany }\end{array}$} & \multirow{2}{*}{ DCS } & \multirow{2}{*}{$\begin{array}{l}\text { AR }>50 \% \\
\text { LTI }>5 \% \\
\text { PWI }>30 \%\end{array}$} & REV changes $(n=27)$ & $6 / 27(22.2 \%)$ & - \\
\hline & & & & & IRR changes $(n=20)$ & - & $17 / 20(85.0 \%)$ \\
\hline \multirow{4}{*}{$\begin{array}{c}\text { Neuloh et al. (2004) } \\
\text { [11] }\end{array}$} & & & & & $\operatorname{REV} \operatorname{AR}(n=16)$ & $8 / 16(50.0 \%)$ & $1 / 16(6.3 \%)$ \\
\hline & 150 & Prospective & & $\mathrm{AR}>50 \%$ & IRR AR $(n=16)$ & $7 / 16(43.8 \%)$ & $4 / 16(25.0 \%)$ \\
\hline & 159 & Germany & DCS & LTI > 10\% & REV loss $(n=22)$ & $8 / 22(36.4 \%)$ & $1 / 22(4.5 \%)$ \\
\hline & & & & & IRR loss $(n=10)$ & $2 / 10(20.0 \%)$ & 8/10 (80.0\%) \\
\hline
\end{tabular}


Table 1. Cont.

\begin{tabular}{|c|c|c|c|c|c|c|c|}
\hline \multirow{2}{*}{ Authors } & \multirow{2}{*}{ No. of Patients } & \multirow{2}{*}{$\begin{array}{l}\text { Study Design/ } \\
\text { Country }\end{array}$} & \multirow{2}{*}{ STT } & \multirow[t]{2}{*}{ Warning Criterion } & \multirow[t]{2}{*}{ MEP Changes } & \multicolumn{2}{|c|}{$\begin{array}{c}\text { Postoperative Motor Deficit in Relation to } \\
\text { MEP Change }\end{array}$} \\
\hline & & & & & & Transient * & Permanent * \\
\hline \multirow{4}{*}{$\begin{array}{c}\text { Kombos et al. (2001) } \\
{[10]}\end{array}$} & \multirow{4}{*}{70} & \multirow{4}{*}{$\begin{array}{l}\text { Prospective } \\
\text { Germany }\end{array}$} & \multirow{4}{*}{ DCS } & \multirow{4}{*}{$\begin{array}{l}\text { AR }>80 \% \\
\text { LTI }>15 \%\end{array}$} & REV LTI $(n=3)$ & - & - \\
\hline & & & & & IRR LTI $(n=1)$ & $1 / 1(100 \%)$, not sp & ssient orpermanent \\
\hline & & & & & REV loss $(n=7)$ & - & - \\
\hline & & & & & IRR loss $(n=1)$ & - & $1 / 1(100 \%)$ \\
\hline \multirow{2}{*}{$\begin{array}{l}\text { Zhou et al. } \\
\text { (2001) } \\
\text { [52] }\end{array}$} & \multirow{2}{*}{50} & \multirow{2}{*}{$\begin{array}{l}\text { Prospective } \\
\text { USA }\end{array}$} & \multirow{2}{*}{ TES } & \multirow{2}{*}{$\mathrm{AR}>50 \%$} & $\operatorname{REV}$ AR $(n=4)$ & & \\
\hline & & & & & IRR AR/loss $(n=8)$ & $8 / 8(100 \%)$, not sp & nsient orpermanent \\
\hline \multirow{2}{*}{$\begin{array}{l}\text { Cedzich et al. (1996) } \\
\text { [53] }\end{array}$} & \multirow{2}{*}{25} & \multirow{2}{*}{$\begin{array}{l}\text { Prospective } \\
\text { Germany }\end{array}$} & \multirow{2}{*}{ DCS } & \multirow{2}{*}{ MEP loss } & REV loss $(n=9)$ & $4 / 9(44.4 \%)$ & $1 / 9(11.1 \%)$ \\
\hline & & & & & IRR loss $(n=6)$ & - & $3 / 6(50.0 \%)$ \\
\hline \multicolumn{8}{|c|}{ EPILEPSY SURGERY } \\
\hline \multirow[t]{2}{*}{$\begin{array}{c}\text { Koo et al. } \\
(2019) \\
{[54]}\end{array}$} & 279 & $\begin{array}{l}\text { Prospective } \\
\text { Korea }\end{array}$ & TES & $\mathrm{AR}>50 \%$ & $\operatorname{REV} \operatorname{AR}(n=6)$ & $1 / 6(16.7 \%)$ & - \\
\hline & & & & & REV loss $(n=4)$ & $1 / 4(25.0 \%)$ & - \\
\hline $\begin{array}{l}\text { Neuloh et al. (2010) } \\
\text { [55] }\end{array}$ & 86 & $\begin{array}{l}\text { Prospective } \\
\text { Germany }\end{array}$ & DCSTES & $\begin{array}{c}\mathrm{AR}>50 \% \\
\mathrm{LTI}>10-15 \%\end{array}$ & IRR changes $(n=11)$ & $2 / 11(18.2 \%)$ & $5 / 11(45.5 \%)$ \\
\hline
\end{tabular}

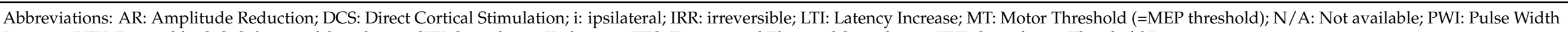
Increase; REV: Reversible; ScS: Subcortical Simulation; STT: Stimulation Technique; TES: Transcranial Electrical Stimulation; THI: Stimulation Threshold Increase. 


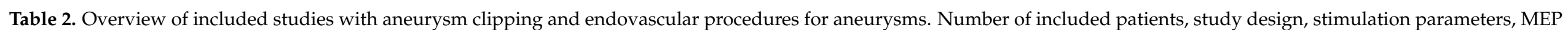

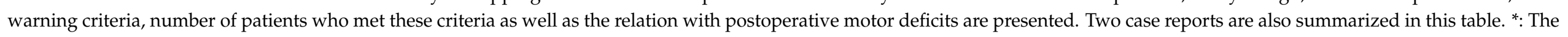

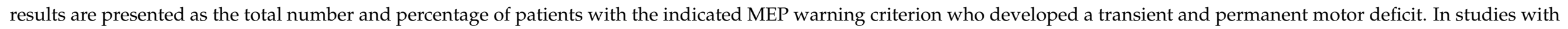

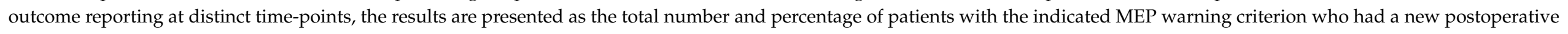
motor deficit still present at the indicated time-point that resolved thereafter. $€: 3 / 116$ cases $=$ not assessable. The absence of cases with a deficit is indicated by the symbol "-".

\begin{tabular}{|c|c|c|c|c|c|c|c|}
\hline \multirow{2}{*}{ Authors } & \multirow{2}{*}{ No. of Patients } & \multirow{2}{*}{ Study Design } & \multirow{2}{*}{ STT } & \multirow{2}{*}{ Warning Criterion } & \multirow{2}{*}{ MEP Changes } & \multicolumn{2}{|c|}{ Postoperative Motor Deficit in Relation to MEP Change } \\
\hline & & & & & & Transient * & Permanent* \\
\hline \multicolumn{8}{|c|}{ ANEURYSM CLIPPING } \\
\hline \multirow{2}{*}{$\begin{array}{c}\text { Guo et al. (2021) } \\
\text { [56] }\end{array}$} & \multirow{2}{*}{285} & \multirow{2}{*}{$\begin{array}{l}\text { Retrospective } \\
\text { China }\end{array}$} & \multirow{2}{*}{ TES } & \multirow{2}{*}{$\mathrm{AR}>50 \%$} & REV AR/loss $(n=49)$ & $5 / 49(10.2 \%)$ & $6 / 49(12.2 \%)$ \\
\hline & & & & & IRR AR/loss $(n=14)$ & $1 / 14(7.1 \%)$ & $10 / 14(71.4 \%)$ \\
\hline \multirow{2}{*}{$\begin{array}{c}\text { Park et al. (2021) } \\
\text { [57] }\end{array}$} & \multirow{2}{*}{319} & \multirow{2}{*}{$\begin{array}{l}\text { Retrospective } \\
\text { Korea }\end{array}$} & \multirow{2}{*}{ TES } & \multirow{2}{*}{$\mathrm{AR}>50 \%$} & $\operatorname{REV} \operatorname{AR}(n=1)$ & $1 / 1(100 \%)$ & - \\
\hline & & & & & $\operatorname{IRR}$ AR $(n=3)$ & $2 / 3(66.6 \%)$ & $1 / 3(33.3 \%)$ \\
\hline \multirow{2}{*}{$\begin{array}{c}\text { You et al. (2021) } \\
\text { [58] }\end{array}$} & \multirow{2}{*}{138} & \multirow{2}{*}{$\begin{array}{l}\text { Retrospective } \\
\text { China }\end{array}$} & \multirow{2}{*}{ TES } & \multirow{2}{*}{$\mathrm{AR}>50 \%$} & $\operatorname{REV} \operatorname{AR}(n=28)$ & \multicolumn{2}{|c|}{$11 / 28(39.3 \%)$, not specified if transient or permanent } \\
\hline & & & & & IRR loss $(n=5)$ & \multicolumn{2}{|c|}{$3 / 5(60.0 \%)$, not specified if transient or permanent } \\
\hline $\begin{array}{c}\text { Kameda et al. (2020) } \\
\text { [59] }\end{array}$ & 42 & $\begin{array}{l}\text { Retrospective } \\
\text { Japan }\end{array}$ & $\begin{array}{c}\text { DCS } \\
\text { TES }\end{array}$ & $\mathrm{AR}>50 \%$ & $\operatorname{REV} \operatorname{AR}(n=2)$ & $1 / 2(50.0 \%)$ & - \\
\hline Byoun et al. (2019) [22] & 115 & $\begin{array}{l}\text { Retrospective } \\
\text { Korea }\end{array}$ & TES & $\mathrm{AR}>50 \%$ & $\operatorname{REV} \operatorname{AR}(n=5)$ & - & $2 / 5(40.0 \%)$ \\
\hline \multirow{2}{*}{$\begin{array}{c}\text { Greve et al. (2019) } \\
\text { [60] }\end{array}$} & \multirow[b]{2}{*}{133} & \multirow{2}{*}{$\begin{array}{l}\text { Retrospective } \\
\text { Germany }\end{array}$} & \multirow[b]{2}{*}{ TES } & \multirow[b]{2}{*}{$\mathrm{AR}>50 \%$} & $\operatorname{REV~AR~}(n=8)$ & $1 / 8(12.5 \%)$ & $1 / 8(12.5 \%)$ \\
\hline & & & & & $\operatorname{IRR}$ AR $(n=4)$ & - & - \\
\hline \multirow{3}{*}{$\begin{array}{l}\text { Li et al. } \\
\text { (2019) } \\
\text { [61] }\end{array}$} & \multirow{3}{*}{92} & \multirow{3}{*}{$\begin{array}{l}\text { Retrospective } \\
\text { China }\end{array}$} & \multirow{3}{*}{ TES } & & $\begin{array}{c}\text { REV } \\
\text { AR/loss }(n=76)\end{array}$ & $\begin{array}{l}24 \mathrm{~h}: 3 / 76(3.9 \%) \\
1 \mathrm{w}: 19 / 76(25 \%)\end{array}$ & $15 / 76(19.7 \%)$ \\
\hline & & & & $\mathrm{AR}>50 \%$ & $\operatorname{IRR} \operatorname{AR}(n=11)$ & $1 \mathrm{w}: 1 / 11(9.1 \%)$ & 9/11 (81.8\%) \\
\hline & & & & & IRR loss $(n=5)$ & $1 \mathrm{w}: 1 / 5(20.0 \%)$ & $4 / 5(80.0 \%)$ \\
\hline & & & & & $\operatorname{REV} \mathrm{AR}(n=4)$ & - & - \\
\hline Choi et al. (2017) & 386 & Retrospective & TES & $\begin{array}{l}\mathrm{AR}>50 \% \\
\end{array}$ & REV loss $(n=5)$ & $1 / 5(20.0 \%)$ & $1 / 5(20.0 \%)$ \\
\hline & & & & & IRR loss $(n=1)$ & - & $1 / 1(100 \%)$ \\
\hline $\begin{array}{c}\text { Komatsu et al. (2017) } \\
\text { [62] }\end{array}$ & 9 & $\begin{array}{l}\text { Retrospective } \\
\text { Japan }\end{array}$ & DCS & $\mathrm{AR}>50 \%$ & $\operatorname{REV} \mathrm{AR}(n=5)$ & - & - \\
\hline
\end{tabular}


Table 2. Cont

\begin{tabular}{|c|c|c|c|c|c|c|c|}
\hline \multirow{2}{*}{ Authors } & \multirow{2}{*}{ No. of Patients } & \multirow{2}{*}{ Study Design } & \multirow{2}{*}{ STT } & \multirow{2}{*}{ Warning Criterion } & \multirow{2}{*}{ MEP Changes } & \multicolumn{2}{|c|}{ Postoperative Motor Deficit in Relation to MEP Change } \\
\hline & & & & & & Transient* & Permanent * \\
\hline \multirow{2}{*}{$\begin{array}{c}\text { Staarman et al. (2017) } \\
\text { [63] }\end{array}$} & \multirow{2}{*}{123} & \multirow{2}{*}{$\begin{array}{c}\text { Retrospective } \\
\text { USA }\end{array}$} & \multirow{2}{*}{ TES } & \multirow{2}{*}{$\mathrm{AR}>50 \%$} & REV AR ( $n=9$ aneurysms) & $1 / 9(11.1 \%)$ & N/A \\
\hline & & & & & IRR AR ( $n=1$ aneurysm) & $1 / 1(100 \%)$ & N/A \\
\hline \multirow{2}{*}{$\begin{array}{c}\text { Kim et al. (2016) } \\
\text { [64] }\end{array}$} & \multirow{2}{*}{685} & \multirow{2}{*}{$\begin{array}{c}\text { Retrospective } \\
\text { Korea }\end{array}$} & \multirow{2}{*}{ TES } & \multirow{2}{*}{$\mathrm{AR}>50 \%$} & REV AR $(n=30)$ & \multicolumn{2}{|c|}{$10 / 30(33.3 \%)$, not specified if transient or permanent } \\
\hline & & & & & $\operatorname{IRR} \operatorname{AR}(n=13)$ & \multicolumn{2}{|c|}{$6 / 13(46.2 \%)$, not specified if transient or permanent } \\
\hline \multirow{3}{*}{$\begin{array}{c}\text { Maruta et al. (2016) } \\
{[65]}\end{array}$} & \multirow{3}{*}{243} & \multirow{3}{*}{$\begin{array}{l}\text { Retrospective } \\
\text { Japan }\end{array}$} & \multirow{3}{*}{$\begin{array}{l}\text { DCS } \\
\text { TES }\end{array}$} & \multirow{3}{*}{$\begin{array}{c}\mathrm{AR}>50 \% \\
(\mathrm{sMEP}+\mathrm{mMEP})\end{array}$} & REV AR $(n=47)$ & $2 / 47(4.2 \%)$ & $1 / 47(2.1 \%)$ \\
\hline & & & & & REV loss $(n=19)$ & $3 / 19(15.7 \%)$ & $4 / 19(21.0 \%)$ \\
\hline & & & & & IRR loss $(n=2)$ & - & $2 / 2(100 \%)$ \\
\hline \multirow{2}{*}{$\begin{array}{c}\text { Song et al. (2015) } \\
\text { [66] }\end{array}$} & \multirow{2}{*}{11} & \multirow{2}{*}{$\begin{array}{l}\text { Unclear } \\
\text { China }\end{array}$} & \multirow{2}{*}{ TES } & \multirow{2}{*}{$\mathrm{AR}>50 \%$} & $\operatorname{REV} \operatorname{AR}(n=5)$ & $2 / 5(40.0 \%)$ & N/A \\
\hline & & & & & $\operatorname{IRR} \operatorname{AR}(n=1)$ & $1 / 1(100 \%)$ & $\mathrm{N} / \mathrm{A}$ \\
\hline \multirow{2}{*}{ Sasaki et al. (2014) [67] } & \multirow{2}{*}{177} & \multirow{2}{*}{$\begin{array}{l}\text { Prospective } \\
\text { Japan }\end{array}$} & & & REV loss $(n=20)$ & $1 / 20(5.0 \%)$ & - \\
\hline & & & TES & MEP loss & IRR loss $(n=2)$ & - & $2 / 2(100 \%)$ \\
\hline Takebayashi et al. (2014) & 50 & Unclear & $\mathrm{DCC}$ & (15 & REV loss $(n=15)$ & $6 / 15(40.0 \%)$ & - \\
\hline & & & & & $\operatorname{REV} \operatorname{AR}(n=5)$ & Immediate: $1 / 5(20.0 \%)$ & - \\
\hline Yue et al. (2014) & 43 & Prospective & TES & $\mathrm{AR}>50 \%$ & REV loss $(n=9)$ & - & $1 / 9(11.1 \%)$ \\
\hline & & & & & IRR loss $(n=1)$ & - & $1 / 1(100 \%)$ \\
\hline Dengler et al. (2013) & 30 & Prospective & TES & $\mathrm{AR}>50 \%$ & $\begin{array}{l}\text { REV changes } \\
(n=14 \text { cases })\end{array}$ & $1 / 14(7.1 \%)$ & - \\
\hline & & & & $\mathrm{LTI}>10 \%$ & IRR changes ( $n=1$ case) & - & $1 / 1(100 \%)$ \\
\hline $\begin{array}{c}\text { Kang et al. (2013) } \\
{[71]}\end{array}$ & 37 & $\begin{array}{l}\text { Unclear } \\
\text { China }\end{array}$ & TES & $\mathrm{AR}>50 \%$ & $\mathrm{AR}(n=8)$ & $3 / 8(37.5 \%)$ & $\mathrm{N} / \mathrm{A}$ \\
\hline Maruta et al. (2012) & 2 & Prospective & DCS & & $\operatorname{REV} \operatorname{AR}(n=1)$ & - & - \\
\hline$[72]$ & 22 & Japan & TES & AR > 50\% & REV loss $(n=3)$ & $2 / 3(66.6 \%)$ & - \\
\hline Shi et al. (2012) & 68 & Unclear & TES & $\Delta R>50 \%$ & $\operatorname{REV} \operatorname{AR}(n=6)$ & - & - \\
\hline [73] & 68 & China & IES & AK > 50\% & $\operatorname{IRR} \operatorname{AR}(n=3)$ & - & $3 / 3(100 \%)$ \\
\hline
\end{tabular}


Table 2. Cont.

\begin{tabular}{|c|c|c|c|c|c|c|c|}
\hline \multirow{2}{*}{ Authors } & \multirow{2}{*}{ No. of Patients } & \multirow{2}{*}{ Study Design } & \multirow{2}{*}{ STT } & \multirow{2}{*}{ Warning Criterion } & \multirow{2}{*}{ MEP Changes } & \multicolumn{2}{|c|}{ Postoperative Motor Deficit in Relation to MEP Change } \\
\hline & & & & & & Transient * & Permanent * \\
\hline \multirow{3}{*}{$\begin{array}{c}\text { Motoyama et al. (2011) } \\
\text { [74] }\end{array}$} & \multirow{3}{*}{48} & \multirow{3}{*}{$\begin{array}{l}\text { Retrospective } \\
\text { Japan }\end{array}$} & \multirow{3}{*}{ DCSTES } & \multirow{3}{*}{$\mathrm{AR}>50 \%$} & $\operatorname{REV} \operatorname{AR}(n=2)$ & - & N/A \\
\hline & & & & & REV loss $(n=2)$ & - & $\mathrm{N} / \mathrm{A}$ \\
\hline & & & & & IRR loss $(n=1)$ & $1 / 5(20.0 \%),<24 \mathrm{~h}$ & $\mathrm{~N} / \mathrm{A}$ \\
\hline \multirow{2}{*}{$\begin{array}{c}\text { Irie et al. } \\
(2010) \\
{[75]} \\
\end{array}$} & \multirow{2}{*}{110} & \multirow{2}{*}{$\begin{array}{l}\text { Retrospective } \\
\text { Japan }\end{array}$} & \multirow{2}{*}{ TES } & \multirow{2}{*}{$\begin{array}{c}\mathrm{AR}>50 \% \\
\mathrm{THI}>20 \mathrm{~mA}\end{array}$} & $\operatorname{REV} \operatorname{AR}(n=2)$ & - & - \\
\hline & & & & & REV +IRR loss $(n=4)$ & $2 / 4(50.0 \%)$ & - \\
\hline $\begin{array}{c}\text { Yeon et al. (2010) } \\
\text { [76] }\end{array}$ & 98 & $\begin{array}{l}\text { Prospective } \\
\text { Japan }\end{array}$ & TES & $\mathrm{AR}>50 \%$ & REV loss $(n=8)$ & $1 / 8(12.5 \%)$ & - \\
\hline \multirow{2}{*}{$\begin{array}{c}\text { Szelényi et al. (2007) } \\
\text { [77] }\end{array}$} & \multirow{2}{*}{108} & \multirow{2}{*}{$\begin{array}{c}\text { Prospective and } \\
\text { Retrospective } \\
\text { Germany/USA }\end{array}$} & \multirow{2}{*}{$\begin{array}{l}\text { DCS } \\
\text { TES }\end{array}$} & \multirow{2}{*}{$\begin{array}{c}\mathrm{AR}>50 \% \\
\mathrm{THI}>20 \mathrm{~mA}(\mathrm{TES}) \\
\mathrm{THI}>2 \mathrm{~mA}(\mathrm{DCS})\end{array}$} & $\begin{array}{c}\text { TES changes } \\
(n=9: 1 \text { IRR THI, } 1 \text { REV AR, } 6 \text { REV loss, } 1 \\
\text { IRR loss })\end{array}$ & $3 / 9(33.3 \%)$ & - \\
\hline & & & & & $\begin{array}{c}\text { DCS changes } \\
(n=13: 1 \text { REV THI, 3 IRR THI, } 2 \text { REV AR, } 6 \\
\text { REV loss, } 1 \text { IRR loss })\end{array}$ & - & $2 / 13(15.4 \%)$ \\
\hline $\begin{array}{l}\text { Weinzierl et al. (2007) } \\
\text { [78] }\end{array}$ & 18 & $\begin{array}{l}\text { Prospective } \\
\text { Germany }\end{array}$ & TES & $\begin{array}{l}\mathrm{AR}>50 \% \\
\mathrm{LTI}>10 \%\end{array}$ & $\operatorname{REV} \operatorname{AR}(n=8)$ & - & - \\
\hline \multirow{4}{*}{$\begin{array}{c}\text { Szelényi et al. (2006) } £ \\
{[16]}\end{array}$} & \multirow{4}{*}{116} & & & & REV loss $(n=8)$ & $1 / 8(12.5 \%)$ & $3 / 8(37.5 \%)$ \\
\hline & & $\begin{array}{l}\text { Prospective and } \\
\text { Retrospective }\end{array}$ & DCS & $\mathrm{AR}>50 \%$ & IRR loss $(n=2)$ & - & $2 / 2(100 \%)$ \\
\hline & & Germany & TES & $\mathrm{THI}>20 \mathrm{~mA}$ & $\operatorname{REV}$ THI $(n=1)$ & $1 / 1(100 \%)$ & - \\
\hline & & & & & IRR THI $(\mathrm{n}=1)$ & - & $1 / 1(100 \%)$ \\
\hline Horiuchi et al & & & & & $\operatorname{REV} \operatorname{AR}(n=3)$ & - & - \\
\hline (2005) & 53 & $\begin{array}{c}\text { Prospective } \\
\text { Japan }\end{array}$ & DCS & $\mathrm{AR}>50 \%$ & REV loss $(n=6)$ & $3 / 6(50.0 \%)$ & - \\
\hline [79] & & & & & IRR loss $(n=1)$ & - & $1 / 1(100 \%)$ \\
\hline $\begin{array}{l}\text { Suzuki et al. } \\
\text { (2003) }\end{array}$ & 108 & Prospective & DCS & $\mathrm{AR}>50 \%$ & REV changes $(n=19)$ & $\begin{aligned} & 4 / 19(21.0 \%): \\
* & <24 \text { h, REV loss }\end{aligned}$ & - \\
\hline [19] & & Japan & & Аार $>30 \%$ & IRR loss $(n=1)$ & - & $1 / 1(100 \%)$ \\
\hline
\end{tabular}


Table 2. Cont.

\begin{tabular}{|c|c|c|c|c|c|c|c|}
\hline \multirow{2}{*}{ Authors } & \multirow{2}{*}{ No. of Patients } & \multirow{2}{*}{ Study Design } & \multirow{2}{*}{ STT } & \multirow{2}{*}{ Warning Criterion } & \multirow{2}{*}{ MEP Changes } & \multicolumn{2}{|c|}{ Postoperative Motor Deficit in Relation to MEP Change } \\
\hline & & & & & & Transient* & Permanent * \\
\hline \multicolumn{8}{|c|}{ ENDOVASCULAR PROCEDURES FOR ANEURYSMS } \\
\hline \multirow{4}{*}{$\begin{array}{l}\text { Nakagawa et al. (2020) } \\
{[80]}\end{array}$} & \multirow{4}{*}{164} & \multirow{4}{*}{$\begin{array}{l}\text { Retrospective } \\
\text { Japan }\end{array}$} & \multirow{4}{*}{ TES } & \multirow{4}{*}{$\mathrm{AR}>50 \%$} & $\operatorname{REV} \operatorname{AR}(n=3)$ & - & $\mathrm{N} / \mathrm{A}$ \\
\hline & & & & & IRR AR $(n=2)$ & $2 / 2(100 \%)$ & $\mathrm{N} / \mathrm{A}$ \\
\hline & & & & & REV loss $(n=1)$ & - & $\mathrm{N} / \mathrm{A}$ \\
\hline & & & & & IRR loss $(n=1)$ & $1 / 1(100 \%)$ & $\mathrm{N} / \mathrm{A}$ \\
\hline $\begin{array}{l}\text { Wilent et al. (2020) } \\
\text { [81] }\end{array}$ & 763 & $\begin{array}{l}\text { Retrospective } \\
\text { USA }\end{array}$ & TES & $\mathrm{AR}>40 \%$ & $\operatorname{REV} \operatorname{AR}(n=15)$ & - & $\mathrm{N} / \mathrm{A}$ \\
\hline \multirow{3}{*}{$\begin{array}{l}\text { Lee et al. (2019) } \\
\quad[82]\end{array}$} & \multirow{3}{*}{561} & \multirow{3}{*}{$\begin{array}{l}\text { Retrospective } \\
\text { Korea }\end{array}$} & \multirow{3}{*}{ TES } & \multirow{3}{*}{$\begin{array}{l}\text { AR }>50 \% \\
\mathrm{LTI}>10 \%\end{array}$} & $\operatorname{REV} \operatorname{AR}(n=5)$ & - & $\mathrm{N} / \mathrm{A}$ \\
\hline & & & & & $\operatorname{IRR} \operatorname{AR}(n=1)$ & - & $\mathrm{N} / \mathrm{A}$ \\
\hline & & & & & IRR loss $(n=1)$ & $1 / 1(100 \%)$ & N/A \\
\hline \multirow{2}{*}{$\begin{array}{l}\text { Piñeiro et al. (2015) } \\
\text { [83] }\end{array}$} & \multirow{2}{*}{8} & \multirow{2}{*}{$\begin{array}{l}\text { Prospective } \\
\text { Spain }\end{array}$} & \multirow{2}{*}{ TES } & \multirow{2}{*}{$\mathrm{AR}>50 \%$} & $\operatorname{REV}$ AR $(n=1)$ & - & - \\
\hline & & & & & IRR AR $(n=1)$ & - & $1 / 1(100 \%)$ \\
\hline $\begin{array}{l}\text { Hiraishi et al. (2011) } \\
\text { [84] }\end{array}$ & 7 & $\begin{array}{l}\text { Unclear } \\
\text { Japan }\end{array}$ & TES & $\mathrm{AR}>50 \%$ & $\operatorname{REV}$ AR $(n=3)$ & 1/3 (33.3\%) & $\mathrm{N} / \mathrm{A}$ \\
\hline \multicolumn{8}{|c|}{ CASE REPORTS } \\
\hline $\begin{array}{l}\text { Iwasaki et al. (2013) } \\
\text { [85] }\end{array}$ & $\begin{array}{c}2 \\
(1 \text { awake })\end{array}$ & $\begin{array}{l}\text { Case report } \\
\text { Japan }\end{array}$ & TES & $\mathrm{AR}>50 \%$ & \multicolumn{3}{|c|}{$\begin{array}{l}\text { Absence of MEP AR > 50\% for }>10 \text { min after clipping as an indicator for the preservation of the long } \\
\text { insular artery }\end{array}$} \\
\hline $\begin{array}{l}\text { Szelényi et al. (2003) } \\
\text { [86] }\end{array}$ & 1 & $\begin{array}{l}\text { Case report } \\
\text { Germany }\end{array}$ & $\begin{array}{l}\text { DCS } \\
\text { TES }\end{array}$ & MEP loss & \multicolumn{3}{|c|}{$\begin{array}{l}\text { Arteriosclerotic aneurysm wall preventing the complete closure of the clip. } \\
\text { REV loss and immediate postoperative hemiplegia still present at discharge ( } 1 \text { month). }\end{array}$} \\
\hline
\end{tabular}

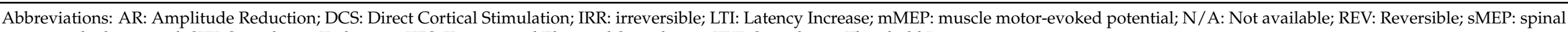
motor-evoked potential; STT: Stimulation Technique; TES: Transcranial Electrical Stimulation; THI: Stimulation Threshold Increase. 
The overall results of the DTA analysis are presented in a heatmap in Figure 2. The corresponding numerical values are described in detail in Tables S3-S6. Sensitivity and specificity estimates of MEPs regarding permanent postoperative motor deficits and their CIs are depicted in Figure 3. The forest plots for transient, early-transient, and all motor deficits can be found in Figures S1-S3, and separate heatmaps for permanent, transient, early-transient, and all postoperative motor deficits are provided in Figures S4-S7 in the Supplementary Material. The relative rates of MEP changes as well as the rates of reversible and irreversible MEP changes and permanent deficits are summarized for all studies in Table 3. Table S7 additionally depicts the total number of early-transient, transient, and permanent motor deficits in conjunction with MEP changes and the relative rate of all motor deficits in all studies. Figure 4 illustrates the results of the correlation analysis in a bubble plot, and the corresponding scatterplot can be found in Figure S8.

Overall, the results obtained from the data analysis suggest the following:

- $\quad$ Reversible MEP changes did not result in a postoperative motor deficit in most cases. If a motor deficit occurred, it was more frequently transient than permanent. Irreversible MEP changes were associated with a higher number of permanent than transient motor deficits;

- In almost all studies of the scoping review, specificity and NPV were high regardless of the timing of postoperative assessment. MEPs can reliably identify the true negative cases, and if no irreversible MEP alterations are observed, then it is not probable that the patient suffers a motor deficit immediately after surgery, in the short-term follow-up or in the long-term follow-up;

- $\quad$ Sensitivity and PPV varied across the studies and were rather low or modest in most of them, whereas some individual studies reported a $100 \%$ sensitivity and others a $100 \%$ PPV. The sensitivity estimates appeared to be higher for permanent motor deficits compared with the early-transient and transient deficits and for the threshold criterion compared with the amplitude criterion. PPV seemed to be higher for the prediction of any motor deficit regardless of the postoperative duration of the deficit. The low and modest values are impacted by the low prevalence of motor deficits;

- $\quad$ There was no remarkable difference in the diagnostic accuracy measures between TES and DCS in the included studies;

- $\quad$ In most cases, the combination of mapping and monitoring yielded higher PPV for all type of deficits compared with monitoring criteria alone;

- $\quad$ The CIs were narrow and indicated high precision of the specificity estimates, but the CIs of the sensitivity estimates were wide, implying greater uncertainty. The wider CIs for sensitivity are also attributed to the low incidence of postoperative deficits;

- The summary of events for each study demonstrated that the rate of postoperative motor deficits and intraoperative MEP changes is low. Regarding MEP changes, reversible alterations appeared to be more frequent than irreversible;

- The correlation analysis revealed a negative correlation between the proportion of reversible MEP changes and the proportion of new postoperative motor deficits associated with MEP changes $\left(\mathrm{r}_{\text {spearman }}=-0.498, p<0.001\right)$. 

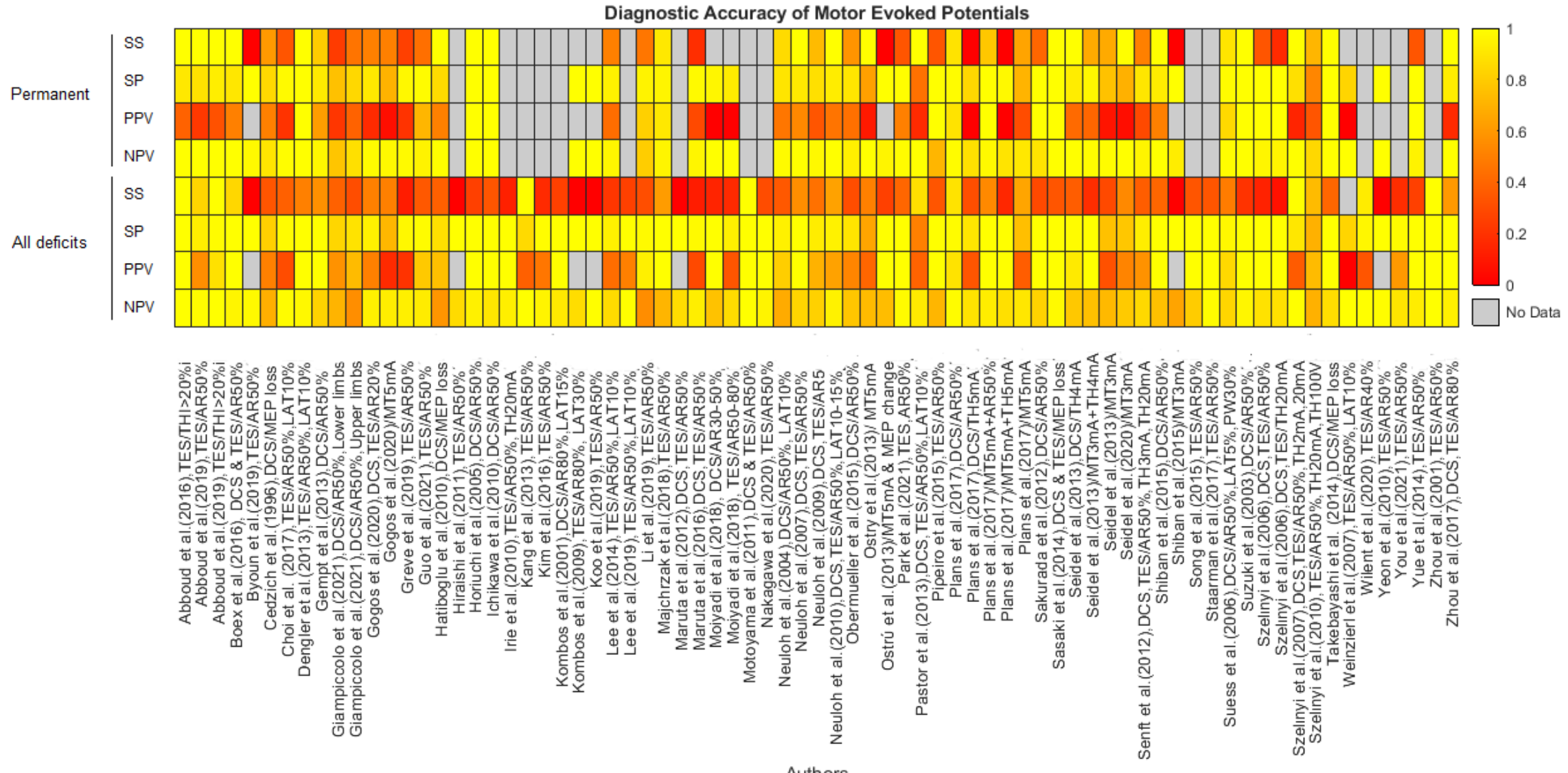

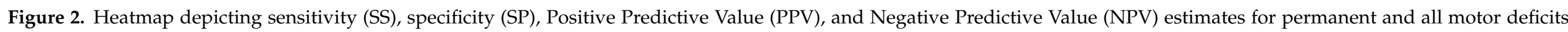

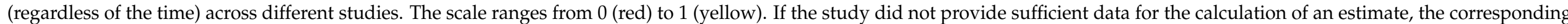

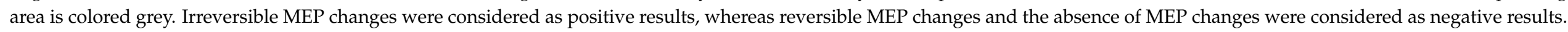


Prediction of Permanent Motor Deficit

Study

Abboud et al.(2016), TES/TH20\%

Abboud et al.(2019),TES/AR50\%

Abboud et al.(2019), TES/TH $20 \%$

Boex et al.(2016),DCS,TES/AR50\%

Byoun et al.(2019),TES/AR50\%

Cedzich et al.(1996),DCS/MEP loss

Choi et al. (2017),TES/AR50\%, LAT10\%

Dengler et al.(2013),TES/AR50\%,LAT10\%

Gempt et al.(2013),DCS/AR50\%

Giampiccolo et al.(2021),DCS/AR50\%,Lower limbs

Giampiccolo et al.(2021).DCS/AR50\%,Upper limbs

Gogos et al.(2020),DCS,TES/AR20\%

Gogos et al.(2020)/MT5mA

Greve et al.(2019),TES/AR50\%

Guo et al.(2021),TES/AR50\%

Hatiboglu et al.(2010),DCS/MEP loss

Horiuchi et al.(2005),DCS/AR50\%

Ichikawa et al.(2010),DCS/AR50\%

Kombos et al.(2009),TES/AR80\%,LAT30\%

Koo et al.(2019),TES/AR50\%

Lee et al.(2014),TES/AR50\%, LAT10\%

Li et al.(2019), TES/AR50\%

Majchrzak et al.(2018),TES/AR50\%

Maruta et al.(2016),DCS,TES/AR50\%

Moiyadi et al.(2018), DCS/AR30-50\%

Moiyadi et al.(2018), TES/AR50-80\%

Neuloh et al.(2004),DCS/AR50\%, LAT10\%.

Neuloh et al.(2007),DCS,TES/AR50\%

Neuloh et al.(2009),DCS,TES/AR50\%

Neuloh et al.(2010),DCS,TES/AR50\%, LAT10-15\%

Obermueller et al.(2015),DCS/AR50\%.

Ostry et al.(2013) MT5mA

Ostry et al.(2013)MT5mA+ MEP change

Park et al.(2021),TES,AR50\%.

Pastor et al.(2013),DCS,TES/AR50\%,LAT10\%

Pineiro et al.(2015),TES/AR50\%

Plans et al (2017).DCS/AR50\%

Plans et

Plans et al.(2017)/MT5mA

Plans et al.(2017)/MT5mA +AR50\%

Plans et al.(2017)/MT5mA+ TH5mA

Sakurada et al.(2012),DCS/AR50\%.

Sasaki et al.(2014),DCS,TES/MEP loss

Seidel et al.(2013),DCS/TH4mA

Seidel et al.(2013)/MT3mA

Seidel et al.(2013)/MT3mA+ TH4mA

Seidel et al.(2020)/MT3mA

Senft et al.(2012),DCS,TES/AR50\%, TH3mA, TH2OmA

Shiban et al.(2015),DCS/AR50\%

Shiban et al.(2015)/MT3mA

Suess et al.(2006),DCS/AR50\%,LAT5\%,PW30\%

Suzuki et al.(2003).DCS/AR50\%

Szelenyi et al.(2006),DCS,TES/AR50\%

Szelenyi et al.(2006),DCS,TES/TH20mA

Szelenyi et al.(2007),DCS,TES/AR50\%,TH2mA,20mA

Szelenyi et al.(2010),TES/AR50\%,TH20mA,100V

Takebayashi et al. (2014),DCS/MEP loss

Weinzier et al.(2007),TES/AR50\%,LAT10\%

Yeon et al.(2010),TES/AR50\%

Yue et al.(2014).TES/AR50\%

Zhou et al.(2017),DCS,TES/AR80\% $\begin{array}{ccccccc}\text { TP } & \text { FP } & \text { FN } & \text { TN } & \text { Sensitivity }(\mathbf{9 5} \% \mathrm{Cl}) & \text { Specificity }(\mathbf{9 5} \% \mathrm{Cl}) & \text { Sensitivity }(\mathbf{9 5 \%} \mathrm{Cl}) \text { Specificity }(\mathbf{9 5 \%} \mathrm{Cl}) \\ 5 & 8 & 0 & 80 & 1.00[0.48,1.00] & 0.91[0.83,0.96]\end{array}$

$1.00[0.63,1.00]$

$1.00[0.63,1.00]$

$1.00[0.63,1.00]$

$0.00[0.00,0.71]$

$0.60[0.15,0.95]$

$0.33[0.04,0.78]$

$1.00[0.03,1.00]$

$0.80[0.44,0.97]$

$0.23[0.05,0.54]$

$0.45[0.24,0.68]$

$0.50[0.01,0.99]$

$0.50[0.01,0.99]$

$0.25[0.01,0.81]$

$0.43[0.23,0.66]$

$1.00[0.16,1.00]$

$1.00[0.03,1.00]$

$1.00[0.03,1.00]$

Not estimable

Not estimable

$0.50[0.12,0.88]$

$0.46[0.28,0.66]$

$0.91[0.59,1.00]$

$0.18[0.02,0.52]$

Not estimable

Not estimable

$0.86[0.57,0.98]$

$1.00[0.63,1.00]$

$0.73[0.45,0.92]$

$1.00[0.48,1.00]$

$0.58[0.33,0.80]$

$1.00[0.03,1.00]$

$0.00[0.00,0.97]$

$0.33[0.04,0.78$

$1.00[0.29,1.00]$

$0.33[0.01,0.91]$

$0.89[0.52,1.00]$

$0.00[0.00,0.34]$

$0.64[0.35,0.87]$

$0.78[0.40,0.97]$

$0.00[0.00,0.34]$

$0.40[0.05,0.85]$

$1.00[0.16,1.00]$

$1.00[0.48,1.00]$

$0.67[0.09,0.99]$

$0.67[0.09,0.99]$

$1.00[0.29,1.00]$

$0.50[0.07,0.93]$

$1.00[0.03,1.00]$

$0.00[0.00,0.97]$

$0.89[0.67,0.99]$

$1.00[0.03,1.00]$

$0.33[0.04,0.78]$
$0.17[0.00,0.64]$

$1.00[0.16,1.00]$

$0.71[0.29,0.96]$

$1.00[0.40,1.00]$

Not estimable

Not estimable

$0.33[0.01,0.91]$

$1.00[0.03,1.00]$
$0.89[0.84,0.92]$

$0.90[0.82,0.96]$

$1.00[0.97,1.00]$

$\longrightarrow$

$0.85[0.62,0.97]$

$0.98[0.96,0.99]$

$1.00[0.89,1.00]$

$0.92[0.82,0.97]$

-

$0.84[0.76,0.91]$

$0.91[0.81,0.97]$

$0.70[0.57,0.82]$

$0.97[0.93,0.99]$

$0.98[0.96,1.00]$

$0.86[0.57,0.98]$

$1.00[0.93,1.00]$

$1.00[0.83,1.00]$

$1.00[0.78,1.00]$

$1.00[0.99,1.00]$

$0.95[0.87,0.99]$

$0.95[0.87,0.99]$

$0.96[0.79,1.00]$

$0.98[0.95,0.99]$

$0.96[0.80,1.00]$

$0.92[0.79,0.98]$

$0.89[0.83,0.94]$

$0.91[0.83,0.96]$

$0.88[0.82,0.92]$

$0.93[0.85,0.97]$

$0.90[0.84,0.94]$

$0.63[0.41,0.81]$

$1.00[0.86,1.00]$

$0.99[0.98,1.00]$

$0.44[0.25,0.65]$

$1.00[0.48,1.00]$

$0.99[0.93,1.00]$

$0.84[0.74,0.92]$

$0.70[0.58,0.81]$

$1.00[0.95,1.00]$

$0.97[0.91,1.00]^{\text {t. }}$

$1.00[0.86,1.00]$

$1.00[0.98,1.00]$

$0.93[0.85,0.97]$

$0.76[0.66,0.84]$

$0.97[0.91,0.99]$

$0.69[0.61,0.76]$

$0.90[0.78,0.97]$

$0.92[0.64,1.00]$

$1.00[0.75,1.00]$

$0.99[0.96,1.00]$

$1.00[0.97,1.00]$

$1.00[0.97,1.00]$

$1.00[0.97,1.00]$
$0.88[0.79,0.93]$

$0.52[0.30,0.74]$

$1.00[0.92,1.00]$

$0.83[0.59,0.96]$

$1.00[0.96,1.00]$

$1.00[0.91,1.00]$

$0.93[0.84,0.98]$

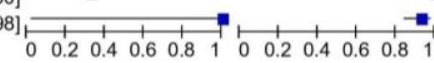

Figure 3. Forest plot of sensitivity and specificity estimates for permanent motor deficits AR: Amplitude criterion; DCS: Direct Cortical Stimulation; FN: False Negative; FP: False Positive; i: ipsilateral; LAT: Latency criterion; MEP: Motor Evoked Potential; MT: Motor Threshold/Mapping criterion; PW: Pulse Width Increase; TES: Transcranial Electrical Stimulation; TH: Threshold criterion; TN: True Negative; TP: True Positive. 


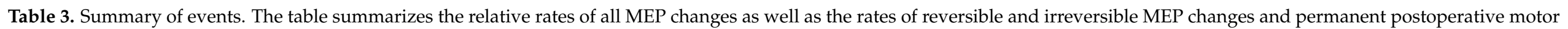
deficits in each study.

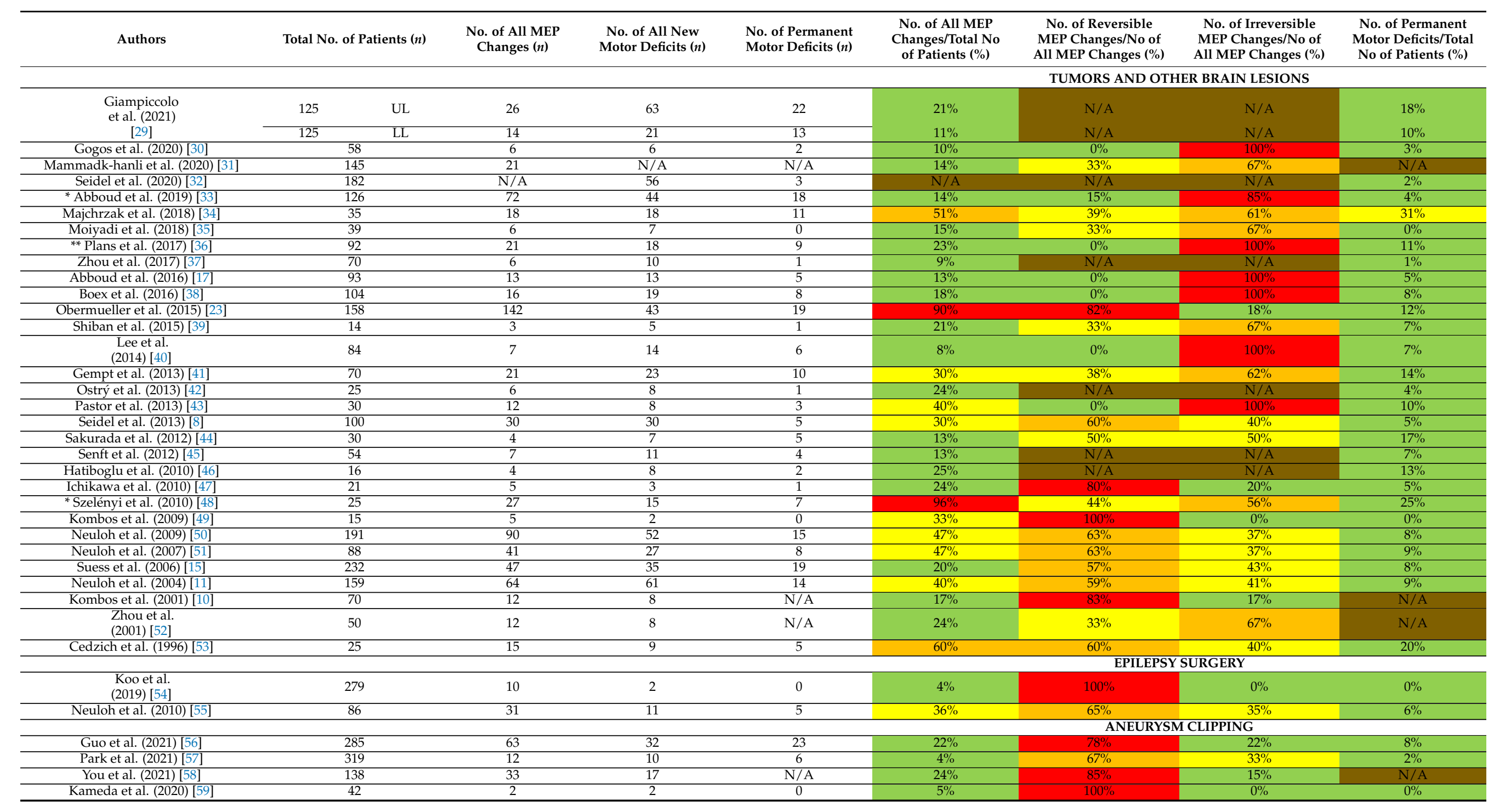


Table 3. Cont

\begin{tabular}{|c|c|c|c|c|c|c|c|c|}
\hline Authors & Total No. of Patients $(n)$ & $\begin{array}{l}\text { No. of All MEP } \\
\text { Changes }(n)\end{array}$ & $\begin{array}{l}\text { No. of All New } \\
\text { Motor Deficits }(n)\end{array}$ & $\begin{array}{l}\text { No. of Permanent } \\
\text { Motor Deficits }(n)\end{array}$ & $\begin{array}{c}\text { No. of All MEP } \\
\text { Changes/Total No } \\
\text { of Patients (\%) }\end{array}$ & $\begin{array}{c}\text { No. of Reversible } \\
\text { MEP Changes/No of } \\
\text { All MEP Changes (\%) }\end{array}$ & $\begin{array}{l}\text { No. of Irreversible } \\
\text { MEP Changes/No of } \\
\text { All MEP Changes (\%) }\end{array}$ & $\begin{array}{c}\text { No. of Permanent } \\
\text { Motor Deficits/Total } \\
\text { No of Patients (\%) }\end{array}$ \\
\hline Byoun et al. (2019) [22] & 115 & 5 & 3 & 3 & $4 \%$ & $100 \%$ & $0 \%$ & $3 \%$ \\
\hline Greve et al. (2019) [60] & 133 & 13 & 9 & 4 & $9 \%$ & $61 \%$ & $39 \%$ & $3 \%$ \\
\hline Li et al.(2019) [61] & 92 & 92 & 52 & 28 & $100 \%$ & $83 \%$ & $17 \%$ & $30 \%$ \\
\hline Choi et al. (2017) [12] & 386 & 10 & 8 & 6 & $3 \%$ & $0 \%$ & $100 \%$ & $2 \%$ \\
\hline Komatsu et al. (2017) [62] & 9 & 5 & 0 & 0 & $56 \%$ & $100 \%$ & $0 \%$ & $0 \%$ \\
\hline Staarman et al. (2017) [63] & 123 & 10 & 3 & $\mathrm{~N} / \mathrm{A}$ & $8 \%$ & $90 \%$ & $10 \%$ & $\mathrm{~N} / \mathrm{A}$ \\
\hline Kim et al. (2016) [64] & 685 & 43 & 36 & N/A & $6 \%$ & $70 \%$ & $30 \%$ & N/A \\
\hline Maruta et al. (2016) [65] & 243 & 73 & 18 & 11 & $30 \%$ & $90 \%$ & $10 \%$ & $5 \%$ \\
\hline Song et al. (2015) [66] & 11 & 6 & 3 & $\mathrm{~N} / \mathrm{A}$ & $55 \%$ & $83 \%$ & $17 \%$ & N/A \\
\hline Takebayashi et al. (2014) [68] & 50 & 19 & 10 & 4 & $38 \%$ & $79 \%$ & $21 \%$ & $8 \%$ \\
\hline Yue et al. (2014) [69] & 43 & 15 & 4 & 3 & $35 \%$ & $93 \%$ & $7 \%$ & $7 \%$ \\
\hline${ }^{*}$ Dengler et al. (2013) [70] & 30 & 15 & 2 & 1 & $44 \%$ & $93 \%$ & $7 \%$ & $3 \%$ \\
\hline Kang et al. (2013) [71] & 37 & 8 & 3 & N/A & $22 \%$ & $0 \%$ & $100 \%$ & N/A \\
\hline Maruta et al. (2012) [72] & 22 & 4 & 3 & $\mathrm{~N} / \mathrm{A}$ & $18 \%$ & $100 \%$ & $0 \%$ & N/A \\
\hline Shi et al. (2012) [73] & 68 & 9 & $\mathrm{~N} / \mathrm{A}$ & N/A & $13 \%$ & $67 \%$ & $33 \%$ & N/A \\
\hline Motoyama et al. (2011) [74] & 48 & 5 & 1 & N/A & $11 \%$ & $80 \%$ & $20 \%$ & N/A \\
\hline Irie et al. (2010) [75] & 110 & 6 & 8 & N/A & $5 \%$ & $83 \%$ & $17 \%$ & N/A \\
\hline Yeon et al. (2010) [76] & 98 & 12 & 1 & 0 & $12 \%$ & $100 \%$ & $0 \%$ & $0 \%$ \\
\hline Szelényi et al. (2007) [77] & 108 & 22 & 5 & 2 & $13 \%$ & $73 \%$ & $27 \%$ & $2 \%$ \\
\hline Weinzierl et al. (2007) [78] & 18 & 4 & 0 & 0 & $22 \%$ & $25 \%$ & $75 \%$ & $0 \%$ \\
\hline Szelényi et al. (2006) [16] & 116 & 12 & 15 & 6 & $11 \%$ & $75 \%$ & $25 \%$ & $5 \%$ \\
\hline Suzuki et al. (2003) [19] & 108 & 20 & 5 & 1 & $19 \%$ & $95 \%$ & $5 \%$ & $1 \%$ \\
\hline \multicolumn{9}{|c|}{ ENDOVASCULAR PROCEDURES FOR ANEURYSMS } \\
\hline Nakagawa et al. (2020) [80] & 164 & 7 & 10 & N/A & $4 \%$ & $57 \%$ & $43 \%$ & N/A \\
\hline Wilent et al. (2020) [81] & 763 & 51 & 13 & N/A & $7 \%$ & $29 \%$ & $71 \%$ & N/A \\
\hline Lee et al. (2019) [82] & 561 & 7 & 4 & N/A & $1 \%$ & $71 \%$ & $29 \%$ & N/A \\
\hline Piñeiro et al. (2015) [83] & 8 & 2 & 3 & 3 & $25 \%$ & $50 \%$ & $50 \%$ & $38 \%$ \\
\hline Hiraishi et al. (2011) [84] & 7 & 3 & 1 & $\mathrm{~N} / \mathrm{A}$ & $43 \%$ & $100 \%$ & $0 \%$ & N/A \\
\hline
\end{tabular}

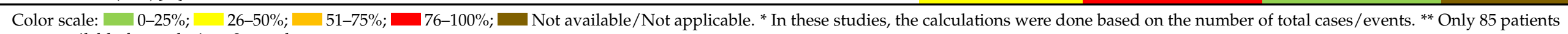
were available for analysis at 3 months. 


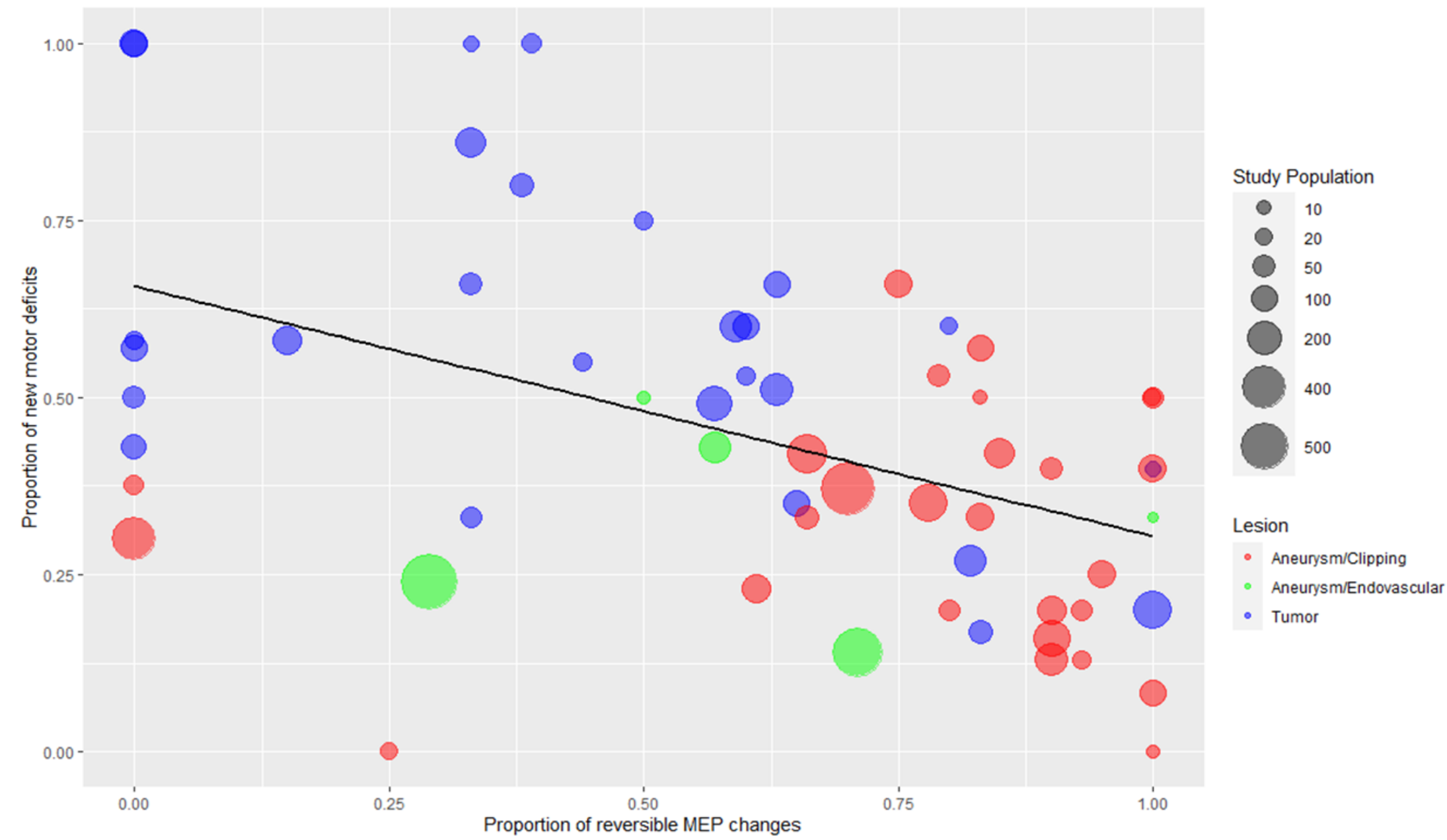

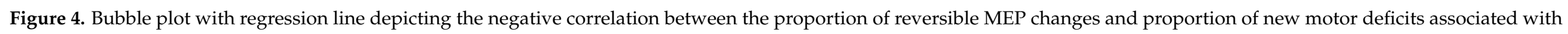

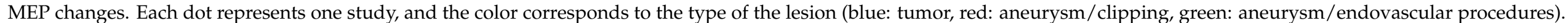

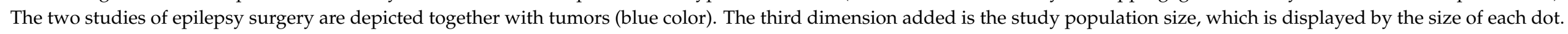
Spearman's rank correlation coefficient $=-0.498(p<0.001)$. 


\section{Discussion}

\subsection{Type and Range of Available Evidence}

This scoping review included 68 primary clinical studies and, more specifically, 31 studies for tumors and other brain lesions, two for epilepsy surgery, 28 for aneurysm clipping, five for endovascular aneurysm procedures, and two case reports. Except for the two case reports, all the studies were observational case series, either prospective $(47 \%)$ or retrospective $(44 \%)$, with a high number of patients. Small-scale studies with less than 20 patients were rare $(12 \%)$, while non-randomized and randomized controlled trials (RCTs) were not identified. Obviously, the lack of RCTs from the body of the existing literature is attributed to ethical considerations that hinder the implementation of this study design [87]. As intraoperative monitoring of MEPs provides data that necessitates a rescue intervention, it would be unethical to ignore the intraoperative alarms in a group of patients or not to use them at all in operation within highly eloquent regions [88].

However, the clinical and methodological heterogeneity across the studies was remarkable, and the main sources of this heterogeneity were patients' characteristics, intraoperative monitoring and mapping techniques, utilized MEP warning criteria, and outcome assessment. Undoubtedly, the varying study protocols and definitions render evidence synthesis quite challenging. This accounts for the relatively few reviews and meta-analyses of MEP warning criteria in supratentorial surgery, although some authors attempted to synthesize the existing research and estimate summary effects for vascular surgeries [89-92]. Due to those factors, we applied a descriptive approach using the systematic format of a scoping review, and we tried, in particular, visualizing instead of pooling the data.

\subsection{Study Population and Type of Lesions}

In many case series, children and adolescents were included in the study population. Except for patients in late adolescence, whose neuroanatomical and neurophysiological characteristics do not differ substantially from adults, the inclusion of young patients may confound the results. Due to incomplete myelination, modifications of intraoperative neurophysiological techniques might be necessary [93]. Especially in children younger than 10 years old, longer stimulating pulse trains and higher stimulation thresholds might be needed to elicit an MEP response [94,95]. However, the evidence regarding the optimal stimulation parameters in younger ages is scarce. It remains unclear if MEP warning criteria that are commonly used in supratentorial surgery of adults are equal in the pediatric population.

Similar MEP warning criteria were applied in surgeries for a broad spectrum of brain lesions, such as intrinsic glioma of different grades, extrinsic metastases, vascular malformations, cortical dysplasia, and aneurysms located in different arteries. Because of the obvious different surgical strategies and approaches, we did analyze studies for tumor surgeries separately from them for aneurysm surgeries (Tables 1 and 2, Figure 4). During tumor surgeries, additional warning criteria provided by subcortical mapping have been suggested by $12 \%$ of the included studies, and this aspect will be discussed in detail below in the paragraph "The mapping-monitoring crosstalk and the warning sign hierarchy". Aneurysm surgeries presented a higher tendency of reversible MEP changes than tumor surgeries, which will be discussed further in the paragraph "MEPs as surrogate markers".

Concerning tumor location, Abboud et al. [33] observed a significant correlation of postoperative motor deterioration with tumor location in the insula. This fact might be attributed to the higher incidence of vascular injury during insular glioma surgery [30]. Krieg et al. [96] found a statistically significant increase in postoperative motor deficits in cases where the tumor was located in the precentral cortex compared with the postcentral and anterior frontal cortex. During resection of tumors located in the precentral gyrus, MEP monitoring might be inferior to mapping methods as either the stimulating electrode interferes with the surgical approach or the MEP might be generated in the corticospinal tract distal to the resected area [97]. Giampiccolo et al. [29] performed a lesion analysis, which showed that motor-evoked potential-related long-term motor deficits were 
associated with direct or ischaemic damage to the corticospinal tract, whereas muscle motor-evoked potential-unrelated deficits occurred when supplementary motor areas were resected in conjunction with dorsal premotor regions and the anterior cingulate. This important observation illustrates the fact that MEP represents the integrity of the primary motor cortex (M1) and the corticospinal tract but not associative motor areas.

\subsection{Stimulation Techniques and Parameters}

Continuous MEP monitoring was performed either with TES (via scalp electrodes) or DCS (electrodes directly placed on the precentral gyrus), but many authors used both stimulation techniques simultaneously or applied them in subgroups of patients in their series. The high-frequency multipulse stimulation technique introduced by Taniguchi et al. [5] was applied in all studies, but there were differences in stimulation parameters, which were more apparent in stimulation intensity. The stimulation intensity has special importance when interpreting the amplitude criterion, as MEP exhibits trial-to-trial variability, and MEP amplitude alterations may be caused by non-surgical factors [9]. There has been much debate regarding the use of TES in supratentorial surgery because TES induces less focal stimulation, and at high intensity, the activation site might be located deeper than the actual level of the lesion $[17,77,98]$. Rothwell et al. [99] stated that strong stimulation currents may activate the CST even at the foramen magnum. Hence, depending on the area of interest, there might be the risk of stimulating the white matter more caudally than the site of neurological damage, leading to a higher rate of false-negative results. Furthermore, loss of cerebrospinal fluid after dural opening leads to brain shift and subdural air accumulation. That fact may interfere with the reliability and evaluation of TES-MEP warning criteria. Further, TES may cause a higher rate of patient movement [100]. Because of these drawbacks, many neurosurgeons opt for DCS, which needs lower stimulation intensities and allows a focal and superficial stimulation of corticospinal neurons [8]. Nonetheless, DCS is not applicable in patients with scar tissue from previous operations. It may also interfere with MEP monitoring due to electrode dislocation on the cortex [101]. Szelényi et al. reported that TES and DCS do not differ in their ability to detect an impending neurological injury. Both paradigms may be alternatively applied during the same surgical procedure, provided if lateral TES montages are not used, and near-threshold stimulation intensities are applied [77]. Our scoping review supports this observation if applied as a general rule. However, a more thorough comparison between the two stimulation modalities depending on the type of surgery, pathology, and tumor location (especially in the precentral area) would be clinically meaningful and may contribute to an optimized implementation of warning criteria.

The inclusion criterion for our review was the use of MEP alarm criteria during continuous MEP monitoring, eventually complemented by a secondary test such as subcortical mapping. Consequently, studies, which applied mapping techniques (such as Penfield or high-frequency stimulation) without MEP monitoring were excluded. In all included studies, the high-frequency multipulse stimulation technique was utilized for subcortical motor mapping, and the stimulation parameters were similar to the ones in MEP monitoring. For subcortical mapping, monopolar cathodal stimulation was applied in all studies except for the study by Kombos et al. [49], who used anodal stimulation. In a comparative study by Shiban et al. [102], the authors pointed out that cathodal stimulation was superior and lower stimulation intensities were required. Gogos et al. [30] utilized bipolar stimulation in a subset of 20 patients in addition to monopolar stimulation and reported that bipolar stimulation elicited MEPs in only $30 \%$ of patients as opposed to the monopolar stimulation, which identified the descending motor tracts in $86.4 \%$ of patients. These results are in concordance with the findings of Szelényi et al. [103], who concluded that monopolar cathodal stimulation is more efficient than bipolar cathodal stimulation in subcortical motor mapping. Applying the short train monopolar paradigm, the current spreads radially towards a distal reference electrode [104]. This pattern of electric current spreading enables the estimation of the distance between stimulation point and CST based 
on the rule that $1 \mathrm{~mA}$ increase in subcortical stimulation threshold corresponds to $1 \mathrm{~mm}$ increase in the distance towards the CST. Up to now, no definitive statement on this relationship is possible; however, the vague rule of thumb " $1 \mathrm{~mA}$ correlates to $1 \mathrm{~mm}$ " is increasingly used when performing subcortical short train monopolar stimulation with five $0.5 \mathrm{~ms}$ cathodal constant-current pulses. Three groups performed continuous (dynamic) subcortical mapping, with two of them integrating the monopolar stimulation probe in the surgical suction device [32,35] and one of them in the ultrasonic aspirator [39]. In the remaining studies, subcortical mapping was performed intermittently with a handheld probe. Allowing an uninterrupted and procedure-driven stimulation [32,105], continuous dynamic mapping via a surgical instrument may improve awareness of the intraoperative conditions and may facilitate immediate reaction to warning signs, but more studies addressing this aspect are needed to make a definitive statement.

\subsection{The Spectrum of MEP Warning Criteria}

The utilized warning criteria varied across the included studies, but in all cases, the disappearance of MEP signal was considered as a major alarming sign that required re-assessment of intraoperative settings and an adjustment of surgical strategy. Apart from MEP loss, the most commonly used warning criteria were amplitude reduction and threshold elevation with cut-off values that differed among the authors. Notably, a $>50 \%$ amplitude reduction was regarded in the vast majority of studies as a significant change, although other magnitudes like $>80 \%$ and $>20 \%$ have also been applied $[10,11,30,37,49]$. Threshold cut-off values that have been used during TES were $>100 \mathrm{~V}$ or $>20 \mathrm{~mA}[16,45$, $48,75,77]$ and during DCS $>3 \mathrm{~mA}[45], \geq 4 \mathrm{~mA}[8,32]$, and $\geq 5 \mathrm{~mA}$ [36]. Interestingly, Ostry et al. [42] used during supratentorial tumor surgery a threshold increase $>2 \mathrm{~mA}$ not as an indicator for surgical intervention but for the performance of subcortical mapping. The definition of a minimum MEP amplitude to be monitored varied significantly among the papers from 10 to $100 \mu \mathrm{V}$ with an average of $30-50 \mu \mathrm{V}[8,10,11,29,32,33,35,38,42,48,53,66$, $73,74,76,78]$. However, in many, it was not clearly defined.

Recently, Abboud et al. [17] introduced a novel threshold criterion and suggested that a TES threshold increase on the affected side of more than $20 \%$ beyond the percentage increase on the unaffected side should be considered as a warning sign. In contrast to the conventional approach of a threshold increase beyond the baseline level, this modification incorporates changes on the unaffected side, which can serve as a negative control for MEP alterations caused by factors other than damage to the CST and highlights the significance of bilateral MEP monitoring. Indeed, the results in their series were highly promising, as none of the patients without threshold increase greater than $20 \%$ beyond the unaffected side suffered a postoperative motor deficit, but further studies are needed for the definite establishment of the novel threshold criterion. Latency increase has never been used as a sole criterion in supratentorial surgery and was always an adjunct to the amplitude criterion. A significant latency increase not accompanied by a consistent amplitude decrease was unusual. This might be obvious, as latency shift would indicate a demyelination process, which is not an expected acute type of injury in supratentorial surgery. Morphology simplification is also a poorly studied warning criterion that remains controversial and may be susceptible to subjectivity.

A significant flaw was that the majority of authors did not report the duration of reversible changes or if they applied a threshold for the duration, above which duration the alteration was considered as irreversible. This clarification is important, as a longer duration of the reversible MEP alteration might explain why some patients develop a postoperative motor deficit despite the successful MEP recovery after the intervention while others do not. Krieg et al. [96] noted that the mean duration of amplitude reduction and latency increase was significantly higher in patients with permanent motor deficit than those with no deficit. In aneurysm surgery, Li et al. [61] proposed $13 \mathrm{~min}$ as the cut-off duration of MEP deterioration for higher risk of ischemic damage, while Guo et al. [56] suggested $8.5 \mathrm{~min}$ and Kameda et al. [59] an even shorter duration of $5 \mathrm{~min}$. The determination of a 
critical threshold to delineate the duration above which an MEP change should be regarded as irreversible and is associated with a higher risk for postoperative motor deficit would guide the neurosurgeon more efficiently and is worth being investigated. Similarly, the borderline between MEP amplitude reduction and MEP loss is still vague, as the maximal stimulation-intensity value has not been defined in many studies.

\subsection{The Mapping-Monitoring "Crosstalk" and the Warning Sign Hierarchy}

Regarding assistant mapping warning criteria, monopolar cathodal subcortical motor thresholds (MT) $\leq 5 \mathrm{~mA}$ and $\leq 3 \mathrm{~mA}$ were the most widely used thresholds that provided an alarming sign for proximity to CST. It has been suggested that the critical MTs might be even lower, but the exact threshold has not been identified yet [8].

As mentioned above, this scoping review included only those subcortical mapping studies that utilized mapping warning criteria combined with MEP monitoring criteria. Due to methodological reasons, subcortical mapping studies, which performed a post-hoc analysis to investigate the critical MT (without using an a priori defined MT as a surrogate to stop resection), studies that did not correlate motor outcome exactly to intraoperative alarm criteria or did not describe precisely the criteria when combining subcortical mapping with continuous MEP monitoring, were excluded [106-111].

Mapping and monitoring warning signs may present a hierarchical "crosstalk" between them [8]. Each method has distinct shortcomings and limitations, and their simultaneous use during surgery may lead to mutual reinforcement. MEP monitoring can assess the functional integrity of the primary motor pathways in real-time and detect potential damage caused by mechanical or vascular injury, providing a trigger for actions to reverse it. Nevertheless, no guarantee is provided that the motor pathway has not already been irreversibly damaged by the time the alarming sign occurs. In other words, the warning criterion may appear after the critical event, and hence, its value is undermined by the eventually irreversible nature of the damage. This fact is also illustrated in Table 3 and in Figure 4. During tumor compared to vascular surgery, a higher rate of irreversible compared to reversible MEP alterations was described. The reason might be the different patterns of injury, especially mechanically induced injury during tumor surgery. If the surgeon injures fibers of the CST, there might be no way back to reverse the damage.

Contrariwise, the mission of subcortical mapping is to localize the motor tracts and provide information about their distance from the operation site. A warning sign obtained from mapping denotes proximity to CST and not functional compromise of the CST. Subcortical motor mapping warns about an impending neurologic injury that has not necessarily taken place but is likely to occur if surgical maneuvers are further continued. Therefore, the surgeon is aware of working close to eloquent structures, meaning that meticulous maneuvers or reappraisal of surgical strategy might be necessary. For mechanical alteration of the CST, the mapping warning signs seem to precede those from monitoring, which may occur at a later moment with low mapping thresholds [8]. However, motor mapping is limited by its inability to detect remote vascular injury, critical end-artery blood supply, and ischemia due to brain retraction that can be detected by MEP monitoring [8]. The advantages of this combinatorial approach with these two neurophysiological techniques during tumor surgery came into focus during the past few years $[8,30,32,35,36,39,49,108-111]$. Our DTA analysis (Figures 2 and 3 ) indicated that their combination results in a more powerful tool. Yet, more evidence is needed to confirm that the combination may achieve the ultimate goal of maximizing resection and minimizing debilitating motor deficits.

\subsection{Different Patterns of Injury-Neurophysiological and Neurosurgical Considerations}

Especially during resection of motor eloquent tumors, permanent motor deficits might be caused by different patterns of injury: direct (mechanical) injury of the primary motor cortex or the corticospinal tract, ischemia due to coagulation of critical perforator arteries, or lesion of multiple supplementary motor areas. In our scoping review, $54.8 \%$ of the included tumor papers did differentiate between injury patterns. If considering the described cases 
of permanent motor deficits, seven groups [30,38-40,44,47,51] described exclusive vascular injury and one group [55] sole mechanical injury as a cause. Nine groups [8,15,23,32,36, $41,46,48,50]$ did observe different injury patterns in their tumor patients with permanent motor deficits with different ratios of vascular, mechanical, or other causes (see also Table S8 in the Supplementary Material).

In our own initial series of 100 motor eloquent tumors, we did describe five patients (5\%) with a postoperative new or worsened motor deficit at three-month follow-up consultation [8]. In all five patients, DCS MEP monitoring alterations were documented (two sudden irreversible threshold increases and three sudden irreversible MEP losses). Of these five patients, two had ischemic vascular lesions, and three had mechanical CST damage. After the introduction of the dynamic mapping method (continuous stimulation via the surgical suction device), the permanent motor deficit rate was 3\%, with direct mechanical injury in three of these patients (1.7\%) [32]. In our series, DCS MEP alterations did occur abruptly, but they could be influenced in $60 \%$ of cases [8]. Further, the stability of DCS-MEPs did provide real-time feedback about the functional integrity of the CST and supported us to continue tumor removal at even very low mapping thresholds. This observation is supported by the recent publication of Gogos et al. [30], where the senior author M. Berger reports in his previous series of 700 motor mapping cases applying bipolar mapping that $41 \%$ of permanent motor deficits had to been attributed to "direct transgression of the motor system" [112]. The authors even concluded that adding monopolar (short train) stimulation and MEP monitoring as an additional neurophysiological tool could significantly reduce permanent motor deficits within the present series being reported at 3.4\%. Giampiccolo et al. [29] observed MEP-related deficits in vascular territories (insular cortex and post-central gyrus) and anatomical territories (internal capsule and precentral gyrus) of the CST. However, they also described MEP-unrelated motor deficits in cases of SMA resection in conjunction with damage to the dorsal premotor and anterior cingulate cortex. Finally, they concluded that MEP drop predicts a permanent, severe motor deficit, which is associated with disconnection of the CST, and they did support MEP monitoring as an important neurophysiological marker.

As already discussed, MEP monitoring may detect different types of vascular damage such as direct vascular damage or injury of perforating vessels, critical end-artery blood supply (for example, in the lenticulostriate territory) due to hypoperfusion, and ischemia due to brain retraction. Those different mechanisms might explain why some MEP alterations can be reversed and others not. This fact is also in accordance with our findings in this scoping review (Table 3 and Figure 4). In the included papers of aneurysm surgery, a higher rate of reversible MEP changes attributed to temporary clipping (mean rate 16.2\% of all temporary clipping cases corresponding to $78 \%$ of all MEP changes during temporary clipping) compared to irreversible MEP changes (mean rate $4.6 \%$ ) was described, which demonstrates that MEP monitoring may successfully guide temporary clipping before definitive aneurysm repair.

Non-surgical factors, such as global or local hypoperfusion, may also affect the MEP amplitude. The autoregulation range of mean arterial pressure (MAP) varies from as low as $55 \mathrm{mmHg}$ to rarely, as high as $113 \mathrm{mmHg}$ [113]. However, the pathology itself or the clinical diseases of the patient may affect the capability of autoregulation, and already small MAP alterations might not be tolerated. In general, it has been described that the MEP amplitude starts to decrease if the cerebral blood flow falls below the threshold of $16 \mathrm{~mL} / \mathrm{min} / 100 \mathrm{~g}$ [114]. In those cases, raising the intraoperative blood pressure could restore blood flow and consequently MEP amplitudes [7].

\subsection{MEP Warning Criteria and Postoperative Motor Deficit}

The DTA analysis revealed that irreversible alterations of MEPs have high specificity and NPV. Sensitivity and PPV varied across the studies, and definite conclusions cannot be drawn, although in most studies, they tended to be low or moderate. This suggests that MEPs cannot always reliably detect the true positive cases. For intraoperative decision- 
making, an important aspect is the confidence in the test's ability to distinguish patients who are likely to develop a motor deficit from those who are not, and in this regard, the high NPV of MEPs is meaningful [115]. In other words, if MEPs remain stable or an MEP change signified by a warning criterion is successfully reversed, then the M1 and the CST are expected to be intact after surgery. Stable or reversed MEPs may reassure the surgeon to continue and, in tumor surgery, achieve a higher extent of tumor resection. If an irreversible MEP change occurs, it does not mean per se that the patient will suffer a new motor impairment, although it is highly possible. Skepticism about false positive alarms and putting the alarm in the right context are important. The ensuing compromise of the surgical goal is reasonable. False alarms may indirectly harm the patient by stopping the surgery. However, too early termination of the surgery may be compensated through a reoperation, whereas a debilitating neurological injury cannot.

Nonetheless, the low prevalence of postoperative deficits has a significant impact on the PPV and may account for the observed low values. Thus, even minor test errors have a considerable effect on the performance of the test. This signifies that a refinement of the alarm criteria cut-off values may not significantly upgrade the PPV. In view of this limitation, the focus should be moved to a multimodal approach and, more specifically, to the combination of MEP monitoring with other intraoperative modalities such as subcortical mapping (see paragraph "The warning sign hierarchy") and intraoperative imaging. Our DTA analysis provides implications for this perspective. The combination of monitoring and mapping criteria seemed to yield higher PPV estimates in tumor surgery. In the future, artificial intelligence and machine learning algorithms may markedly contribute to a better outcome prediction, counterbalancing the interrater variability and the inherent subjectivity of MEP evaluation. However, intraoperative decision-making based on MEP alarms should not be regarded as a rigidly mechanistic process. Thus, the neurophysiologist's/neurosurgeon's contextualization and intraoperative judgment are indispensable.

Secondary postoperative events such as delayed ischemia due to vasospasm, hemorrhage, and edema may lead to motor deficits that will not be detected intraoperatively with MEP monitoring. Therefore, those events cannot be regarded as false-negative outcomes [45]. Moreover, motor function compromise following supratentorial surgery may result from resection of associative motor areas such as the supplementary motor area (SMA) [45]. The classical described SMA syndrome is characterized by impaired ability to initiate voluntary movements (or speech) and resembles muscle weakness after injury of the CST [116]. The disturbances are, in most cases, temporary and may resolve within some weeks after surgery [116]. Given that the SMA is not assessed by MEP intraoperatively, SMA syndrome should not be considered false-negative $[50,116,117]$. These elucidations have been scarcely provided by authors, and this may imply that the real number of false-negative cases in the body of literature might be lower than previously thought.

\subsection{MEPs as Surrogate Markers}

Intraoperative MEPs have a dual function with regard to postoperative motor deficits. Firstly, they may serve as a diagnostic tool for the detection of neurological injury and prediction of postoperative motor status [28]. Secondly, they may contribute to the prevention of motor impairment, acting as surrogate endpoints that trigger a rescue intervention [28]. In the studies of our review, a reversible MEP change did not result in a postoperative motor deficit in most cases, and if a motor deficit manifested, it was transient, with only a few patients suffering a permanent deficit. Irreversible MEP changes were associated with a higher number of transient deficits compared with the reversible ones. Additionally, patients with irreversible alterations were more likely to develop permanent motor deficits. These observations suggest that in case of a successful intervention and reversal of MEP changes, the fatal damage is avoided, and if motor deficits occur, they are expected to resolve during the short-term follow-up. On the contrary, if the intervention was not 
effective and MEP changes were not reversed by the end of the surgery, postoperative motor deficits are more likely to occur and persist.

Table 3 provides an overview of intraoperative events and the rate of permanent motor deficits across different studies. Five percent of the studies had a high number of MEP changes related to all monitored patients, indicating that either these studies had a tendency towards (too) early alarms or alternatively high-risk surgeries were performed. Thirty-eight percent of the studies had a high rate of reversible related to all MEP changes, suggesting that an intraoperative intervention was successful in most cases. On the contrary, $14 \%$ of studies had a high rate of irreversible MEP changes indicating that the warning sign appeared rather (too) late or that it has been impossible by the surgeon to reverse the injury. Remarkably, no study in which the number of permanent motor deficits in the whole study population was high. Further, the bubble plot (Figure 4) illustrates that aneurysm procedures tend to cluster at the right-bottom part of the plot, signifying that vascular surgeries have a higher rate of reversible MEP changes compared with tumor surgery. This observation may be attributed to the fact that the rescue interventions in the two types of surgeries have a different potential for success. Admittedly, ischemia caused by a temporary clip can be reversed more easily than a mechanical injury of the CST.

The characterization of reversible MEP changes followed by postoperative motor deficit either as false-negative or as true-positive is a controversial point. In our DTA analysis, we regarded only irreversible MEP changes as positive results. A question that arises is whether the reversible alterations followed by motor deficit should be considered as true-positive cases that were partially reversed after successful intervention and the postoperative deficit as the residue of a partially reversed injury. This issue is more prominent in cases of immediate postoperative (early-transient) motor deficits that resolve in a short time. Indeed, the rescue intervention that takes place between the occurrence of the intraoperative alarm and the time of motor function evaluation may alter the outcome and confounds the assessment of MEPs as diagnostic tools. However, the diagnostic performance of MEPs in itself does not encompass the rescue intervention. Undoubtedly, the rescue intervention can be triggered by MEP alarms, but this is rather a matter of MEP performance as a surrogate and not as diagnostic markers. Thus, reversible MEP changes should be evaluated under the concept of MEP surrogacy [92].

MEPs may function as surrogate endpoints in the sense of substituting the postoperative motor deficit, which is the clinical endpoint but cannot be assessed on the anesthetized patient intraoperatively $[28,92]$. Although similar, surrogacy is not identical with diagnosis, and useful diagnostic markers are not necessarily useful surrogate markers and vice versa [118]. The diagnostic performance of MEPs is more related to the accuracy in prediction of the neurological deficit after surgery as a post-hoc event, whereas the surrogate performance is more related to the indication of the neurological injury during surgery as an intraoperative event that warrants intervention. The link to the postoperative condition lies in the effect of the triggered intervention on the onset of new deficits at that time [92]. Therefore, MEPs can be regarded as useful surrogate endpoints if successful intervention and reversal of MEP change are correlated with a lower number of postoperative motor deficits [28]. Holdefer et al. [28] reported this significant negative correlation between the proportion of reversible MEP alterations and the proportion of new motor deficits associated with MEP changes in vascular surgery $\left(\mathrm{r}_{\text {pearson }}=-0.81\right.$, $p<0.05)$. This negative association was also found during our own correlation analysis $\left(\mathrm{r}_{\text {spearman }}=-0.5, p<0.001\right.$, Figure 4$)$. Our results are in concordance with those by Holdefer et al. [28], but the difference is that in their study, a total of ten studies with intracranial aneurysm surgeries were included, while in our own correlation analysis, we included 59 studies (25 tumor surgery, 2 epilepsy surgery, 27 aneurysm/clipping, and 5 aneurysm/endovascular). The fact that this finding was replicated with a higher number of studies should corroborate this observation and suggest that reversible MEP changes following intervention indicate a successful reversal of an impending neurological injury and motor function preservation postoperatively. 


\subsection{Implications for Research}

This scoping review summarized the existing evidence on MEP warning criteria in supratentorial surgery. The appraisal of this heterogeneous literature should provide some insights into research gaps and concepts. The sources of evidence on MEP warning criteria are observational studies, and it is unlikely that RCTs will be implemented in the future due to ethical considerations. Efforts for evidence synthesis are hindered by the heterogeneity of primary studies that lessens the power of summary estimates. In this regard, the interest should be focused on strategies to upgrade the evidence provided by observational studies and to mitigate the heterogeneity across them in order to enable evidence synthesis with more robust results in the future. First, basic concepts in the field of MEP warning criteria need to be clarified, and a standard terminology needs to be utilized by authors when reporting outcomes. To define the exact time-points at which a motor deficit is registered as early-transient, transient, or permanent, as well as which MEP alterations are considered reversible and irreversible, will facilitate a consensus among authors of future studies. The anesthetic regimen, stimulation protocols, minimal MEP amplitude, and recorded muscles should be described in detail. If more than one warning criteria or stimulation techniques are utilized, it is essential that the outcomes are clearly described separately so that the contribution of each criterion can be assessed. Data should be presented in such a way that the calculation of diagnostic accuracy measures is feasible. For this purpose, documentation protocols of intraoperative events with standard terminology might be established to facilitate intra-institutional as well as inter-institutional comparisons.

In this context, the sequence of actions undertaken when an alarm criterion occurs during surgery may be emphasized. Although the interventions after a warning sign were mentioned in most of the studies in our review, it was unclear how these actions were prioritized, if technical troubleshooting preceded the surgical measures and which intervention finally managed to reverse the alteration. These clarifications are essential to assess the efficacy of interventions and could contribute to the development of algorithms for the efficient management of intraoperative events signified by MEP alarms.

\subsection{Limitations}

We did not perform a risk of bias assessment of the included studies, as our objective was not to assess the quality of the existing studies but rather to provide a broad overview of the available evidence to identify gaps and clarify concepts. Secondly, in a few studies of the DTA analysis, MEP changes were not reported as irreversible but were characterized as significant. These MEP changes were regarded as irreversible in our analysis, although they were not clearly defined as such. Moreover, the discrimination between transient and permanent deficit was based on reporting provided by the authors and not on a specific time-point because of the heterogeneity in outcome reporting. Therefore, in a few studies, there were some deviations from the most commonly utilized cut-off time of 3 months. Further, we did not analyze studies, which performed subcortical mapping without simultaneous MEP monitoring as this was not within the scope of our review. Finally, it is important to highlight that correlation analysis should not be confounded by causality, especially when analyzing reversible MEP alterations.

Due to the severe heterogeneity of the included studies, we have not been able to pool the data, which would either allow a systematic review or even be the first step in preparing big data analysis. To train models in machine learning algorithms and thus, extract meaningful patterns or predict future classes relies on the way the data is collected. Further, it depends on the amount of data available. Small data has meaningful information but also contains a lot of noise. If we would train any machine learning model on such data as reported in our review, the chances that it will learn the noise "too well" might be huge, and when applied for deployment on new data, it will fail at making predictions due to "overfitting". However, our scoping review may raise awareness to solve this limitation in future research studies. 


\section{Conclusions}

In conclusion, the existing evidence for MEP warning criteria in supratentorial surgery derives from observational case series with high heterogeneity in terms of the study population, intraoperative neuromonitoring settings, utilized warning criteria, and outcome reporting. MEP signal loss was always considered as a major warning sign that triggered a cascade of actions in order to reverse impending motor damage. Additional common MEP warning criteria were amplitude reduction followed by threshold elevation. Irreversible MEP alterations were associated with a higher number of transient deficits compared with the reversible MEP changes and a higher likelihood that these motor deficits did persist.

In almost all studies, MEPs showed high specificity and NPV. Thus, the absence of an irreversible alteration may reassure the surgeon that the patient will not suffer a motor deficit in the short-term and long-term follow-up. On the contrary, less consistency was found for sensitivity estimates and PPV, which were rather low to modest, which could probably be attributed to the low prevalence of events. Further, in tumor surgery, the combination with subcortical mapping warning criteria did increase the test accuracy. Moreover, the role of neurophysiologist/neurosurgeon contextualization and intraoperative judgment are essential. MEPs seem to perform well as surrogate markers, and successful intervention followed by a reversal of MEP deterioration indicates postoperative motor function preservation.

In future studies, a consensus regarding the definitions of MEP alteration, critical duration of alterations, and outcome reporting should be established. Documentation protocols with standard terminology could facilitate comparisons and combinations of patient datasets to enable evidence synthesis.

Supplementary Materials: The following are available online at https:/ / www.mdpi.com/article / 10.3390/cancers13112803/s1, Figure S1: Forest plot of sensitivity and specificity estimates for all motor deficits, Figure S2: Forest plot of sensitivity and specificity estimates for transient motor deficits, Figure S3: Forest plot of sensitivity and specificity estimates for early-transient motor deficits, Figure S4: Heatmap depicting the diagnostic accuracy measures of MEPs for permanent motor deficits, Figure S5: Heatmap depicting the diagnostic accuracy measures of MEPs for transient motor deficits, Figure S6: Heatmap depicting the diagnostic accuracy measures of MEPs for early-transient motor deficits, Figure S7: Heatmap depicting the diagnostic accuracy measures of MEPs for all motor deficits, Figure S8: Scatterplot with regression line and 95\% confidence intervals depicting the negative correlation between the proportion of reversible MEP changes and the proportion of new motor deficits associated with MEP changes. Each dot represents one study. Spearman's rank correlation coefficient $=-0.498(p<0.001)$ Table S1: Definitions of true positive (TP), false positive (FP), false negative (FN), and true negative (TN) outcomes across the four different DTA sub-analyses, Table S2: Patient characteristics, neuromonitoring settings and interventions, Table S3: Diagnostic accuracy measures for all postoperative motor deficits, Table S4: Diagnostic accuracy measures for permanent postoperative motor deficits, Table S5: Diagnostic accuracy measures for transient postoperative motor deficits, Table S6: Diagnostic accuracy measures for early-transient postoperative motor deficits, Table S7: The table summarizes the relative rates of all motor deficits as well as the total number of early-transient, transient and permanent motor deficits in conjunction with MEP changes, Table S8: Causes of injury in tumor patients with permanent motor deficits.

Author Contributions: Conceptualization: K.S.; methodology: E.A., P.A.A., and K.S.; formal analysis: E.A., P.A.A., and K.S.; investigation: E.A., P.A.A., and K.S.; resources: A.R.; data curation: E.A. and P.A.A.; writing—original draft preparation: E.A. and K.S.; writing—review and editing: E.A., P.A.A., A.R., and K.S.; visualization: E.A.; supervision: K.S. All authors have read and agreed to the published version of the manuscript.

Funding: This research received no external funding.

Conflicts of Interest: The mentioned mapping-suction device was developed by two of the authors (A.R. and K.S.). The University of Bern receives royalties from Inomed. The other authors report no conflict of interest concerning the materials or methods used in this study or the findings specified in this paper. 


\section{Appendix A}

\section{Database and Search Strategy}

\section{PubMed}

Key concepts

Concept 1: Motor evoked potentials

Keywords: "motor evoked potential ${ }^{* \prime}[\mathrm{tw}], \mathrm{MEP}[\mathrm{tw}]$

MeSH terms: "Evoked Potentials, Motor"[Mesh]

Query 1: (("motor evoked potential*"[tw]) OR (MEP[tw])) OR ("Evoked Potentials, Motor"[Mesh])

Concept 2: warning criteria

Keywords: “warning criteri*” ${ }^{*}$ tw], warning [tw], alarm [tw], alert [tw], “alarm criteri*”[tw], mapping[tw], monitoring[tw]

MeSH terms: "Intraoperative Neurophysiological Monitoring"[Mesh], "Brain Mapping"[Mesh]

Query 2: $\left(\left(\left(\left(\left(\left(\left({ }^{\prime \prime} w a r n i n g ~ c r i t e r i * ”[t w]\right)\right.\right.\right.\right.\right.\right.$ OR (warning [tw])) OR (alarm [tw])) OR (alert [tw])) OR ("alarm criteri*”[tw])) OR (mapping[tw])) OR (monitoring[tw])) OR

("Intraoperative Neurophysiological Monitoring"[Mesh])) OR ("Brain Mapping"[Mesh])

Concept 3: motor deficit

Keywords: "motor deficit" [tw], paresis[tw], hemiparesis[tw], paralysis[tw]

MeSH terms: "Predictive Value of Tests" $[\mathrm{MeSH}]$, "Paresis/prevention and control”[Mesh], "Paralysis/prevention and control”[Mesh], "Neurologic

Manifestations/injuries"[Mesh], "Neurologic Manifestations/prevention and control"[Mesh], "Neurologic Manifestations/surgery"[Mesh]

Query 3: ((((“Predictive Value of Tests"[Mesh]) AND “Paresis/prevention and control”[Mesh]) AND “Paralysis/prevention and control”[Mesh]) AND (“Neurologic

Manifestations/injuries"[Mesh] OR "Neurologic Manifestations/prevention and control"[Mesh] OR "Neurologic Manifestations/surgery"[Mesh])) OR ("motor

deficit"[tw])) OR (paresis[tw])) OR (hemiparesis[tw])) OR (paralysis[tw])

Concept 4: supratentorial brain surgery

Keywords: supratentorial [tw], brain surgery[tw], "supratentorial surgery"[tw], tumor*[tw], aneurysm*[tw], epilepsy[tw]

MeSH terms: "Neurosurgical Procedures"[Mesh], "Brain Injuries/diagnosis"[Mesh], "Intracranial Aneurysm/surgery"[Mesh], “Brain Neoplasms/surgery"[Mesh],

"Epilepsy/surgery"[Mesh], "Central Nervous System Vascular Malformations/surgery"[Mesh]

Query 3: $((((()(((($ supratentorial[tw]) OR (brain surgery[tw])) OR (“supratentorial surgery”[tw])) OR (tumor*[tw])) OR (aneurysm*[tw])) OR (epilepsy[tw])) OR

("Neurosurgical Procedures"[Mesh])) OR ("Brain Injuries/diagnosis"[Mesh])) OR ("Intracranial Aneurysm/surgery"[Mesh])) OR ("Brain

Neoplasms/surgery”[Mesh]))) OR (“Epilepsy/surgery”[Mesh])) OR (“Central Nervous System Vascular Malformations/surgery"[Mesh])

\section{Combined query}

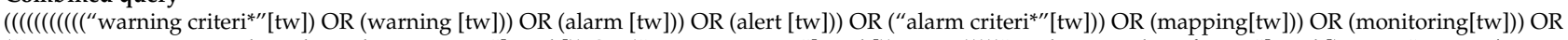

("Intraoperative Neurophysiological Monitoring"[Mesh])) OR (“Brain Mapping"[Mesh])) AND ((((“Predictive Value of Tests"[Mesh]) AND “Paresis/prevention and

control"[Mesh]) AND "Paralysis/prevention and control"[Mesh]) AND ("Neurologic Manifestations/injuries"[Mesh] OR “Neurologic Manifestations/prevention

and control"[Mesh] OR “Neurologic Manifestations/surgery"[Mesh])) OR ("motor deficit"[tw])) OR (paresis[tw])) OR (hemiparesis[tw])) OR (paralysis[tw])) AND

$(((((()(((($ supratentorial[tw]) OR (brain surgery[tw])) OR ("supratentorial surgery"[tw])) OR (tumor*[tw])) OR (aneurysm*[tw])) OR $($ epilepsy[tw])) OR

("Neurosurgical Procedures"[Mesh])) OR ("Brain Injuries/diagnosis"[Mesh])) OR ("Intracranial Aneurysm/surgery"[Mesh])) OR ("Brain

Neoplasms/surgery"[Mesh]))) OR ("Epilepsy/surgery"[Mesh])) OR ("Central Nervous System Vascular Malformations/surgery"[Mesh]))) AND ((("motor evoked potential $^{*}$ "[tw]) OR (MEP[tw])) OR (“Evoked Potentials, Motor"[Mesh]))

\section{Embase, Scopus, CINAHL, Cochrane Library}

("warning criteri*” OR warning OR alarm OR alert OR “alarm criteri*” OR mapping OR monitoring OR “Intraoperative Neurophysiological Monitoring" OR “Brain

Mapping") AND ("motor deficit" OR paresis OR hemiparesis OR paralysis) AND (supratentorial OR brain surgery OR "supratentorial surgery" OR tumor* OR

aneurysm* OR epilepsy OR arteriovenous malformation) AND ("motor evoked potential*" OR MEP)

\section{Grey literature databases (OpenGrey, NTIS, British Library Direct Plus, York's CRD, Mednar)}

("warning criteri*” OR warning OR alarm OR alert OR “alarm criteri*” OR mapping OR monitoring OR "Intraoperative Neurophysiological Monitoring" OR “Brain

Mapping") AND ("motor deficit" OR paresis OR hemiparesis OR paralysis) AND (supratentorial OR brain surgery OR "supratentorial surgery" OR tumor* OR

aneurysm* OR epilepsy OR arteriovenous malformation) AND ("motor evoked potential*" OR MEP)

\section{Appendix B}

\begin{tabular}{|c|c|}
\hline Authors & Reason for Exclusion \\
\hline \multicolumn{2}{|l|}{ After full-text review $(n=140)$} \\
\hline Bidkar et al. (2021) [119] & Not a primary study \\
\hline Keeble et al. (2021) [120] & No preoperatively defined MEP warning criteria \\
\hline Lee et al. (2021) [121] & No MEP warning criteria \\
\hline Simon et al. (2021) [122] & No MEP warning criteria \\
\hline Wang et al. (2021) [123] & No motor outcome analysis \\
\hline Bander et al. (2020) [124] & No MEP warning criteria \\
\hline Brage et al. (2020) [125] & No sufficient motor outcome data in conjunction with MEP warning criteria \\
\hline Fekete et al. (2020) [126] & Only spinal and brainstem lesions \\
\hline Hayashi et al. (2020) [127] & No MEP warning criteria \\
\hline Jahodová et al. (2020) [128] & No preoperatively defined cutoff value for MEP warning criteria \\
\hline Kim et al. (2020) [129] & No MEP warning criteria \\
\hline Lee et al. (2020) [130] & No MEP warning criteria \\
\hline Porčnik et al. (2020) [131] & Motor outcome data of asleep patients cannot be distinguished from those of awake patients \\
\hline Roth et al. (2020) [132] & No cutoff values for MEP warning criteria \\
\hline Balaji et al. (2019) [133] & No MEP warning criteria \\
\hline Chung et al. (2019) [134] & Only analysis of false-positive and false-negative cases \\
\hline Hu et al. (2019) [135] & No MEP warning criteria \\
\hline
\end{tabular}




\begin{tabular}{|c|c|}
\hline Authors & Reason for Exclusion \\
\hline \multicolumn{2}{|l|}{ After full-text review $(n=140)$} \\
\hline Kanaya et al. (2019) [136] & No MEP warning criteria \\
\hline Rossi et al. (2019) [137] & No sufficient motor outcome data in conjunction with MEP warning criteria \\
\hline Wang et al. (2019) [138] & No MEP warning criteria \\
\hline Della Puppa et al. (2018) [139] & No MEP warning criteria \\
\hline Han et al. (2018) [140] & No MEP warning criteria \\
\hline Silverstein et al. (2018) [141] & No MEP warning criteria \\
\hline Skrap et al. (2018) [142] & $\begin{array}{l}\text { No clear MEP monitoring warning criteria and no sufficient motor outcome data in conjunction with MEPs-mixture } \\
\text { with SSEP }\end{array}$ \\
\hline Umemura et al. (2018) [143] & Motor outcome data of patients with supratentorial lesions were not clearly reported and could not be extracted \\
\hline Wakui et al. (2018) [144] & No MEP warning criteria \\
\hline Abboud et al. (2017) [100] & $\begin{array}{l}\text { Predefined analysis of patients without a postoperative deficit and without MEP warning criteria to investigate } \\
\text { pneumocephalus with MRI }\end{array}$ \\
\hline Akiyama et al. (2017) [145] & No preoperatively defined MEP warning criteria \\
\hline Lv X et al. (2017) [146] & No MEP monitoring \\
\hline Pintea et al. (2017) [147] & No MEP warning criteria \\
\hline Takagaki et al. (2017) [148] & No MEP monitoring \\
\hline Carrabba et al. (2016) [149] & No MEP warning criteria \\
\hline Gripp et al. (2016) [150] & No MEP warning criteria \\
\hline Grossauer et al. (2016) [151] & No preoperatively defined MEP warning criteria \\
\hline Ikedo et al. (2016) [152] & $\begin{array}{l}\text { Evacuation of hematoma and control of the presence of MEPs after evacuation -not tumor, vascular or epileptogenic } \\
\text { lesion }\end{array}$ \\
\hline Imai et al. (2016) [153] & No motor outcome analysis \\
\hline Isozaki et al. (2016) [154] & No MEP warning criteria \\
\hline Koenig et al. (2016) [155] & No preoperatively defined MEP warning criteria \\
\hline Nakagomi et al. (2016) [156] & No MEP warning criteria \\
\hline Rossetto et al. (2016) [157] & No MEP warning criteria \\
\hline Zhuang et al. (2016) [158] & Data for patients with supratentorial lesions cannot be extracted with certainty \\
\hline Zhukov et al. (2016) [159] & No preoperatively defined MEP warning criteria \\
\hline Wang et al. (2016) [160] & No MEP warning criteria \\
\hline Eldin et al. (2015) [161] & No MEP warning criteria \\
\hline Erdoğan et al. (2015) [162] & $\begin{array}{l}\text { "Presence or absence" warning criterion but only the spinal and brainstem cases are adequately related to } \\
\text { postoperative motor outcome }\end{array}$ \\
\hline Jo et al. (2015) [163] & No MEP warning criteria \\
\hline Joksimovic et al. (2015) [164] & No MEP warning criteria \\
\hline Okamoto et al. (2015) [165] & No MEP warning criteria \\
\hline Quan et al. (2015) [166] & No MEP warning criteria \\
\hline Rashad et al. (2015) [167] & No MEP warning criteria \\
\hline Shiban et al. (2015) [102] & No clear MEP warning criteria \\
\hline Udaka et al. (2015) [168] & No MEP warning criteria \\
\hline Raabe et al. (2014) [105] & Overlapping series from the same institution \\
\hline Sahaya et al. (2014) [169] & Only 3 cases with MEP monitoring and no reporting of motor outcome for them \\
\hline Schucht et al. (2014) [170] & No sufficient motor outcome data in conjunction with MEP warning criteria and mapping thresholds \\
\hline Bulusu et al. (2013) [171] & No MEP warning criteria \\
\hline Krieg et al. (2013) [172] & Overlapping series from the same institution \\
\hline Krieg et al. (2013) [173] & $\begin{array}{l}\text { No sufficient motor outcome data in conjunction with MEP warning criteria, data for asleep patients, and } \\
\text { postoperative motor deficit cannot be extracted with certainty }\end{array}$ \\
\hline Shah P.A. (2013) [174] & No clear MEP warning criteria \\
\hline Vassal et al. (2013) [175] & No MEP warning criteria \\
\hline Chen et al. (2012) [176] & No clear MEP warning criteria \\
\hline Horton et al. (2012) [177] & No cutoff values for MEP warning criteria \\
\hline Krieg et al. (2012) [96] & Overlapping series from the same institution \\
\hline
\end{tabular}




\begin{tabular}{|c|c|}
\hline Authors & Reason for Exclusion \\
\hline \multicolumn{2}{|l|}{ After full-text review $(n=140)$} \\
\hline Ohue et al. (2012) [107] & No preoperatively defined MEP warning criteria \\
\hline Ritzl EK. (2012) [178] & Not a primary study \\
\hline Schucht et al. (2012) [179] & No sufficient motor outcome data in conjunction with MEP warning criteria \\
\hline Seidel et al. (2012) [97] & No MEP monitoring warning criteria, only mapping warning criteria \\
\hline Uchino et al. (2012) [180] & No sufficient motor outcome data in conjunction with MEP warning criteria \\
\hline Zhu et al. (2012) [181] & No clear MEP warning criteria \\
\hline Chang et al. (2011) [182] & No MEP warning criteria \\
\hline Chen et al. (2011) [183] & No MEP monitoring \\
\hline Fukaya et al. (2011) [184] & No MEP warning criteria \\
\hline González-Darder(2011) [185] & No MEP warning criteria \\
\hline Li et al. (2011) [186] & No sufficient motor outcome data in conjunction with MEP warning criteria \\
\hline Lin et al. (2011) [187] & No cutoff values for MEP warning criteria \\
\hline Nossek et al. (2011) [108] & $\begin{array}{l}\text { No clear MEP monitoring warning criteria. No sufficient motor outcome data in conjunction with mapping warning } \\
\text { criteria for the asleep patients. }\end{array}$ \\
\hline Prabhu et al. (2011) [106] & No preoperatively defined MEP warning criteria \\
\hline Szelényi et al. (2011) [103] & No MEP warning criteria \\
\hline Tanaka et al. (2011) [188] & $\begin{array}{l}\text { Numbers of MEP changes reported in percentages. Only motor palsy }<2 / 5 \mathrm{MMRC} \text { and not postoperative motor } \\
\text { deterioration is reported. }\end{array}$ \\
\hline von Der Brelie et al. (2011) [189] & No MEP monitoring \\
\hline Walter et al. (2011) [190] & No MEP warning criteria \\
\hline Bello et al. (2010) [191] & No preoperatively defined MEP warning criteria \\
\hline Bozzao et al. (2010) [192] & No MEP warning criteria \\
\hline Feigl et al. (2010) [193] & No sufficient motor outcome data in conjunction with MEP warning criteria \\
\hline Juretschke et al. (2010) [194] & No MEP warning criteria \\
\hline Maesawa et al. (2010) [195] & No preoperatively defined MEP warning criteria \\
\hline Sala et al. (2010) [196] & Not a primary study \\
\hline Sanai et al. (2010) [197] & Not a primary study \\
\hline Talacchi et al. (2010) [1] & No MEP monitoring warning criteria \\
\hline Tanaka et al. (2010) [198] & Earlier series from the same institution \\
\hline Yang et al. (2010) [199] & No MEP warning criteria \\
\hline Gorji et al. (2009) [200] & No clear MEP warning criteria \\
\hline Hattingen et al. (2009) [201] & Data for patients with supratentorial lesions cannot be extracted with certainty \\
\hline Kamada et al. (2009) [109] & No preoperatively defined MEP warning criteria \\
\hline Kombos et al. (2009) [202] & No sufficient motor outcome data in conjunction with MEP warning criteria \\
\hline Krammer et al. (2009) [203] & Motor outcome data of patients with supratentorial lesions were not clearly reported and could not be extracted \\
\hline Ozawa et al. (2009) [204] & No MEP warning criteria \\
\hline Simon et al. (2009) [205] & No MEP warning criteria \\
\hline Sugita et al. (2009) [206] & No MEP warning criteria \\
\hline Von Lehe et al. (2009) [207] & No MEP warning criteria \\
\hline Yamaguchi et al. (2009) [208] & No motor outcome analysis \\
\hline Calancie et al. (2008) [209] & Only spinal cases \\
\hline Berman et al. (2007) [210] & No MEP warning criteria \\
\hline Mikuni et al. (2007) [211] & No MEP warning criteria \\
\hline Neuloh et al. (2007) [212] & Overlapping series from the same institution \\
\hline Szelényi et al. (2007) [6] & No MEP warning criteria \\
\hline Yamaguchi et al. (2007) [213] & No motor outcome analysis \\
\hline Fujiki et al. (2006) [214] & No clear preoperatively defined MEP warning criteria \\
\hline Okada et al. (2006) [215] & No MEP warning criteria \\
\hline Kamada et al. (2005) [216] & No MEP warning criteria \\
\hline Szelényi et al. (2005) [101] & No motor outcome data in conjunction with MEP warning criteria \\
\hline Keles et al. (2004) [217] & No MEP warning criteria \\
\hline
\end{tabular}




\begin{tabular}{|c|c|}
\hline Authors & Reason for Exclusion \\
\hline \multicolumn{2}{|l|}{ After full-text review $(n=140)$} \\
\hline Kombos et al. (2004) [218] & No MEP warning criteria \\
\hline Neuloh et al. (2004) [219] & No clear and preoperatively defined MEP warning criteria \\
\hline $\begin{array}{l}\text { Quiñones-Hinojosa et al. (2004) } \\
\text { [220] }\end{array}$ & No sufficient motor outcome data in conjunction with MEP warning criteria \\
\hline Sakuma et al. (2004) [221] & No MEP warning criteria \\
\hline Signorelli et al. (2004) [222] & No MEP warning criteria \\
\hline Yamamoto et al. (2004) [223] & Only D-wave recording \\
\hline Duffau et al. (2003) [224] & No MEP monitoring warning criteria \\
\hline Fukaya et al. (2003) [225] & $\begin{array}{l}\text { Inclusion criterion in the study that the patient did not exhibit MEP amplitude decrease of }>50 \% \text { (warning criteria) } \\
\text { intraoperatively }\end{array}$ \\
\hline Sala et al. (2003) [111] & No sufficient motor outcome data in conjunction with MEP warning criteria \\
\hline Suess et al. (2002) [226] & No MEP warning criteria \\
\hline Kombos et al. (2000) [227] & No MEP warning criteria \\
\hline Kofler et al. (1999) [228] & No MEP warning criteria \\
\hline Kombos et al. (1999) [229] & No MEP warning criteria \\
\hline Rohde et al. (1999) [230] & MEPs elicited through Transcranial Magnetic Stimulation(TMS) \\
\hline Yingling et al. (1999) [231] & No MEP warning criteria \\
\hline Krombach et al. (1998) [232] & No MEP warning criteria \\
\hline Zentner et al. (1998) [233] & No correlation of MEPs with postoperative but with preoperative motor deficit \\
\hline Zentner et al. (1996) [117] & No MEP warning criteria \\
\hline Kawaguchi et al. (1996) [234] & No clear MEP warning criteria \\
\hline Maertens et al. (1996) [235] & No clear MEP warning criteria \\
\hline Pechstein et al. (1996) [236] & No MEP warning criteria \\
\hline Rodi et al. (1996) [237] & No MEP warning criteria \\
\hline Skirboll et al. (1996) [238] & No MEP warning criteria \\
\hline Taniguchi et al. (1993) [5] & No MEP warning criteria \\
\hline Ebeling et al. (1992) [239] & No MEP warning criteria \\
\hline Schramm et al. (1990) [240] & Only SSEP monitoring \\
\hline Zentner et al. (1988) [241] & No clear MEP warning criteria \\
\hline \multicolumn{2}{|l|}{ After abstract screening $(\mathrm{n}=73)$} \\
\hline Chen et al. (2021) [242] & Technical report, presentation of a new technique \\
\hline Machetanz et al. (2021) [243] & MEPs elicited through Transcranial Magnetic Stimulation(TMS) \\
\hline Cattaneo et al. (2020) [244] & Use of MEPs to investigate brain connectivity \\
\hline Kang et al. (2020) [245] & Not a primary study \\
\hline Policicchio et al. (2020) [246] & Not a primary study \\
\hline Shibata et al. (2020) [247] & Awake craniotomy \\
\hline Wang et al. (2020) [248] & Only SSEP analysis \\
\hline Zuo et al. (2020) [249] & Not a primary study \\
\hline NCT04178395(2019) [250] & Protocol for clinical trial \\
\hline Hiruta et al. (2019) [251] & Technical report (cortical and subcortical stimulation ratio), no motor outcome data \\
\hline Zhu et al. (2019) [91] & Not a primary study \\
\hline Rajan et al. (2018) [252] & Not a primary study \\
\hline Valci et al. (2018) [253] & No MEP monitoring to avoid a postoperative deficit, no MEP warning criteria \\
\hline Abdulrauf et al. (2017) [254] & Awake surgery \\
\hline Benavides et al. (2017) [255] & Not a clinical study; study in pigs \\
\hline Bharadwaj et al. (2017) [256] & Technical report, application, and feasibility of a new monitoring system \\
\hline Calancie B. (2017) [257] & Not a primary study \\
\hline Grasso et al. (2017) [258] & Not a primary study \\
\hline Hemmer et al. (2017) [259] & Not a primary study \\
\hline Journée et al. (2017) [20] & Not a primary study \\
\hline
\end{tabular}




\begin{tabular}{|c|c|}
\hline Authors & Reason for Exclusion \\
\hline \multicolumn{2}{|l|}{ After full-text review $(n=140)$} \\
\hline Ku et al. (2017) [260] & Case report of a patient with vestibular schwannoma \\
\hline Liu et al. (2017) [21] & Spinal surgery \\
\hline MacDonald DB. (2017) [9] & Not a primary study \\
\hline Moser et al. (2017) [261] & MEPs elicited through Transcranial Magnetic Stimulation (TMS) \\
\hline Sanmillan et al. (2017) [98] & Not a primary study \\
\hline Schucht et al. (2017) [104] & Not a primary study \\
\hline Thomas et al. (2017) [89] & Not a primary study \\
\hline $\begin{array}{l}\text { Alimohamadi et al. (2016) } \\
\text { [262] }\end{array}$ & Awake craniotomy \\
\hline Coppola et al. (2016) [263] & Not a primary study \\
\hline Holdefer et al. (2016) [28] & Not a primary study \\
\hline König, R. (2016) [264] & Not a primary study \\
\hline Raabe et al. (2016) [265] & Not a primary study \\
\hline Yao et al. (2016) [266] & The term MEP referred to Meningiomas-en-plaque, no MEP monitoring \\
\hline Holdefer et al. (2015) [92] & Not a primary study \\
\hline Ottenhausen et al. (2015) [267] & Not a primary study \\
\hline Sala et al. (2015) [87] & Not a primary study \\
\hline Nakamura et al. (2014) [268] & Only abstract available \\
\hline Suzuki et al. (2014) [269] & Awake aneurysm clipping \\
\hline Yang et al. (2014) [270] & Intraoperative neuromonitoring used as a mapping technique to find the corticospinal projections \\
\hline Landazuri et al. (2013) [271] & Not a primary study \\
\hline MacDonald et al. (2013) [7] & Not a primary study \\
\hline Rajapakse et al. (2013) [272] & Not a primary study \\
\hline Yamashita et al. (2013) [273] & Only abstract available \\
\hline Bacigaluppi et al. (2012) [274] & Not a primary study \\
\hline $\begin{array}{l}\text { De Witt Hamer et al. (2012) } \\
\text { [275] }\end{array}$ & Not a primary study \\
\hline Emerson et al. (2012) [276] & Not a primary study \\
\hline Hotson et al. (2012) [277] & Electrocorticography analysis \\
\hline Ito et al. (2012) [278] & Spinal surgery \\
\hline Guo et al. (2011) [90] & Review/Not a primary study \\
\hline Guo et al. (2011) [279] & Letter to the Editor/not a primary study \\
\hline Li et al. (2011) [280] & Case report of a patient with high-grade brainstem glioma \\
\hline Deiner S. (2010) [281] & Spinal surgery \\
\hline Pabon et al. (2010) [282] & Only abstract available \\
\hline Lefaucheur et al. (2009) [283] & Electrode placement for neuropathic pain treatment \\
\hline Sun et al. (2009) [284] & MEPs elicited through Transcranial Magnetic Stimulation (TMS) \\
\hline Duffau, H. (2008)-1 [285] & Not a primary study \\
\hline Duffau, H. (2008)-2 [286] & Not a primary study \\
\hline Takashima et al. (2008) [287] & Not a primary study \\
\hline Duffau H. (2007) [288] & Not a primary study \\
\hline Tharin et al. (2007) [289] & Not a primary study \\
\hline Duffau, H. (2006) [290] & Not a primary study \\
\hline Schramm et al. (2006) [291] & Only abstract available \\
\hline Shinoura et al. (2006) [292] & Awake surgery \\
\hline Kuzniecky et al. (2005) [293] & Not a primary study \\
\hline Binder et al. (2004) [294] & Correlation of intraoperative neuromonitoring and imaging with Kernohan's notch syndrome \\
\hline Hashiguchi et al. (2004) [295] & Only abstract available \\
\hline Kondo et al. (2004) [296] & Only abstract available \\
\hline Neuloh et al. (2004) [297] & Not a primary study \\
\hline
\end{tabular}




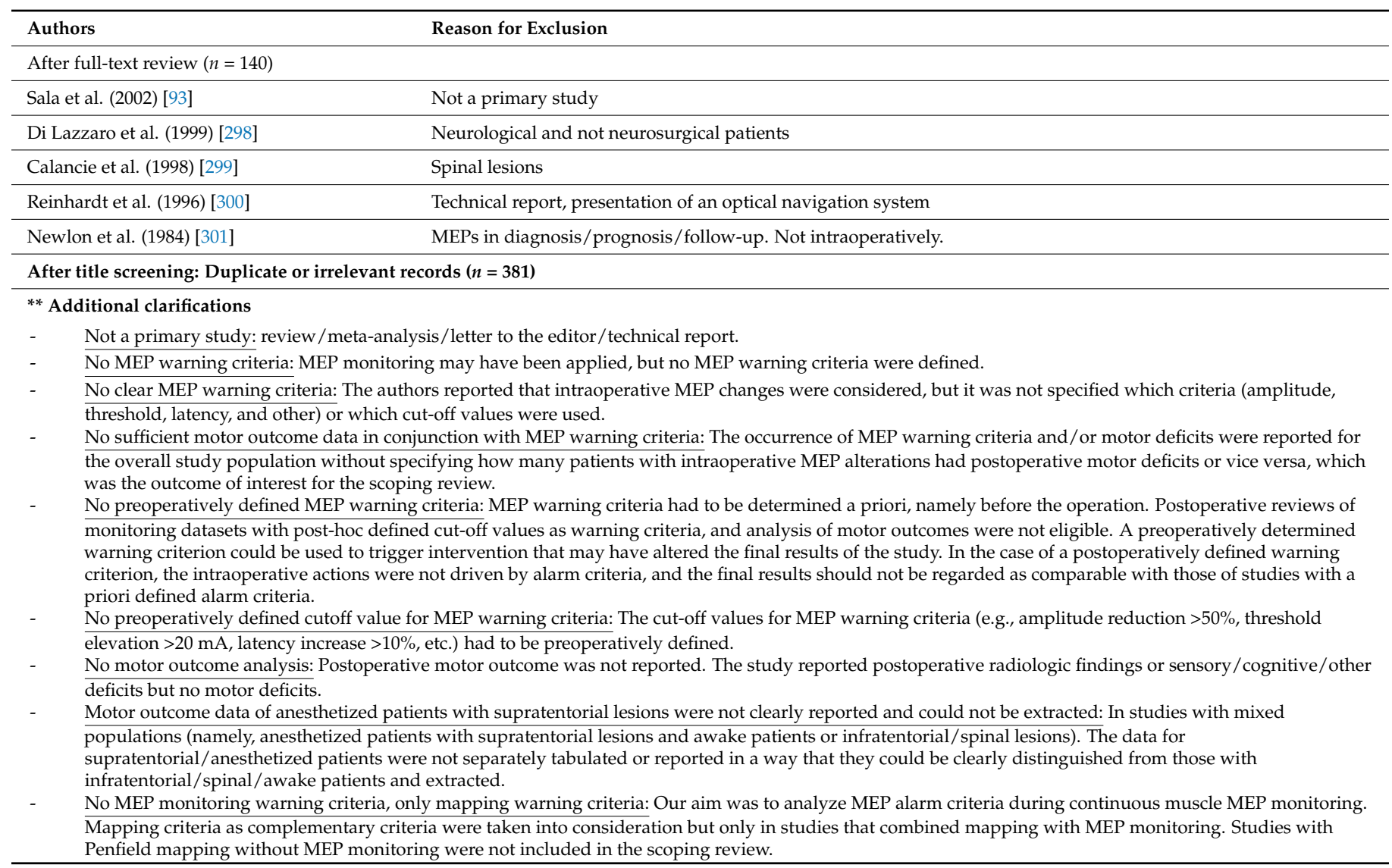

\section{References}

1. Talacchi, A.; Turazzi, S.; Locatelli, F.; Sala, F.; Beltramello, A.; Alessandrini, F.; Manganotti, P.; Lanteri, P.; Gambin, R.; Ganau, M.; et al. Surgical treatment of high-grade gliomas in motor areas. The impact of different supportive technologies: A 171-patient series. J. Neuro Oncol. 2010, 100, 417-426. [CrossRef] [PubMed]

2. Deletis, V. What does intraoperative monitoring of motor evoked potentials bring to the neurosurgeon? Acta Neurochir. 2005, 147, 1015-1017. [CrossRef] [PubMed]

3. Deletis, V.; Isgum, V.; Amassian, V.E. Neurophysiological mechanisms underlying motor evoked potentials in anesthetized humans.: Part 1. Recovery time of corticospinal tract direct waves elicited by pairs of transcranial electrical stimuli. Clin. Neurophysiol. 2001, 112, 438-444. [CrossRef]

4. Deletis, V.; Rodi, Z.; Amassian, V.E. Neurophysiological mechanisms underlying motor evoked potentials in anesthetized humans.: Part 2. Relationship between epidurally and muscle recorded MEPs in man. Clin. Neurophysiol. 2001, 112, 445-452. [CrossRef]

5. Taniguchi, M.; Cedzich, C.; Schramm, J. Modification of Cortical Stimulation for Motor Evoked Potentials under General Anesthesia. Neurosurgery 1993, 32, 219-226. [CrossRef]

6. Szelényi, A.; Kothbauer, K.F.; Deletis, V. Transcranial electric stimulation for intraoperative motor evoked potential monitoring: Stimulation parameters and electrode montages. Clin. Neurophysiol. 2007, 118, 1586-1595. [CrossRef] [PubMed]

7. Macdonald, D.; Skinner, S.; Shils, J.; Yingling, C. Intraoperative motor evoked potential monitoring-A position statement by the American Society of Neurophysiological Monitoring. Clin. Neurophysiol. 2013, 124, 2291-2316. [CrossRef] [PubMed]

8. Seidel, K.; Beck, J.; Stieglitz, L.; Schucht, P.; Raabe, A. The warning-sign hierarchy between quantitative subcortical motor mapping and continuous motor evoked potential monitoring during resection of supratentorial brain tumors. J. Neurosurg. 2013, 118, 287-296. [CrossRef] [PubMed]

9. Macdonald, D.B. Overview on Criteria for MEP Monitoring. J. Clin. Neurophysiol. 2017, 34, 4-11. [CrossRef] [PubMed]

10. Kombos, T.; Suess, O.; Ciklatekerlio, Ö.; Brock, M. Monitoring of intraoperative motor evoked potentials to increase the safety of surgery in and around the motor cortex. J. Neurosurg. 2001, 95, 608-614. [CrossRef]

11. Neuloh, G.; Pechstein, U.; Cedzich, C.; Schramm, J. Motor Evoked Potential Monitoring with Supratentorial Surgery. Neurosurgery 2004, 54, 1061-1072. [CrossRef] [PubMed]

12. Choi, H.H.; Ha, E.J.; Cho, W.-S.; Kang, H.-S.; Kim, J.E. Effectiveness and Limitations of Intraoperative Monitoring with Combined Motor and Somatosensory Evoked Potentials During Surgical Clipping of Unruptured Intracranial Aneurysms. World Neurosurg. 2017, 108, 738-747. [CrossRef] [PubMed] 
13. Li, F.; Gorji, R.; Allott, G.; Modes, K.; Lunn, R.; Yang, Z.-J. The Usefulness of Intraoperative Neurophysiological Monitoring in Cervical Spine Surgery. J. Neurosurg. Anesthesiol. 2012, 24, 185-190. [CrossRef] [PubMed]

14. Malcharek, M.J.; Hesse, J.; Hesselbarth, K.; Thoma, K.; Wegner, C.; Sablotzki, A.; Hennig, G.; Gille, J. Warning criteria for MEP monitoring during carotid endarterectomy: A retrospective study of 571 patients. J. Clin. Monit. 2019, 34, 589-595. [CrossRef]

15. Suess, O.; Suess, S.; Brock, M.; Kombos, T. Intraoperative electrocortical stimulation of Brodman area 4: A 10-year analysis of 255 cases. Head Face Med. 2006, 2, 20. [CrossRef] [PubMed]

16. Szelényi, A.; Langer, D.; Kothbauer, K.; De Camargo, A.B.; Flamm, E.S.; Deletis, V. Monitoring of muscle motor evoked potentials during cerebral aneurysm surgery: Intraoperative changes and postoperative outcome. J. Neurosurg. 2006, 105, 675-681. [CrossRef] [PubMed]

17. Abboud, T.; Schaper, M.; Dührsen, L.; Schwarz, C.; Schmidt, N.O.; Westphal, M.; Martens, T. A novel threshold criterion in transcranial motor evoked potentials during surgery for gliomas close to the motor pathway. J. Neurosurg. 2016, 125, 795-802. [CrossRef] [PubMed]

18. Malcharek, M.; Ulkatan, S.; Marinò, V.; Geyer, M.; Lladó-Carbó, E.; Perez-Fajardo, G.; Arranz-Arranz, B.; Climent, J.; Aloj, F.; Franco, E.; et al. Intraoperative monitoring of carotid endarterectomy by transcranial motor evoked potential: A multicenter study of 600 patients. Clin. Neurophysiol. 2013, 124, 1025-1030. [CrossRef]

19. Suzuki, K.; Kodama, N.; Sasaki, T.; Matsumoto, M.; Konno, Y.; Sakuma, J.; Oinuma, M.; Murakawa, M. Intraoperative monitoring of blood flow insufficiency in the anterior choroidal artery during aneurysm surgery. J. Neurosurg. 2003, 98, 507-514. [CrossRef] [PubMed]

20. Journée, H.L.; Berends, H.; Kruyt, M.C. The Percentage of Amplitude Decrease Warning Criteria for Transcranial MEP Monitoring. J. Clin. Neurophysiol. 2017, 34, 22-31. [CrossRef]

21. Liu, Q.; Wang, Q.; Liu, H.; Wu, W.K.; Chan, M.T. Warning criteria for intraoperative neurophysiologic monitoring. Curr. Opin. Anaesthesiol. 2017, 30, 557-562. [CrossRef]

22. Byoun, H.S.; Oh, C.W.; Kwon, O.-K.; Lee, S.U.; Ban, S.P.; Kim, S.H.; Kim, T.; Bang, J.S.; Choi, J.; Park, K.S. Intraoperative neuromonitoring during microsurgical clipping for unruptured anterior choroidal artery aneurysm. Clin. Neurol. Neurosurg. 2019, 186, 105503. [CrossRef] [PubMed]

23. Obermueller, T.; Schaeffner, M.; Shiban, E.; Droese, D.; Negwer, C.; Meyer, B.; Ringel, F.; Krieg, S.M. Intraoperative neuromonitoring for function-guided resection differs for supratentorial motor eloquent gliomas and metastases. BMC Neurol. 2015, 15, 1-11. [CrossRef] [PubMed]

24. Tricco, A.C.; Lillie, E.; Zarin, W.; O’Brien, K.K.; Colquhoun, H.; Levac, D.; Moher, D.; Peters, M.D.; Horsley, T.; Weeks, L.; et al. PRISMA extension for scoping reviews (PRISMA-ScR): Checklist and explanation. Ann. Intern. Med. 2018, 169, 467-473. [CrossRef] [PubMed]

25. Arksey, H.; O’Malley, L. Scoping studies: Towards a methodological framework. Int. J. Soc. Res. Methodol. 2005, 8, 19-32. [CrossRef]

26. Levac, D.; Colquhoun, H.; O’Brien, K.K. Scoping studies: Advancing the methodology. Implement. Sci. 2010, 5, 69. [CrossRef] [PubMed]

27. Review Manager (RevMan) [Computer Program]. Version 5.4. The Cochrane Collaboration. 2020. Available online: https: //training.cochrane.org/system/files/uploads/protected_file/RevMan5.4_user_guide.pdf (accessed on 15 April 2021).

28. Holdefer, R.N.; MacDonald, D.B.; Guo, L.; Skinner, S.A. An evaluation of motor evoked potential surrogate endpoints during intracranial vascular procedures. Clin. Neurophysiol. 2016, 127, 1717-1725. [CrossRef] [PubMed]

29. Giampiccolo, D.; Parisi, C.; Meneghelli, P.; Tramontano, V.; Basaldella, F.; Pasetto, M.; Pinna, G.; Cattaneo, L.; Sala, F. Long-term motor deficit in brain tumour surgery with preserved intra-operative motor-evoked potentials. Brain Commun. 2021, 3, fcaa226. [CrossRef] [PubMed]

30. Gogos, A.J.; Young, J.S.; Morshed, R.A.; Avalos, L.N.; Noss, R.S.; Villanueva-Meyer, J.E.; Hervey-Jumper, S.L.; Berger, M.S. Triple motor mapping: Transcranial, bipolar, and monopolar mapping for supratentorial glioma resection adjacent to motor pathways. J. Neurosurg. 2020. [CrossRef] [PubMed]

31. Mammadkhanli, O.; Bozkurt, M.; Caglar, Y.S. Assesment of functional results for lesions located in eloquent areas with intraoperative cortical-subcortical stimulation and cortical mapping. Turk. Neurosurg. 2020. [CrossRef] [PubMed]

32. Seidel, K.; Schucht, P.; Beck, J.; Raabe, A. Continuous Dynamic Mapping to Identify the Corticospinal Tract in Motor Eloquent Brain Tumors: An Update. J. Neurol. Surg. Part A Cent. Eur. Neurosurg. 2020, 81, 105-110. [CrossRef]

33. Abboud, T.; Schwarz, C.; Westphal, M.; Martens, T. A comparison between threshold criterion and amplitude criterion in transcranial motor evoked potentials during surgery for supratentorial lesions. J. Neurosurg. 2019, 131, 740-749. [CrossRef]

34. Majchrzak, K.; Bobek-Billewicz, B.; Hebda, A.; Adamczyk, P.; Majchrzak, H.; Ładziński, P. Surgical treatment of adult patients with thalamic tumors with the aid of tractography, fMRI, transcranial electrical stimulation and direct electrical stimulation of the subcortical white matter. Neurol. Neurochir. Pol. 2018, 52, 720-730. [CrossRef] [PubMed]

35. Moiyadi, A.; Velayutham, P.; Shetty, P.; Seidel, K.; Janu, A.; Madhugiri, V.; Singh, V.K.; Patil, A.; John, R. Combined Motor Evoked Potential Monitoring and Subcortical Dynamic Mapping in Motor Eloquent Tumors Allows Safer and Extended Resections. World Neurosurg. 2018, 120, e259-e268. [CrossRef] [PubMed] 
36. Plans, G.; Fernández-Conejero, I.; Rifà-Ros, X.; Fernández-Coello, A.; Rosselló, A.; Gabarrós, A. Evaluation of the High-Frequency Monopolar Stimulation Technique for Mapping and Monitoring the Corticospinal Tract in Patients With Supratentorial Gliomas. A Proposal for Intraoperative Management Based on Neurophysiological Data Analysis in a Series of Ninety-Two Patients. Neurosurgery 2017, 81, 585-594. [CrossRef] [PubMed]

37. Zhou, Q.; Li, M.; Yi, L.; He, B.; Li, X.; Jiang, Y. Intraoperative neuromonitoring during brain arteriovenous malformation microsurgeries and postoperative dysfunction. Medicine 2017, 96, e8054. [CrossRef] [PubMed]

38. Boex, C.; Haemmerli, J.; Momjian, S.; Schaller, K. Prognostic Values of Motor Evoked Potentials in Insular, Precental, or Postcentral Resections. J. Clin. Neurophysiol. 2016, 33, 51-59. [CrossRef] [PubMed]

39. Shiban, E.; Krieg, S.M.; Obermueller, T.; Wostrack, M.; Meyer, B.; Ringel, F. Continuous subcortical motor evoked potential stimulation using the tip of an ultrasonic aspirator for the resection of motor eloquent lesions. J. Neurosurg. 2015, 123, 301-306. [CrossRef] [PubMed]

40. Lee, J.J.; Kim, Y.I.; Hong, J.T.; Sung, J.H.; Lee, S.W.; Yang, S.H. Intraoperative Monitoring of Motor-Evoked Potentials for Supratentorial Tumor Surgery. J. Korean Neurosurg. Soc. 2014, 56, 98-102. [CrossRef] [PubMed]

41. Gempt, J.; Krieg, S.M.; Hüttinger, S.; Buchmann, N.; Ryang, Y.-M.; Shiban, E.; Meyer, B.; Zimmer, C.; Förschler, A.; Ringel, F. Postoperative ischemic changes after glioma resection identified by diffusion-weighted magnetic resonance imaging and their association with intraoperative motor evoked potentials. J. Neurosurg. 2013, 119, 829-836. [CrossRef] [PubMed]

42. Ostrý, S.; Belsan, T.; Otáhal, J.; Beneš, V.; Netuka, D. Is Intraoperative Diffusion Tensor Imaging at 3.0T Comparable to Subcortical Corticospinal Tract Mapping? Neurosurgery 2013, 73, 797-807. [CrossRef] [PubMed]

43. Pastor, J.; Vega-Zelaya, L.; Pulido, P.; Garnés-Camarena, O.; Abreu, A.; Sola, R.G. Role of intraoperative neurophysiological monitoring during fluorescence-guided resection surgery. Acta Neurochir. 2013, 155, 2201-2213. [CrossRef]

44. Sakurada, K.; Matsuda, K.; Funiu, H.; Kuge, A.; Takemura, S.; Sato, S.; Kayama, T. Usefulness of Multimodal Examination and Intraoperative Magnetic Resonance Imaging System in Glioma Surgery. Neurol. Med. Chir. 2012, 52, 553-557. [CrossRef] [PubMed]

45. Senft, C.; Forster, M.-T.; Bink, A.; Mittelbronn, M.; Franz, K.; Seifert, V.; Szelényi, A. Optimizing the extent of resection in eloquently located gliomas by combining intraoperative MRI guidance with intraoperative neurophysiological monitoring. $J$. Neuro Oncol. 2012, 109, 81-90. [CrossRef]

46. Hatiboglu, M.A.; Weinberg, J.S.; Suki, D.; Tummala, S.; Rao, G.; Sawaya, R.; Prabhu, S.S. Utilization of Intraoperative Motor Mapping in Glioma Surgery with High-Field Intraoperative Magnetic Resonance Imaging. Ster. Funct. Neurosurg. 2010, 88, 345-352. [CrossRef] [PubMed]

47. Ichikawa, T.; Suzuki, K.; Sasaki, T.; Matsumoto, M.; Sakuma, J.; Oinuma, M.; Kasuya, H.; Kodama, N. Utility and the Limit of Motor Evoked Potential Monitoring for Preventing Complications in Surgery for Cerebral Arteriovenous Malformation. Oper. Neurosurg. 2010, 67, ons222-ons228. [CrossRef] [PubMed]

48. Szelényi, A.; Hattingen, E.; Weidauer, S.; Seifert, V.; Ziemann, U. Intraoperative Motor Evoked Potential Alteration in Intracranial Tumor Surgery and Its Relation to Signal Alteration in Postoperative Magnetic Resonance Imaging. Neurosurgery 2010, 67, 302-313. [CrossRef] [PubMed]

49. Kombos, T.; Süss, O.; Vajkoczy, P. Subcortical mapping and monitoring during insular tumor surgery. Neurosurg. Focus 2009, 27, E5. [CrossRef] [PubMed]

50. Neuloh, G.; Schramm, J. Are there False-negative Results of Motor Evoked Potential Monitoring in Brain Surgery? Central Eur. Neurosurg. 2009, 70, 171-175. [CrossRef] [PubMed]

51. Neuloh, G.; Pechstein, U.; Schramm, J. Motor tract monitoring during insular glioma surgery. J. Neurosurg. 2007, 106, 582-592. [CrossRef]

52. Zhou, H.H.; Kelly, P.J. Transcranial Electrical Motor Evoked Potential Monitoring for Brain Tumor Resection. Neurosurgery 2001, 48, 1075-1081. [CrossRef]

53. Cedzich, C.; Taniguchi, M.; Schäfer, S.; Schramm, J. Somatosensory Evoked Potential Phase Reversal and Direct Motor Cortex Stimulation during Surgery in and around the Central Region. Neurosurgery 1996, 38, 962-970. [CrossRef] [PubMed]

54. Koo, D.L.; Lee, W.G.; Hong, S.-C.; Seo, D.-W. Clinical Usefulness of Intraoperative Motor-Evoked Potential Monitoring during Temporal Lobe Epilepsy Surgery. J. Clin. Neurol. 2019, 15, 285-291. [CrossRef] [PubMed]

55. Neuloh, G.C.; Bien, C.G.; Clusmann, H.; Von Lehe, M.; Schramm, J. Continuous motor monitoring enhances functional preservation and seizure-free outcome in surgery for intractable focal epilepsy. Acta Neurochir. 2010, 152, 1307-1314. [CrossRef] [PubMed]

56. Guo, D.; Fan, X.; You, H.; Tao, X.; Qi, L.; Ling, M.; Li, Z.; Liu, J.; Qiao, H. Prediction of postoperative motor deficits using intraoperative motor-evoked potentials in middle cerebral artery aneurysm. Neurosurg. Rev. 2021, 44, 495-501. [CrossRef] [PubMed]

57. Park, D.; Kim, B.H.; Lee, S.-E.; Jeong, E.; Cho, K.; Park, J.K.; Choi, Y.-J.; Jin, S.; Hong, D.; Kim, M.-C. Usefulness of Intraoperative Neurophysiological Monitoring During the Clipping of Unruptured Intracranial Aneurysm: Diagnostic Efficacy and Detailed Protocol. Front. Surg. 2021, 8, 17. [CrossRef] [PubMed]

58. You, H.; Fan, X.; Guo, D.; Li, Z.; Tao, X.; Qi, L.; Ling, M.; Liu, J.; Qiao, H. Efficacy of evoked potential monitoring for predicting postoperative motor status in internal carotid artery aneurysm surgeries. J. Clin. Monit. 2021. [CrossRef] 
59. Kameda, M.; Hishikawa, T.; Hiramatsu, M.; Yasuhara, T.; Kurozumi, K.; Date, I. Precise MEP monitoring with a reduced interval is safe and useful for detecting permissive duration for temporary clipping. Sci. Rep. 2020, 10, 3507. [CrossRef] [PubMed]

60. Greve, T.; Stoecklein, V.M.; Dorn, F.; Laskowski, S.; Thon, N.; Tonn, J.-C.; Schichor, C. Introduction of intraoperative neuromonitoring does not necessarily improve overall long-term outcome in elective aneurysm clipping. J. Neurosurg. 2020, 132, $1188-1196$. [CrossRef]

61. Li, Z.; Fan, X.; Wang, M.; Tao, X.; Qi, L.; Ling, M.; Guo, D.; Qiao, H. Prediction of postoperative motor deficits using motor evoked potential deterioration duration in intracranial aneurysm surgery. Clin. Neurophysiol. 2019, 130, 707-713. [CrossRef] [PubMed]

62. Komatsu, K.; Mikami, T.; Yokoyama, R.; Suzuki, Y.; Komura, S.; Enatsu, R.; Noshiro, S.; Miyata, K.; Akiyama, Y.; Mikuni, N. Electrophysiological influence of temporal occlusion of the parent artery during aneurysm surgery. J. Clin. Neurosci. 2017, 45, 199-204. [CrossRef] [PubMed]

63. Staarmann, B.; O’Neal, K.; Magner, M.; Zuccarello, M. Sensitivity and Specificity of Intraoperative Neuromonitoring for Identifying Safety and Duration of Temporary Aneurysm Clipping Based on Vascular Territory, a Multimodal Strategy. World Neurosurg. 2017, 100, 522-530. [CrossRef] [PubMed]

64. Kim, S.-H.; Jin, S.-J.; Karm, M.-H.; Moon, Y.-J.; Jeong, H.-W.; Kim, J.-W.; Ha, S.-I.; Kim, J.-U. Comparison of false-negative/positive results of intraoperative evoked potential monitoring between no and partial neuromuscular blockade in patients receiving propofol/remifentanil-based anesthesia during cerebral aneurysm clipping surgery. Medicine 2016, 95, e4725. [CrossRef]

65. Maruta, Y.; Fujii, M.; Imoto, H.; Nomura, S.; Tanaka, N.; Inamura, A.; Sadahiro, H.; Oka, F.; Goto, H.; Shirao, S.; et al. Strategies and Pitfalls of Motor-Evoked Potential Monitoring during Supratentorial Aneurysm Surgery. J. Stroke Cerebrovasc. Dis. 2016, 25, 484-495. [CrossRef]

66. Song, J.; Lang, L.; Zhu, W.; Gu, Y.; Xu, B.; Cai, J.; Yue, Q.; Xu, G.; Chen, L.; Mao, Y. Application of intraoperative motor evoked potential monitoring during giant internal carotid artery aneurysm surgery using prolonged temporary occlusion. Acta Neurochir 2015, 157, 1833-1840. [CrossRef] [PubMed]

67. Sasaki, T.; Kon, H.; Saito, A.; Nakamura, T.; Abe, M.; Nishijima, M. Intraoperative Supporting Tools in Aneurysm Surgery: Roles of Electrophysiological Monitoring. Jpn. J. Neurosurg. 2014, 23, 716-720. [CrossRef]

68. Takebayashi, S.; Kamiyama, H.; Takizawa, K.; Kobayashi, T.; Saitoh, N. The Significance of Intraoperative Monitoring of Muscle Motor Evoked Potentials during Unruptured Large and Giant Cerebral Aneurysm Surgery. Neurol. Med. Chir. 2014, 54, 180-188. [CrossRef] [PubMed]

69. Yue, Q.; Zhu, W.; Gu, Y.; Xu, B.; Lang, L.; Song, J.; Cai, J.; Xu, G.; Chen, L.; Mao, Y. Motor Evoked Potential Monitoring During Surgery of Middle Cerebral Artery Aneurysms: A Cohort Study. World Neurosurg. 2014, 82, 1091-1099. [CrossRef] [PubMed]

70. Dengler, J.; Cabraja, M.; Faust, K.; Picht, T.; Kombos, T.; Vajkoczy, P. Intraoperative neurophysiological monitoring of extracranialintracranial bypass procedures. J. Neurosurg. 2013, 119, 207-214. [CrossRef] [PubMed]

71. Kang, D.; Yao, P.; Wu, Z.; Yu, L. Ischemia changes and tolerance ratio of evoked potential monitoring in intracranial aneurysm surgery. Clin. Neurol. Neurosurg. 2013, 115, 552-556. [CrossRef]

72. Maruta, Y.; Fujii, M.; Imoto, H.; Nomura, S.; Oka, F.; Goto, H.; Shirao, S.; Yoshikawa, K.; Yoneda, H.; Ideguchi, M.; et al. Intra-operative monitoring of lower extremity motor-evoked potentials by direct cortical stimulation. Clin. Neurophysiol. 2012, 123, 1248-1254. [CrossRef] [PubMed]

73. Shi, C.; Zhou, Q.; Zhang, M.; Jiang, Y. Assessment of intraoperative motor-evoked potentials for predicting postoperative motor function during the surgical clipping of intracranial aneurysms. Zhong Nan Da Xue Xue Bao Yi Xue Ban 2012, 37, $244-249$. [PubMed]

74. Motoyama, Y.; Kawaguchi, M.; Yamada, S.; Nakagawa, I.; Nishimura, F.; Hironaka, Y.; Park, Y.-S.; Hayashi, H.; Abe, R.; Nakase, H. Evaluation of Combined Use of Transcranial and Direct Cortical Motor Evoked Potential Monitoring During Unruptured Aneurysm Surgery. Neurol. Med. Chir. 2011, 51, 15-22. [CrossRef] [PubMed]

75. Irie, T.; Yoshitani, K.; Ohnishi, Y.; Shinzawa, M.; Miura, N.; Kusaka, Y.; Miyazaki, S.; Miyamoto, S. The Efficacy of Motor-evoked Potentials on Cerebral Aneurysm Surgery and New-onset Postoperative Motor Deficits. J. Neurosurg. Anesthesiol. 2010, 22, 247-251. [CrossRef] [PubMed]

76. Yeon, J.Y.; Seo, D.-W.; Hong, S.-C.; Kim, J.-S. Transcranial motor evoked potential monitoring during the surgical clipping of unruptured intracranial aneurysms. J. Neurol. Sci. 2010, 293, 29-34. [CrossRef]

77. Szelenyi, A.; Langer, D.; Beck, J.; Raabe, A.; Flamm, E.; Seifert, V.; Deletis, V. Transcranial and direct cortical stimulation for motor evoked potential monitoring in intracerebral aneurysm surgery. Neurophysiol. Clin. Neurophysiol. 2007, 37, 391-398. [CrossRef] [PubMed]

78. Weinzierl, M.R.; Reinacher, P.; Gilsbach, J.M.; Rohde, V. Combined motor and somatosensory evoked potentials for intraoperative monitoring: Intra- and postoperative data in a series of 69 operations. Neurosurg. Rev. 2007, 30, 109-116. [CrossRef] [PubMed]

79. Horiuchi, K.; Suzuki, K.; Sasaki, T.; Matsumoto, M.; Sakuma, J.; Konno, Y.; Oinuma, M.; Itakura, T.; Kodama, N. Intraoperative monitoring of blood flow insufficiency during surgery of middle cerebral artery aneurysms. J. Neurosurg. 2005, 103, 275-283. [CrossRef]

80. Nakagawa, I.; Park, H.; Kotsugi, M.; Motoyama, Y.; Myochin, K.; Takeshima, Y.; Matsuda, R.; Nishimura, F.; Yamada, S.; Takatani, T.; et al. Diagnostic impact of monitoring transcranial motor-evoked potentials to prevent ischemic complications during endovascular treatment for intracranial aneurysms. Neurosurg. Rev. 2021, 44, 1493-1501. [CrossRef] [PubMed] 
81. Wilent, W.B.; Belyakina, O.; Korsgaard, E.; Tjoumakaris, S.I.; Gooch, M.R.; Jabbour, P.; Rosenwasser, R.; English, J.D.; Kim, W.; Tesdahl, E.; et al. Intraoperative vascular complications during 2278 cerebral endovascular procedures with multimodality IONM: Relationship between signal change, complication, intervention and postoperative outcome. J. NeuroInterventional. Surg. 2021, 13, 378-383. [CrossRef]

82. Lee, S.; Kim, D.Y.; Bin Kim, S.; Kim, W.; Kang, M.-R.; Kim, H.-J.; Lee, K.H.; Yoo, M.; Choi, B.-S.; Kim, J.S.; et al. Predictive value of neurophysiologic monitoring during neurovascular intervention for postoperative new neurologic deficits. Neuroradiology 2018, 61, 207-215. [CrossRef] [PubMed]

83. Cubells, C.; Garcia, P.; Coll-Canti, J. Implementation of Intraoperative Neurophysiological Monitoring during Endovascular Procedures in the Central Nervous System. Interv. Neurol. 2015, 3, 85-100. [CrossRef]

84. Hiraishi, T.; Fukuda, M.; Oishi, M.; Nishino, K.; Shinbo, J.; Sorimachi, T.; Ito, Y.; Fujii, Y. Usefulness of motor-evoked potential monitoring during coil embolization of anterior choroidal artery aneurysms: Technical reports. Neurol. Res. 2011, 33, 360-362. [CrossRef] [PubMed]

85. Iwasaki, M.; Kumabe, T.; Saito, R.; Kanamori, M.; Yamashita, Y.; Sonoda, Y.; Tominaga, T. Preservation of the Long Insular Artery to Prevent Postoperative Motor Deficits After Resection of Insulo-opercular Glioma: Technical Case Reports. Neurol. Med. Chir. 2014, 54, 321-326. [CrossRef] [PubMed]

86. Szelényi, A.; De Camargo, A.B.; Flamm, E.S.; Deletis, V. Neurophysiological criteria for intraoperative prediction of pure motor hemiplegia during aneurysm surgery. J. Neurosurg. 2003, 99, 575-578. [CrossRef] [PubMed]

87. Sala, F.; Di Rocco, C. Intraoperative Neurophysiological Monitoring in Neurosurgery: Moving the Debate from Evidence and Cost-Effectiveness to Education and Training. World Neurosurg. 2015, 83, 32-34. [CrossRef] [PubMed]

88. Howick, J.; Cohen, B.A.; McCulloch, P.; Thompson, M.; Skinner, S.A. Foundations for evidence-based intraoperative neurophysiological monitoring. Clin. Neurophysiol. 2016, 127, 81-90. [CrossRef] [PubMed]

89. Thomas, B.; Guo, D. The Diagnostic Accuracy of Evoked Potential Monitoring Techniques During Intracranial Aneurysm Surgery for Predicting Postoperative Ischemic Damage: A Systematic Review and Meta-Analysis. World Neurosurg. 2017, 103, 829-840.e3. [CrossRef]

90. Guo, L.; Gelb, A.W. The use of motor evoked potential monitoring during cerebral aneurysm surgery to predict pure motor deficits due to subcortical ischemia. Clin. Neurophysiol. 2011, 122, 648-655. [CrossRef]

91. Zhu, F.; Chui, J.; Herrick, I.; Martin, J. Intraoperative evoked potential monitoring for detecting cerebral injury during adult aneurysm clipping surgery: A systematic review and meta-analysis of diagnostic test accuracy. BMJ Open 2019, 9, e022810. [CrossRef] [PubMed]

92. Holdefer, R.; Macdonald, D.; Skinner, S. Somatosensory and motor evoked potentials as biomarkers for post-operative neurological status. Clin. Neurophysiol. 2015, 126, 857-865. [CrossRef] [PubMed]

93. Sala, F.; Kržan, M.J.; Deletis, V. Intraoperative neurophysiological monitoring in pediatric neurosurgery: Why, when, how? Child's Nerv. Syst. 2002, 18, 264-287. [CrossRef] [PubMed]

94. Lieberman, J.A.; Lyon, R.; Feiner, J.; Diab, M.; Gregory, G.A. The Effect of Age on Motor Evoked Potentials in Children Under Propofol/Isoflurane Anesthesia. Anesthesia Analg. 2006, 103, 316-321. [CrossRef] [PubMed]

95. Resnick, T.J.; Alvarez, L.A.; Duchowny, M. Cortical stimulation thresholds in children being evaluated for resective surgery. Epilepsia 1998, 29, 651-652.

96. Krieg, S.M.; Shiban, E.; Droese, D.; Gempt, J.; Buchmann, N.; Pape, H.; Ryang, Y.M.; Meyer, B.; Ringel, F. Predictive Value and Safety of Intraoperative Neurophysiological Monitoring With Motor Evoked Potentials in Glioma Surgery. Neurosurgery 2011, 70, 1060-1071. [CrossRef] [PubMed]

97. Seidel, K.; Beck, J.; Stieglitz, L.; Schucht, P.; Raabe, A. Low-Threshold Monopolar Motor Mapping for Resection of Primary Motor Cortex Tumors. Oper. Neurosurg. 2012, 71, ons104-ons115. [CrossRef] [PubMed]

98. SanMillan, J.L.; Plans, G.; Gabarrós, A.; Fernández-Conejero, I. Letter to the Editor: Threshold criterion in transcranial motor evoked potentials. J. Neurosurg. 2017, 126, 1744-1746. [CrossRef]

99. Rothwell, J.; Burke, D.; Hicks, R.; Stephen, J.; Woodforth, I.; Crawford, M. Transcranial electrical stimulation of the motor cortex in man: Further evidence for the site of activation. J. Physiol. 1994, 481, 243-250. [CrossRef]

100. Abboud, T.; Huckhagel, T.; Stork, J.-H.; Hamel, W.; Schwarz, C.; Vettorazzi, E.; Westphal, M.; Martens, T. Why Does Threshold Level Change in Transcranial Motor-evoked Potentials During Surgery for Supratentorial Lesions? J. Neurosurg. Anesthesiol. 2017, 29, 393-399. [CrossRef]

101. Szelényi, A.; Kothbauer, K.; De Camargo, A.B.; Langer, D.; Flamm, E.S.; Deletis, V. Motor Evoked Potential Monitoring during Cerebral Aneurysm Surgery: Technical Aspects and Comparison of Transcranial and Direct Cortical Stimulation. Oper. Neurosurg. 2005, 57, 331. [CrossRef] [PubMed]

102. Shiban, E.; Krieg, S.M.; Haller, B.; Buchmann, N.; Obermueller, T.; Boeckh-Behrens, T.; Wostrack, M.; Meyer, B.; Ringel, F. Intraoperative subcortical motor evoked potential stimulation: How close is the corticospinal tract? J. Neurosurg. 2015, 123, 711-720. [CrossRef]

103. Szelényi, A.; Senft, C.; Jardan, M.; Forster, M.; Franz, K.; Seifert, V.; Vatter, H. Intra-operative subcortical electrical stimulation: A comparison of two methods. Clin. Neurophysiol. 2011, 122, 1470-1475. [CrossRef] 
104. Schucht, P.; Seidel, K.; Jilch, A.; Beck, J.; Raabe, A. A review of monopolar motor mapping and a comprehensive guide to continuous dynamic motor mapping for resection of motor eloquent brain tumors. Neurochirurgie 2017, 63, 175-180. [CrossRef] [PubMed]

105. Raabe, A.; Beck, J.; Schucht, P.; Seidel, K. Continuous dynamic mapping of the corticospinal tract during surgery of motor eloquent brain tumors: Evaluation of a new method. J. Neurosurg. 2014, 120, 1015-1024. [CrossRef] [PubMed]

106. Prabhu, S.S.; Gasco, J.; Tummala, S.; Weinberg, J.S.; Rao, G. Intraoperative magnetic resonance imaging-guided tractography with integrated monopolar subcortical functional mapping for resection of brain tumors. J. Neurosurg. 2011, 114, 719-726. [CrossRef] [PubMed]

107. Ohue, S.; Kohno, S.; Inoue, A.; Yamashita, D.; Harada, H.; Kumon, Y.; Kikuchi, K.; Miki, H.; Ohnishi, T. Accuracy of Diffusion Tensor Magnetic Resonance Imaging-Based Tractography for Surgery of Gliomas Near the Pyramidal Tract. Neurosurgery 2011, 70, 283-294. [CrossRef] [PubMed]

108. Nossek, E.; Korn, A.; Shahar, T.; Kanner, A.A.; Yaffe, H.; Marcovici, D.; Ben-Harosh, C.; Ben Ami, H.; Weinstein, M.; ShapiraLichter, I.; et al. Intraoperative mapping and monitoring of the corticospinal tracts with neurophysiological assessment and 3-dimensional ultrasonography-based navigation. J. Neurosurg. 2011, 114, 738-746. [CrossRef] [PubMed]

109. Kamada, K.; Todo, T.; Ota, T.; Ino, K.; Masutani, Y.; Aoki, S.; Takeuchi, F.; Kawai, K.; Saito, N. The motor-evoked potential threshold evaluated by tractography and electrical stimulation. J. Neurosurg. 2009, 111, 785-795. [CrossRef] [PubMed]

110. Bello, L.; Riva, M.; Fava, E.; Ferpozzi, V.; Castellano, A.; Raneri, F.; Pessina, F.; Bizzi, A.; Falini, A.; Cerri, G. Tailoring neurophysiological strategies with clinical context enhances resection and safety and expands indications in gliomas involving motor pathways. Neuro Oncol. 2014, 16, 1110-1128. [CrossRef]

111. Sala, F.; Lanteri, P. Brain surgery in motor areas: The invaluable assistance of intraoperative neurophysiological monitoring. $J$. Neurosurg. Sci. 2003, 47.

112. Han, S.J.; Morshed, R.A.; Troncon, I.; Jordan, K.M.; Henry, R.G.; Hervey-Jumper, S.L.; Berger, M.S. Subcortical stimulation mapping of descending motor pathways for perirolandic gliomas: Assessment of morbidity and functional outcome in 702 cases. J. Neurosurg. 2019, 131, 201-208. [CrossRef] [PubMed]

113. Drummond, J.C. The Lower Limit of Autoregulation. Anesthesiology 1997, 86, 1431-1433. [CrossRef] [PubMed]

114. Ito, Y.; Yamazaki, K.; Chiba, Y.; Isobe, M.; Isu, T.; Hokari, M. The Relationship between Carotid Stump Pressure and Changes in Motor-Evoked Potentials in Carotid Endarterectomy Patients. J. Neurol. Surg. Part A Cent. Eur. Neurosurg. 2016, 77, $291-296$. [CrossRef] [PubMed]

115. Trevethan, R. Sensitivity, Specificity, and Predictive Values: Foundations, Pliabilities, and Pitfalls in Research and Practice. Front. Public Heal. 2017, 5, 307. [CrossRef] [PubMed]

116. Sjöberg, R.L.; Stålnacke, M.; Andersson, M.; Eriksson, J. The supplementary motor area syndrome and cognitive control. Neuropsychologia 2019, 129, 141-145. [CrossRef] [PubMed]

117. Zentner, J.; Hufnagel, A.; Pechstein, U.; Wolf, H.K.; Schramm, J. Functional results after resective procedures involving the supplementary motor area. J. Neurosurg. 1996, 85, 542-549. [CrossRef] [PubMed]

118. Aronson, J.K. Biomarkers and surrogate endpoints. Br. J. Clin. Pharmacol. 2005, 59, 491-494. [CrossRef]

119. Bidkar, P.U.; Thakkar, A.; Manohar, N.; Rao, K.S. Intraoperative neurophysiological monitoring in paediatric neurosurgery. Int. J. Clin. Pract. 2021, e14160. [CrossRef]

120. Keeble, H.; Lavrador, J.P.; Pereira, N.; Lente, K.; Brogna, C.; Gullan, R.; Bhangoo, R.; Vergani, F.; Ashkan, K. Electromagnetic Navigation Systems and Intraoperative Neuromonitoring: Reliability and Feasibility Study. Oper. Neurosurg. 2021, $20,373-382$. [CrossRef] [PubMed]

121. Lee, S.; Jeon, Y.T.; Oh, T.K.; Lee, J.; Choi, E.S. Predictive factors of unacceptable movement and motor-evoked potentials during intraoperative neurophysiological monitoring in adult patients undergoing brain surgery: A retrospective study. Medicine 2021, 100, e24148. [CrossRef]

122. Simon, M.V.; Lee, D.K.; Choi, B.D.; Talati, P.A.; Yang, J.C.; Koch, M.J.; Jones, P.S.; Curry, W.T. Neurophysiologic Mapping of Thalamocortical Tract in Asleep Craniotomies: Promising Results From an Early Experience. Oper. Neurosurg. 2021, 20, $219-225$. [CrossRef]

123. Wang, G.; Zhang, X.; Gou, Y.; Wen, Y.; Zhang, G.; Li, M.; Zhang, S.; Yin, Y.; Chen, S.; Qi, S.; et al. A Hybrid Strategy for Patients With Complex Cerebral Aneurysm: STA-MCA Bypass in Combination With Endovascular Embolization. Front. Neurol. 2021, 11, 614601. [CrossRef] [PubMed]

124. Bander, E.D.; Shelkov, E.; Modik, O.; Kandula, P.; Karceski, S.C.; Ramakrishna, R. Use of the train-of-five bipolar technique to provide reliable, spatially accurate motor cortex identification in asleep patients. Neurosurg. Focus 2020, 48, E4. [CrossRef] [PubMed]

125. Brage, L.; Pérez-Lorensu, P.J.; Plata-Bello, J.; Saponaro-González, Á.; Pérez-Orribo, L.; García-Conde, M.; Febles-García, P.; Roldán-Delgado, H.; García-Marín, V. Direct cortical stimulation with cylindrical depth electrodes in the interhemispheric fissure for leg motor evoked potential monitoring. Clin. Neurophysiol. 2020, 131, 127-132. [CrossRef]

126. Fekete, G.; Bognár, L.; Gutema, E.; Novák, L. Intraoperative electrophysiology in children—Single institute experience of 96 examinations. Neurol. India 2020, 68, 407-412. [CrossRef] [PubMed] 
127. Hayashi, H.; Bebawy, J.F.; Koht, A.; Hemmer, L.B. Cautionary findings for motor evoked potential monitoring in intracranial aneurysm surgery after a single administration of rocuronium to facilitate tracheal intubation. J. Clin. Monit. Comput. 2020. [CrossRef] [PubMed]

128. Jahodová, A.; Beňová, B.; Kudr, M.; Ježdík, P.; Janča, R.; Bělohlávková, A.; Liby, P.; Leško, R.; Tichý, M.; Čelakovský, P.; et al. A novel effective paradigm of intraoperative electrical stimulation mapping in children. J. Neurosurg. Pediatrics 2020, 26, 150-156. [CrossRef] [PubMed]

129. Kim, S.Y.; Jeon, H.J.; Kim, S.; Chung, J.; Park, K.Y.; Huh, S.K.; Lee, J.W. Microsurgical clipping of ruptured anterior choroidal artery aneurysms: Incidence of and risk factors for ischemic complications. Clin. Neurol. Neurosurg. 2020, 195, 105884. [CrossRef] [PubMed]

130. Lee, S.; Lee, H.; Choi, B.S.; Jin, S.C. Unexpected abnormal intraoperative neurophysiologic monitoring change by multiple spontaneous intracerebral haemorrhage during endovascular coiling. Br. J. Neurosurg. 2020, 34, 342-345. [CrossRef]

131. Porčnik, A.; Pešak, J.; Žele, T.; Koritnik, B.; Rodi, Z.; Prestor, B. Continuous Dynamic Mapping of the Corticospinal Tract in Motor Eloquent Tumor Surgery: Our Experience and Evaluation of the Method. Acta. Med. Acad. 2020, 49, 63-69. [CrossRef] [PubMed]

132. Roth, J.; Korn, A.; Sala, F.; Benvenisti, H.; Jubran, M.; Bitan-Talmor, Y.; Ekstein, M.; Constantini, S. Intraoperative neurophysiology in pediatric supratentorial surgery: Experience with 57 cases. Childs. Nerv. Syst. 2020, 36, 315-324. [CrossRef] [PubMed]

133. Balaji, A.; Rajagopal, N.; Yamada, Y.; Teranishi, T.; Kawase, T.; Kato, Y. A Retrospective Study in Microsurgical Procedures of Large and Giant Intracranial Aneurysms: An Outcome Analysis. World Neurosurg. X 2019, 2, 100007. [CrossRef] [PubMed]

134. Chung, J.; Park, W.; Hong, S.H.; Park, J.C.; Ahn, J.S.; Kwun, B.D.; Lee, S.A.; Kim, S.H.; Jeon, J.Y. Intraoperative use of transcranial motor/sensory evoked potential monitoring in the clipping of intracranial aneurysms: Evaluation of false-positive and falsenegative cases. J. Neurosurg. 2018, 130, 936-994. [CrossRef] [PubMed]

135. Hu, P.; Zhang, H.Q.; Li, X.Y.; Tong, X.Z. Double-Barrel Superficial Temporal Artery to Proximal Middle Cerebral Artery Bypass to Treat Complex Intracranial Aneurysms: A Reliable High Blood Flow Bypass. World Neurosurg. 2019, 125, e884-e890. [CrossRef] [PubMed]

136. Kanaya, K.; Goto, T.; Horiuchi, T.; Hongo, K. Threshold variation of transcranial motor evoked potential with threshold criterion in frontotemporal craniotomy. Clin. Neurophysiol. Pract. 2019, 4, 184-189. [CrossRef] [PubMed]

137. Rossi, M.; Conti Nibali, M.; Viganò, L.; Puglisi, G.; Howells, H.; Gay, L.; Sciortino, T.; Leonetti, A.; Riva, M.; Fornia, L.; et al. Resection of tumors within the primary motor cortex using high-frequency stimulation: Oncological and functional efficiency of this versatile approach based on clinical conditions. J. Neurosurg. 2019, 133, 642-654. [CrossRef] [PubMed]

138. Wang, S.S.; Yang, Y.; Velz, J.; Keller, E.; Luft, A.R.; Regli, L.; Neidert, M.C.; Bozinov, O. Management of brainstem haemorrhages. Swiss Med. Wkly. 2019, 149, w20062. [CrossRef] [PubMed]

139. Della Puppa, A.; Rossetto, M.; Volpin, F.; Rustemi, O.; Grego, A.; Gerardi, A.; Ortolan, R.; Causin, F.; Munari, M.; Scienza, R. Microsurgical Clipping of Intracranial Aneurysms Assisted by Neurophysiological Monitoring, Microvascular Flow Probe, and ICG-VA: Outcomes and Intraoperative Data on a Multimodal Strategy. World Neurosurg. 2018, 113, e336-e344. [CrossRef] [PubMed]

140. Han, S.; Kwon, Y.C.; Kim, S.M.; Hyun, S.J.; Jahng, T.A.; Kim, K.J.; Kim, H.J.; Choi, H.Y.; Park, Y.S.; Seok Park, K. Risk Factor Analysis of Change in Intraoperative Neurophysiologic Monitoring During Cervical Open Door Laminoplasty. World Neurosurg. 2018, 119, e235-e243. [CrossRef]

141. Silverstein, J.W.; Rosenthal, A.; Ellis, J.A. Direct Cortical Motor Evoked Potentials Versus Transcranial Motor Evoked Potentials for the Detection of Cortical Ischemia During Supratentorial Craniotomy: Case Report. Cureus 2018, 10, e3771. [CrossRef] [PubMed]

142. Skrap, M.; Vescovi, M.C.; Pauletto, G.; Maieron, M.; Tomasino, B.; Bagatto, D.; Tuniz, F. Supratentorial Cavernous Malformations Involving the Corticospinal Tract and Sensory Motor Cortex: Treatment Strategies, Surgical Considerations, and Outcomes. Oper. Neurosurg. 2018, 15, 483-497. [CrossRef] [PubMed]

143. Umemura, T.; Nishizawa, S.; Nakano, Y.; Saito, T.; Kitagawa, T.; Miyaoka, R.; Suzuki, K.; Yamamoto, J. Intraoperative monitoring of motor-evoked potential for parenchymal brain tumor removal: An analysis of false-negative cases. J. Clin. Neurosci. 2018, 57, 105-110. [CrossRef] [PubMed]

144. Wakui, D.; Ito, H.; Takasuna, H.; Onodera, H.; Oshio, K.; Tanaka, Y. Surgical removal of an arteriovenous malformation in the anterior perforated substance in a pregnant woman. Surg. Neurol. Int. 2018, 9, 117. [CrossRef] [PubMed]

145. Akiyama, Y.; Ohtaki, S.; Komatsu, K.; Toyama, K.; Enatsu, R.; Mikami, T.; Wanibuchi, M.; Mikuni, N. Intraoperative Mapping and Monitoring of the Pyramidal Tract Using Endoscopic Depth Electrodes. World Neurosurg. 2017, 105, 14-19. [CrossRef] [PubMed]

146. Lv, X.; Hu, X.; Li, W.; He, H.; Jiang, C.; Li, Y. Curative and adjunctive AVM Onyx embolization of AVMs through the choroidal arteries. Interv. Neuroradiol. 2017, 23, 392-398. [CrossRef] [PubMed]

147. Pintea, B.; Baumert, B.; Kinfe, T.M.; Gousias, K.; Parpaley, Y.; Boström, J.P. Early motor function after local treatment of brain metastases in the motor cortex region with stereotactic radiotherapy/radiosurgery or microsurgical resection: A retrospective study of two consecutive cohorts. Radiat. Oncol. 2017, 12, 177. [CrossRef] [PubMed]

148. Takagaki, M.; Togami, Y.; Murasawa, A.; Nakao, K. Multiple fusiform aneurysms of the distal middle cerebral artery showing different radiological courses: A case report. Interdiscip. Neurosurg. 2017, 10, 8-10. [CrossRef]

149. Carrabba, G.; Bertani, G.; Cogiamanian, F.; Ardolino, G.; Zarino, B.; Di Cristofori, A.; Locatelli, M.; Caroli, M.; Rampini, P. Role of Intraoperative Neurophysiologic Monitoring in the Resection of Thalamic Astrocytomas. World Neurosurg. 2016, $94,50-56$. [CrossRef] [PubMed] 
150. Gripp, D.A.; Nakasone, F.J.; Maldaun, M.V.; de Aguiar, P.H.; Mathias, L.R., Jr. Giant pseudoaneurysm originated from distal middle cerebral artery dissection treated by trapping under sensitive evoked potential and motor evoked potential monitoring: Case report and discussion. Surg. Neurol. Int. 2016, 7 (Suppl. 9), S214-S218. [CrossRef]

151. Grossauer, S.; Koeck, K.; Kraschl, J.; Olipitz, O.; Hausegger, K.A.; Vince, G.H. Detection of Cerebral Vasospasm Following Aneurysmal Subarachnoid Hemorrhage Using Motor Evoked Potentials. Neurosurgery 2016, 78, 265-273. [CrossRef] [PubMed]

152. Ikedo, T.; Nakamura, K.; Sano, N.; Nagata, M.; Okada, Y.; Terakawa, Y.; Murata, T. Intraoperative Transcranial Motor-Evoked Potentials Predict Motor Function Outcome in Intracerebral Hemorrhage Surgery. World Neurosurg. 2016, 90, 518-523. [CrossRef] [PubMed]

153. Imai, H.; Watanabe, K.; Miyagishima, T.; Yoshimoto, Y.; Kin, T.; Nakatomi, H.; Saito, N. The outcome of a surgical protocol based on ischemia overprotection in large and giant aneurysms of the anterior cerebral circulation. Neurosurg. Rev. 2016, 39, 505-517. [CrossRef] [PubMed]

154. Isozaki, M.; Satow, T.; Matsushige, T.; Mori, H.; Iihara, K. Superselective Provocative Test with Propofol Using Motor-Evoked Potential Monitoring for Managing Cerebral Arteriovenous Malformations Fed by the Anterior Choroidal Artery. J.Stroke. Cerebrovasc. Dis. 2016, 25, e153-e157. [CrossRef] [PubMed]

155. Koenig, R.W.; Kapapa, T.; Antoniadis, G.; Roehrer, S.; Hagel, V.; Wirtz, C.R.; Pedro, M.T.; Kretschmer, T.; Schmidt, T.; Coburger, J. Surgery for brain arteriovenous malformations (BAVMs): The role of intraoperative imaging and neuromonitoring. Neurol. Psychiatry Brain Res. 2016, 22, 110-118. [CrossRef]

156. Nakagomi, T.; Furuya, K.; Tanaka, J.; Takanashi, S.; Watanabe, T.; Shinohara, T.; Ogawa, A.; Fujii, N. Clipping Surgery for Unruptured Middle Cerebral Artery Aneurysms. Acta. Neurochir. Suppl. 2016, 123, 85-88. [CrossRef] [PubMed]

157. Rossetto, M.; Ciccarino, P.; Lombardi, G.; Rolma, G.; Cecchin, D.; Della Puppa, A. Surgery on motor area metastasis. Neurosurg. Rev. 2016, 39, 71-77; discussion 77-78. [CrossRef] [PubMed]

158. Zhuang, D.X.; Wu, J.S.; Yao, C.J.; Qiu, T.M.; Lu, J.F.; Zhu, F.P.; Xu, G.; Zhu, W.; Zhou, L.F. Intraoperative Multi-Information-Guided Resection of Dominant-Sided Insular Gliomas in a 3-T Intraoperative Magnetic Resonance Imaging Integrated Neurosurgical Suite. World Neurosurg. 2016, 89, 84-92. [CrossRef] [PubMed]

159. Zhukov, V.Y.; Goryaynov, S.A.; Ogurtsova, A.A.; Ageev, I.S.; Protskiy, S.V.; Pronin, I.N.; Tonoyan, A.S.; Kobyakov, G.L.; Nenashev, E.A.; Smirnov, A.S.; et al. Diffusion tensor imaging tractography and intraoperative neurophysiological monitoring in surgery of intracranial tumors located near the pyramidal tract. Zhurnal Vopr. Neirokhirurgii Im. N. N. Burd. 2016, 80, 5-18. [CrossRef] [PubMed]

160. Wang, L.J.; Lin, F.X.; Zhao, B.; Wu, J.; Cao, Y.; Wang, S. Testing the Reliability of BOLD-fMRI Motor Mapping in Patients with Cerebral Arteriovenous Malformations by Electric Cortical Stimulation and Surgery Outcomes. World Neurosurg. 2016, 92, 386-396. [CrossRef] [PubMed]

161. Eldin, S.S.; Iwasaki, M.; Nishio, Y.; Jin, K.; Nakasato, N.; Tominaga, T. Resection of focal cortical dysplasia located in the upper pre-central gyrus. Epileptic. Disord. 2015, 17, 479-484. [CrossRef]

162. Erdoğan, E.T.; Karamürsel, S.; Kiriş, T. Effective Use of Multimodal Intraoperative Neuromonitoring in Neurosurgery. Neurosurg. Q. 2015, 25, 452-457. [CrossRef]

163. Jo, K.I.; Kim, H.R.; Yeon, J.Y.; Hong, S.C.; Kim, J.S. Treatment outcomes of surgical clipping for unruptured anterior circulation aneurysm-single institute experiences in the era of neurophysiologic monitoring and endovascular treatment. Neurosurg. Rev. 2015, 38, 677-682. [CrossRef] [PubMed]

164. Joksimovic, B.; Szelenyi, A.; Seifert, V.; Damjanovic, A.; Damjanovic, A.; Rasulic, L. Transcranial electric stimulation for intraoperative motor evoked potential monitoring: Dependence of required stimulation current on interstimulus interval value. $J$. Neurol. Surg. A. Cent. Eur. Neurosurg. 2015, 76, 190-198. [CrossRef] [PubMed]

165. Okamoto, E.; Ishikawa, E.; Yamamoto, T.; Matsuda, M.; Nakai, K.; Matsushita, A.; Masuda, Y.; Akutsu, H.; Ayuzawa, S.; Sakamaki, F.; et al. Variability in amplitude and stimulation threshold values in motor evoked potential (MEP) monitoring during the resection of brain lesions. Clin. Neurophysiol. 2015, 126, 1271-1278. [CrossRef]

166. Quan, K.; Xu, G.; Zhao, F.; Zhu, W. Tailored keyhole surgery for basal ganglia cavernous malformation with preoperative three-dimensional pyramidal tracts assessment and intraoperative electrophysiological monitoring. Chin. Neurosurg. J. 2015, 1, 15. [CrossRef]

167. Rashad, S.; Endo, H.; Sultan, A.E.; Shimizu, H.; Fujimura, M.; Sato, K.; Matsumoto, Y.; Tominaga, T. Therapeutic Clip Occlusion of the Anterior Choroidal Artery Involved with Partially Thrombosed Fusiform Aneurysm: A Case Report. J. Stroke. Cerebrovasc. Dis. 2015, 24, e227-e230. [CrossRef]

168. Udaka, Y.T.; Yoon, J.M.; Malicki, D.M.; Khanna, P.C.; Levy, M.L.; Crawford, J.R. Atypical Teratoid Rhabdoid Tumor in a Teenager with Unusual Infiltration Into the Jugular Foramen. World Neurosurg. 2015, 84, 2075.e13-2075.e16. [CrossRef] [PubMed]

169. Sahaya, K.; Pandey, A.S.; Thompson, B.G.; Bush, B.R.; Minecan, D.N. Intraoperative monitoring for intracranial aneurysms: The Michigan experience. J. Clin. Neurophysiol. 2014, 31, 563-567. [CrossRef] [PubMed]

170. Schucht, P.; Seidel, K.; Beck, J.; Murek, M.; Jilch, A.; Wiest, R.; Fung, C.; Raabe, A. Intraoperative monopolar mapping during 5-ALA-guided resections of glioblastomas adjacent to motor eloquent areas: Evaluation of resection rates and neurological outcome. Neurosurg. Focus 2014, 37, E16. [CrossRef]

171. Bulusu, S.; Kassam, A.B.; Houlden, D.A.; Alkherayf, F. Intraoperative neurophysiological monitoring during circulatory arrest using deep hypothermia: A case report during brain aneurysm clipping. Neurodiagn. J. 2013, 53, 121-141. [PubMed] 
172. Krieg, S.M.; Schäffner, M.; Shiban, E.; Droese, D.; Obermüller, T.; Gempt, J.; Meyer, B.; Ringel, F. Reliability of intraoperative neurophysiological monitoring using motor evoked potentials during resection of metastases in motor-eloquent brain regions: Clinical article. J. Neurosurg. 2013, 118, 1269-1278. [CrossRef] [PubMed]

173. Krieg, S.M.; Schnurbus, L.; Shiban, E.; Droese, D.; Obermueller, T.; Buchmann, N.; Gempt, J.; Meyer, B.; Ringel, F. Surgery of highly eloquent gliomas primarily assessed as non-resectable: Risks and benefits in a cohort study. BMC Cancer 2013, 13, 51 [CrossRef] [PubMed]

174. Shah, P.A. Transcranial motor evoked potential monitoring outcome in the high-risk brain and spine surgeries: Correlation of clinical and neurophysiological data-An Indian perspective. Ann. Indian. Acad. Neurol. 2013, 16, 609-613. [CrossRef]

175. Vassal, F.; Schneider, F.; Nuti, C. Intraoperative use of diffusion tensor imaging-based tractography for resection of gliomas located near the pyramidal tract: Comparison with subcortical stimulation mapping and contribution to surgical outcomes. $\mathrm{Br}$. $\mathrm{J}$. Neurosurg. 2013, 27, 668-675. [CrossRef] [PubMed]

176. Chen, L.; Lang, L.; Zhou, L.; Song, D.; Mao, Y. Bypass or not? Adjustment of surgical strategies according to motor evoked potential changes in large middle cerebral artery aneurysm surgery. World Neurosurg. 2012, 77, 398.e1-398.e6. [CrossRef]

177. Horton, T.G.; Barnes, M.; Johnson, S.; Kalapos, P.C.; Link, A.; Cockroft, K.M. Feasibility and efficacy of transcranial motor-evoked potential monitoring in neuroendovascular surgery. AJNR. Am. J. Neuroradiol. 2012, 33, 1825-1831. [CrossRef] [PubMed]

178. Ritzl, E.K. Intraoperative neuromonitoring during glioma surgery: Bring in the expert neurophysiologists! J. Clin. Neurophysiol. 2012, 29, 151-153. [CrossRef] [PubMed]

179. Schucht, P.; Beck, J.; Abu-Isa, J.; Andereggen, L.; Murek, M.; Seidel, K.; Stieglitz, L.; Raabe, A. Gross total resection rates in contemporary glioblastoma surgery: Results of an institutional protocol combining 5-aminolevulinic acid intraoperative fluorescence imaging and brain mapping. Neurosurgery 2012, 71, 927-935; discussion 935-936. [CrossRef] [PubMed]

180. Uchino, H.; Nakamura, T.; Kuroda, S.; Houkin, K.; Murata, J.; Saito, H. Intraoperative dual monitoring during carotid endarterectomy using motor evoked potentials and near-infrared spectroscopy. World Neurosurg. 2012, 78, 651-657. [CrossRef] [PubMed]

181. Zhu, F.P.; Wu, J.S.; Song, Y.Y.; Yao, C.J.; Zhuang, D.X.; Xu, G.; Tang, W.J.; Qin, Z.Y.; Mao, Y.; Zhou, L.F. Clinical application of motor pathway mapping using diffusion tensor imaging tractography and intraoperative direct subcortical stimulation in cerebral glioma surgery: A prospective cohort study. Neurosurgery 2012, 71, 1170-1183; discussion 1183-1184. [CrossRef] [PubMed]

182. Chang, E.F.; Clark, A.; Smith, J.S.; Polley, M.Y.; Chang, S.M.; Barbaro, N.M.; Parsa, A.T.; McDermott, M.W.; Berger, M.S. Functional mapping-guided resection of low-grade gliomas in eloquent areas of the brain: Improvement of long-term survival. Clinical article. J. Neurosurg. 2011, 114, 566-573. [CrossRef] [PubMed]

183. Chen, L.; Spetzler, R.F.; McDougall, C.G.; Albuquerque, F.C.; Xu, B. Detection of ischemia in endovascular therapy of cerebral aneurysms: A perspective in the era of neurophysiological monitoring. Neurosurg. Rev. 2011, 34, 69-75. [CrossRef]

184. Fukaya, C.; Sumi, K.; Otaka, T.; Shijo, K.; Nagaoaka, T.; Kobayashi, K.; Oshima, H.; Watanabe, T.; Yamamoto, T.; Katayama, Y. Corticospinal descending direct wave elicited by subcortical stimulation. J. Clin. Neurophysiol. 2011, 28, 297-301. [CrossRef] [PubMed]

185. González-Darder, J.M.; González-López, P.; Talamantes, F.; Quilis, V.; Cortés, V.; García-March, G.; Roldán, P. Multimodal navigation in the functional microsurgical resection of intrinsic brain tumors located in eloquent motor areas: Role of tractography. Neurosurg. Focus. 2010, 28, E5. [CrossRef] [PubMed]

186. Li, F.; Deshaies, E.; Allott, G.; Gorji, R. Transcranial motor evoked potential changes induced by provocative testing during embolization of cerebral arteriovenous malformations in patients under total intravenous anesthesia. Am. J. Electroneurodiagnostic. Technol. 2011, 51, 264-273. [CrossRef] [PubMed]

187. Lin, J.; Zhao, J.; Zhao, Y.; Zhang, D.; Wang, R.; Qiao, H.; Wang, S. Multiple intraoperative monitoring-assisted microneurosurgical treatment for anterior circulation cerebral aneurysm. J. Int. Med. Res. 2011, 39, 891-903. [CrossRef] [PubMed]

188. Tanaka, S.; Tashiro, T.; Gomi, A.; Takanashi, J.; Ujiie, H. Sensitivity and specificity in transcranial motor-evoked potential monitoring during neurosurgical operations. Surg. Neurol. Int. 2011, 2, 111. [CrossRef] [PubMed]

189. von der Brelie, C.; von Lehe, M. Long term outcome in cerebral cavernous malformation associated drug resistant epilepsy. Acta Neurochirurgica 2011, 153, 1892.

190. Walter, J.; Kuhn, S.A.; Waschke, A.; Kalff, R.; Ewald, C. Operative treatment of subcortical metastatic tumours in the central region. J. Neurooncol. 2011, 103, 567-573. [CrossRef] [PubMed]

191. Bello, L.; Castellano, A.; Fava, E.; Casaceli, G.; Riva, M.; Scotti, G.; Gaini, S.M.; Falini, A. Intraoperative use of diffusion tensor imaging fiber tractography and subcortical mapping for resection of gliomas: Technical considerations. Neurosurg. Focus. 2010, 28, E6. [CrossRef]

192. Bozzao, A.; Romano, A.; Angelini, A.; D’Andrea, G.; Calabria, L.F.; Coppola, V.; Mastronardi, L.; Fantozzi, L.M.; Ferrante, L. Identification of the pyramidal tract by neuronavigation based on intraoperative magnetic resonance tractography: Correlation with subcortical stimulation. Eur. Radiol. 2010, 20, 2475-2481. [CrossRef] [PubMed]

193. Feigl, G.C.; Ritz, R.; Moraes, M.; Klein, J.; Ramina, K.; Gharabaghi, A.; Krischek, B.; Danz, S.; Bornemann, A.; Liebsch, M.; et al. Resection of malignant brain tumors in eloquent cortical areas: A new multimodal approach combining 5-aminolevulinic acid and intraoperative monitoring. J. Neurosurg. 2010, 113, 352-357. [CrossRef] [PubMed] 
194. Juretschke, F.R.; Güresir, E.; Marquardt, G.; Berkefeld, J.; Rosahl, S.; Klisch, J.; Raabe, A.; Seifert, V.; Gerlach, R. Trigonal and peritrigonal lesions of the lateral ventricle-surgical considerations and outcome analysis of 20 patients. Neurosurg. Rev. 2010, 33, 457-464. [CrossRef] [PubMed]

195. Maesawa, S.; Fujii, M.; Nakahara, N.; Watanabe, T.; Wakabayashi, T.; Yoshida, J. Intraoperative tractography and motor evoked potential (MEP) monitoring in surgery for gliomas around the corticospinal tract. World Neurosurg. 2010, 74, 153-161. [CrossRef]

196. Sala, F.; Manganotti, P.; Grossauer, S.; Tramontanto, V.; Mazza, C.; Gerosa, M. Intraoperative neurophysiology of the motor system in children: A tailored approach. Child's Nerv. Syst. 2010, 26, 473-490. [CrossRef] [PubMed]

197. Sanai, N.; Berger, M.S. Intraoperative stimulation techniques for functional pathway preservation and glioma resection. Neurosurg. Focus. 2010, 28, E1. [CrossRef]

198. Tanaka, S.; Kawasaki, M.; Kimura, I.; Takanashi, J.; Ujiie, H. Alarm Points in Transcranial Motor-Evoked Potential Monitoring during Neurosurgical Operations. Jpn. J. Neurosurg. 2010, 19, 57-65. [CrossRef]

199. Yang, W.D.; Chen, Z.J.; Yu, Q.; Wang, Z.G.; Hao, Z.D.; Li, H.; Zhang, C.Z. Applications of blood oxygenation level dependentfunctional magnetic resonance imaging, diffusion tensor imaging and intraoperative neurophysiology monitoring in secondary epileptic surgery in M1 area. Zhonghua Yi Xue Za Zhi 2010, 90, 2755-2758. [CrossRef] [PubMed]

200. Gorji, R.; Deshaies, E.; Allott, G.; Li, F. Transcranial motor evoked potentials reliably predict changes in cerebral blood flow during methohexital testing. J. Neurosurg. Anesthesiol. 2009, 21, 424-425.

201. Hattingen, E.; Szelényi, A.; Rathert, J.; Blasel, S.; Zanella, F.; Weidauer, S. Perioperative Läsionen des Tractus corticospinalis. Atiologie, neuroradiologische Befunde und klinischer Verlauf [Perioperative lesions of the corticospinal tract. Etiology, neuroradiological features and clinical outcome]. Radiologe 2009, 49, 439-448. [CrossRef] [PubMed]

202. Kombos, T.; Picht, T.; Derdilopoulos, A.; Suess, O. Impact of intraoperative neurophysiological monitoring on surgery of high-grade gliomas. J. Clin. Neurophysiol. 2009, 26, 422-425. [CrossRef]

203. Krammer, M.J.; Wolf, S.; Schul, D.B.; Gerstner, W.; Lumenta, C.B. Significance of intraoperative motor function monitoring using transcranial electrical motor evoked potentials (MEP) in patients with spinal and cranial lesions near the motor pathways. $B r$. $J$. Neurosurg. 2009, 23, 48-55. [CrossRef]

204. Ozawa, N.; Muragaki, Y.; Nakamura, R.; Iseki, H. Identification of the pyramidal tract by neuronavigation based on intraoperative diffusion-weighted imaging combined with subcortical stimulation. Stereotact. Funct. Neurosurg. 2009, 87, 18-24. [CrossRef] [PubMed]

205. Simon, M.; Neuloh, G.; von Lehe, M.; Meyer, B.; Schramm, J. Insular gliomas: The case for surgical management. J. Neurosurg. 2009, 110, 685-695. [CrossRef]

206. Sugita, M.; Kinouchi, H.; Nishiyama, Y.; Kanemaru, K.; Yoshioka, H.; Horikoshi, T. Direct clipping of a thrombosed giant cerebral aneurysm after thrombectomy without bleeding to minimize the temporary occlusion time-technical case report. Neurol. Med. Chir. 2009, 49, 600-603. [CrossRef] [PubMed]

207. von Lehe, M.; Wellmer, J.; Urbach, H.; Schramm, J.; Elger, C.E.; Clusmann, H. Epilepsy surgery for insular lesions. Rev. Neurol. 2009, 165, 755-761. [CrossRef] [PubMed]

208. Yamaguchi, F.; Takahashi, H.; Teramoto, A. Navigation-assisted subcortical mapping: Intraoperative motor tract detection by bipolar needle electrode in combination with neuronavigation system. J. Neurooncol. 2009, 93, 121-125. [CrossRef] [PubMed]

209. Calancie, B.; Molano, M.R. Alarm criteria for motor-evoked potentials: What's wrong with the "presence-or-absence" approach? Spine 2008, 33, 406-414. [CrossRef] [PubMed]

210. Berman, J.I.; Berger, M.S.; Chung, S.W.; Nagarajan, S.S.; Henry, R.G. Accuracy of diffusion tensor magnetic resonance imaging tractography assessed using intraoperative subcortical stimulation mapping and magnetic source imaging. J. Neurosurg. 2007, 107, 488-494. [CrossRef] [PubMed]

211. Mikuni, N.; Okada, T.; Enatsu, R.; Miki, Y.; Hanakawa, T.; Urayama, S.; Kikuta, K.; Takahashi, J.A.; Nozaki, K.; Fukuyama, H.; et al. Clinical impact of integrated functional neuronavigation and subcortical electrical stimulation to preserve motor function during resection of brain tumors. J. Neurosurg. 2007, 106, 593-598. [CrossRef] [PubMed]

212. Neuloh, G.; Simon, M.; Schramm, J. Stroke prevention during surgery for deep-seated gliomas. Neurophysiol. Clin. 2007, 37, 383-389. [CrossRef]

213. Yamaguchi, F.; Takahashi, H.; Teramoto, A. Intra-operative detection of motor pathways using a simple electrode provides safe brain tumor surgery. J. Clin. Neurosci. 2007, 14, 1106-1110. [CrossRef] [PubMed]

214. Fujiki, M.; Furukawa, Y.; Kamida, T.; Anan, M.; Inoue, R.; Abe, T.; Kobayashi, H. Intraoperative corticomuscular motor evoked potentials for evaluation of motor function: A comparison with corticospinal D and I waves. J. Neurosurg. 2006, 104, 85-92. [CrossRef] [PubMed]

215. Okada, T.; Mikuni, N.; Miki, Y.; Kikuta, K.; Urayama, S.; Hanakawa, T.; Fushimi, Y.; Yamamoto, A.; Kanagaki, M.; Fukuyama, H.; et al. Corticospinal tract localization: Integration of diffusion-tensor tractography at 3-T MR imaging with intraoperative white matter stimulation mapping-preliminary results. Radiology 2006, 240, 849-857. [CrossRef] [PubMed]

216. Kamada, K.; Todo, T.; Masutani, Y.; Aoki, S.; Ino, K.; Takano, T.; Kirino, T.; Kawahara, N.; Morita, A. Combined use of tractography-integrated functional neuronavigation and direct fiber stimulation. J. Neurosurg. 2005, 102, 664-672. [CrossRef]

217. Keles, G.E.; Lundin, D.A.; Lamborn, K.R.; Chang, E.F.; Ojemann, G.; Berger, M.S. Intraoperative subcortical stimulation mapping for hemispherical perirolandic gliomas located within or adjacent to the descending motor pathways: Evaluation of morbidity and assessment of functional outcome in 294 patients. J. Neurosurg. 2004, 100, 369-375. [CrossRef] [PubMed] 
218. Kombos, T.; Suess, O.; Brock, M. Prognostic value of improved intraoperative motor evoked potentials. A case report. Zentralbl. Neurochir. 2004, 65, 198-202. [CrossRef] [PubMed]

219. Neuloh, G.; Schramm, J. Monitoring of motor evoked potentials compared with somatosensory evoked potentials and microvascular Doppler ultrasonography in cerebral aneurysm surgery. J. Neurosurg. 2004, 100, 389-399. [CrossRef] [PubMed]

220. Quiñones-Hinojosa, A.; Alam, M.; Lyon, R.; Yingling, C.D.; Lawton, M.T. Transcranial motor evoked potentials during basilar artery aneurysm surgery: Technique application for 30 consecutive patients. Neurosurgery 2004, 54, 916-924; discussion 924. [CrossRef] [PubMed]

221. Sakuma, J.; Suzuki, K.; Sasaki, T.; Matsumoto, M.; Oinuma, M.; Kawakami, M.; Itakura, T.; Kodama, N. Monitoring and preventing blood flow insufficiency due to clip rotation after the treatment of internal carotid artery aneurysms. J. Neurosurg. 2004, 100, 960-962. [CrossRef]

222. Signorelli, F.; Guyotat, J.; Mottolese, C.; Schneider, F.; D'Acunzi, G.; Isnard, J. Intraoperative electrical stimulation mapping as an aid for surgery of intracranial lesions involving motor areas in children. Childs. Nerv. Syst. 2004, 20, 420-426. [CrossRef]

223. Yamamoto, T.; Katayama, Y.; Nagaoka, T.; Kobayashi, K.; Fukaya, C. Intraoperative monitoring of the corticospinal motor evoked potential (D-wave): Clinical index for postoperative motor function and functional recovery. Neurol. Med. Chir. 2004, 44, 170-180; discussion 181-182. [CrossRef] [PubMed]

224. Duffau, H.; Capelle, L.; Denvil, D.; Sichez, N.; Gatignol, P.; Taillandier, L.; Lopes, M.; Mitchell, M.C.; Roche, S.; Muller, J.C.; et al. Usefulness of intraoperative electrical subcortical mapping during surgery for low-grade gliomas located within eloquent brain regions: Functional results in a consecutive series of 103 patients. J. Neurosurg. 2003, 98, 764-778. [CrossRef] [PubMed]

225. Fukaya, C.; Katayama, Y.; Kobayashi, K.; Kasai, M.; Oshima, H.; Yamamoto, T. Impairment of motor function after frontal lobe resection with preservation of the primary motor cortex. Acta. Neurochir. Suppl. 2003, 87, 71-74. [CrossRef]

226. Suess, O.; Kombos, T.; Ciklatekerlio, O.; Stendel, R.; Suess, S.; Brock, M. Impact of brain shift on intraoperative neurophysiological monitoring with cortical strip electrodes. Acta. Neurochir. 2002, 144, 1279-1289; discussion 1289. [CrossRef] [PubMed]

227. Kombos, T.; Suess, O.; Pietilä, T.; Brock, M. Subdural air limits the elicitation of compound muscle action potentials by highfrequency transcranial electrical stimulation. Br. J. Neurosurg. 2000, 14, 240-243. [CrossRef] [PubMed]

228. Kofler, M.; Morota, N.; Deletis, V. Preserved motor evoked potentials fail to predict functional outcome in quadriplegia because of bilateral lesions of the supplementary motor areas: A brief report. Am. J. Phys. Med. Rehabil. 1999, 78, 66-71. [CrossRef]

229. Kombos, T.; Suess, O.; Kern, B.C.; Funk, T.; Hoell, T.; Kopetsch, O.; Brock, M. Comparison between monopolar and bipolar electrical stimulation of the motor cortex. Acta. Neurochir. 1999, 141, 1295-1301. [CrossRef] [PubMed]

230. Rohde, V.; Will, B.E.; Hahn, G.; Bien, S.; Zentner, J. Motorisch evozierte Potentiale während der Embolisation arteriovenöser Malformationen zur Erfassung ischämischer Komplikationen [Motor evoked potentials during embolization of arteriovenous malformations for the detection of ischemic complications]. Zentralbl. Neurochir. 1999, 60, 74-80. [PubMed]

231. Yingling, C.D.; Ojemann, S.; Dodson, B.; Harrington, M.J.; Berger, M.S. Identification of motor pathways during tumor surgery facilitated by multichannel electromyographic recording. J. Neurosurg. 1999, 91, 922-927. [CrossRef]

232. Krombach, G.A.; Spetzger, U.; Rohde, V.; Gilsbach, J.M. Intraoperative localization of functional regions in the sensorimotor cortex by neuronavigation and cortical mapping. Comput. Aided. Surg. 1998, 3, 64-73. [CrossRef]

233. Zentner, J.; Meyer, B. Diagnostic significance of MEP elicited by electrical and magnetoelectric stimulation in acute/subacute supratentorial lesions. Electromyogr. Clin. Neurophysiol. 1998, 38, 33-40. [PubMed]

234. Kawaguchi, M.; Sakamoto, T.; Ohnishi, H.; Shimizu, K.; Karasawa, J.; Furuya, H. Intraoperative myogenic motor evoked potentials induced by direct electrical stimulation of the exposed motor cortex under isoflurane and sevoflurane. Anesth. Analg. 1996, 82, 593-599. [CrossRef]

235. Maertens de Noordhout, A.; Born, J.D.; Hans, P.; Remacle, J.M.; Delwaide, P.J. Intraoperative localisation of the primary motor cortex using single electrical stimuli. J. Neurol. Neurosurg. Psychiatry 1996, 60, 442-444. [CrossRef] [PubMed]

236. Pechstein, U.; Cedzich, C.; Nadstawek, J.; Schramm, J. Transcranial high-frequency repetitive electrical stimulation for recording myogenic motor evoked potentials with the patient under general anesthesia. Neurosurgery 1996, 39, 335-343; discussion 343-344. [CrossRef]

237. Rodi, Z.; Deletis, V.; Morota, N.; Vodusek, D.B. Motor evoked potentials during brain surgery. Pflug. Arch. 1996, 431, R291-R292. [CrossRef] [PubMed]

238. Skirboll, S.S.; Ojemann, G.A.; Berger, M.S.; Lettich, E.; Winn, H.R. Functional cortex and subcortical white matter located within gliomas. Neurosurgery 1996, 38, 678-684; discussion 684-685. [CrossRef] [PubMed]

239. Ebeling, U.; Schmid, U.D.; Ying, H.; Reulen, H.J. Safe surgery of lesions near the motor cortex using intra-operative mapping techniques: A report on 50 patients. Acta. Neurochir. 1992, 119, 23-28. [CrossRef] [PubMed]

240. Schramm, J.; Koht, A.; Schmidt, G.; Pechstein, U.; Taniguchi, M.; Fahlbusch, R. Surgical and electrophysiological observations during clipping of 134 aneurysms with evoked potential monitoring. Neurosurgery 1990, 26, 61-70. [CrossRef] [PubMed]

241. Zentner, J.; Schumacher, M.; Bien, S. Motor evoked potentials during interventional neuroradiology. Neuroradiology 1988, 30, 252-255. [CrossRef]

242. Chen, D.F.; Willie, J.T.; Cabrera, D.; Bullinger, K.L.; Karakis, I. Continuous Intraoperative Neurophysiological Monitoring of the Motor Pathways Using Depth Electrodes During Surgical Resection of an Epileptogenic Lesion: A Novel Technique. Oper. Neurosurg. 2021, 20, E379-E385. [CrossRef] [PubMed] 
243. Machetanz, K.; Gallotti, A.L.; Leao Tatagiba, M.T.; Liebsch, M.; Trakolis, L.; Wang, S.; Tatagiba, M.; Gharabaghi, A.; Naros, G. Time-Frequency Representation of Motor Evoked Potentials in Brain Tumor Patients. Front. Neurol. 2021, 11, 633224. [CrossRef]

244. Cattaneo, L.; Giampiccolo, D.; Meneghelli, P.; Tramontano, V.; Sala, F. Cortico-cortical connectivity between the superior and inferior parietal lobules and the motor cortex assessed by intraoperative dual cortical stimulation. Brain. Stimul. 2020, 13, 819-831. [CrossRef] [PubMed]

245. Kang, P.B.; McMillan, H.J.; Kuntz, N.L.; Lehky, T.J.; Alter, K.E.; Fitzpatrick, K.F.; El Kosseifi, C.; Quijano-Roy, S. Utility and practice of electrodiagnostic testing in the pediatric population: An AANEM consensus statement. Muscle Nerve 2020, 61, 143-155. [CrossRef] [PubMed]

246. Policicchio, D.; Ticca, S.; Dipellegrini, G.; Doda, A.; Muggianu, G.; Boccaletti, R. Multimodal Surgical Management of Cerebral Lesions in Motor-Eloquent Areas Combining Intraoperative 3D Ultrasound with Neurophysiological Mapping. J. Neurol. Surg. A Cent. Eur. Neurosurg. 2020. [CrossRef]

247. Shibata, S.; Yamao, Y.; Kunieda, T.; Inano, R.; Nakae, T.; Nishida, S.; Inada, T.; Takahashi, Y.; Kikuchi, T.; Arakawa, Y.; et al. Intraoperative Electrophysiologic Mapping of Medial Frontal Motor Areas and Functional Outcomes. World Neurosurg. 2020, 138, e389-e404. [CrossRef] [PubMed]

248. Wang, M.; Li, Z.; Fan, X.; Tao, X.; Qi, L.; Ling, M.; Guo, D.; Qiao, H. A prediction of postoperative neurological deficits following intracranial aneurysm surgery using somatosensory evoked potential deterioration duration. Neurosurg. Rev. 2020, 43, 293-299. [CrossRef]

249. Zuo, F.; Hu, K.; Kong, J.; Zhang, Y.; Wan, J. Surgical Management of Brain Metastases in the Perirolandic Region. Front. Oncol. 2020, 10, 572644. [CrossRef] [PubMed]

250. ClinicalTrials.gov. National Library of Medicine (U.S.). (2011 Apr 8- 2013 Nov 9). Early Neurophysiological Interventions in Acute Cerebral Lesions. Identifier NCT04178395. Available online: https:/ / linicaltrials.gov/ct2/show/NCT04178395?cond= NCT04178395\&draw=2\&rank=1 (accessed on 22 April 2021).

251. Hiruta, R.; Fujii, M.; Furukawa, Y.; Ichikawa, T.; Suzuki, K.; Watanabe, Y.; Nemoto, M.; Sato, T.; Sakuma, J.; Saito, K. Corticospinal Tract Mapping by Calculating the Ratio of Subcortical to Cortical Stimulation Intensity: A Technical Note. No Shinkei Geka. 2019, 47, 957-960. [CrossRef] [PubMed]

252. Rajan, S.; Sharma, D. Neuroanesthesia and Monitoring for Cranial and Complex Spinal Surgery. In Principles of Neurological Surgery, 4th ed.; Elsevier: Amsterdam, The Netherlands, 2018; pp. 87-102; ISBN 978-03-2343-140-8.

253. Valci, L.; Dalolio, M.; Kuhlen, D.; Pravatà, E.; Gobbi, C.; Reinert, M. Intradiploic encephalocele of the primary motor cortex in an adult patient: Electrophysiological implications during surgery. J. Neurosurg. 2018, 128, 871-874. [CrossRef] [PubMed]

254. Abdulrauf, S.I.; Vuong, P.; Patel, R.; Sampath, R.; Ashour, A.M.; Germany, L.M.; Lebovitz, J.; Brunson, C.; Nijjar, Y.; Dryden, J.K.; et al. "Awake" clipping of cerebral aneurysms: Report of initial series. J. Neurosurg. 2017, 127, 311-318. [CrossRef]

255. Benavides, F.D.; Santamaria, A.J.; Bodoukhin, N.; Guada, L.G.; Solano, J.P.; Guest, J.D. Characterization of Motor and Somatosensory Evoked Potentials in the Yucatan Micropig Using Transcranial and Epidural Stimulation. J. Neurotrauma. 2017, 34, 2595-2608. [CrossRef] [PubMed]

256. Bharadwaj, S.; Haji, F.; Hebb, M.; Chui, J. Direct motor evoked potentials and cortical mapping using the NIM ${ }^{\circledR}$ nerve monitoring system: A technical note. J. Clin. Neurosci. 2017, 38, 111-113. [CrossRef] [PubMed]

257. Calancie, B. Intraoperative Neuromonitoring and Alarm Criteria for Judging MEP Responses to Transcranial Electric Stimulation: The Threshold-Level Method. J. Clin. Neurophysiol. 2017, 34, 12-21. [CrossRef] [PubMed]

258. Grasso, G.; Landi, A.; Alafaci, C. Multimodal Intraoperative Neuromonitoring in Aneurysm Surgery. World.Neurosurg. 2017, 101, 763-765. [CrossRef] [PubMed]

259. Hemmer, L.B.; Zeeni, C. Intracranial Arteriovenous Malformation Surgery. In Monitoring the Nervous System for Anesthesiologists and Other Health Care Professionals; Springer International Publishing: New York, NY, USA, 2017; pp. 367-376; ISBN 978-33-1946$542-5$.

260. Ku, J.; Mendelsohn, D.; Chew, J.; Shewchuk, J.; Dong, C.; Akagami, R. Ipsilateral Motor Innervation Discovered Incidentally on Intraoperative Monitoring: A Case Report. Neurosurgery 2017, 80, E194-E200. [CrossRef]

261. Moser, T.; Bulubas, L.; Sabih, J.; Conway, N.; Wildschutz, N.; Sollmann, N.; Meyer, B.; Ringel, F.; Krieg, S.M. Resection of Navigated Transcranial Magnetic Stimulation-Positive Prerolandic Motor Areas Causes Permanent Impairment of Motor Function. Neurosurgery 2017, 81, 99-110. [CrossRef]

262. Alimohamadi, M.; Shirani, M.; Shariat Moharari, R.; Pour-Rashidi, A.; Ketabchi, M.; Khajavi, M.; Arami, M.; Amirjamshidi, A. Application of Awake Craniotomy and Intraoperative Brain Mapping for Surgical Resection of Insular Gliomas of the Dominant Hemisphere. World Neurosurg. 2016, 92, 151-158. [CrossRef] [PubMed]

263. Coppola, A.; Tramontano, V.; Basaldella, F.; Arcaro, C.; Squintani, G.; Sala, F. Intra-operative neurophysiological mapping and monitoring during brain tumour surgery in children: An update. Childs. Nerv. Syst. 2016, 32, 1849-1859. [CrossRef]

264. König, R. Surgical therapy of aneurysms. In Spontaneous Subarachnoid Haemorrhage: Well-Known and New Approaches, 1st ed.; Nova Science Publishers Inc.: New York, NY, USA, 2016; pp. 81-89; ISBN 978-16-3485-270-8.

265. Raabe, A.; Seidel, K. Prevention of ischemic complications during aneurysm surgery. J. Neurosurg. Sci. 2016, 60, 95-103. [PubMed]

266. Yao, A.; Sarkiss, C.A.; Lee, J.; Zarzour, H.K.; Shrivastava, R.K. Surgical limitations in convexity meningiomas en-plaque: Is radical resection necessary? J. Clin. Neurosci. 2016, 27, 28-33. [CrossRef] [PubMed] 
267. Ottenhausen, M.; Krieg, S.M.; Meyer, B.; Ringel, F. Functional preoperative and intraoperative mapping and monitoring: Increasing safety and efficacy in glioma surgery. Neurosurg. Focus 2015, 38, E3. [CrossRef] [PubMed]

268. Nakamura, K.; Ikedo, T.; Sano, N.; Okada, Y.; Murata, T. Aneurysm and Vascular Malformations Transcranial electric motorevoked potentials monitoring for intracranial aneurysm surgery: WSC-1330. Int. J. Stroke 2014, 9, 123. [CrossRef]

269. Suzuki, K.; Mikami, T.; Sugino, T.; Wanibuchi, M.; Miyamoto, S.; Hashimoto, N.; Mikuni, N. Discrepancy between voluntary movement and motor-evoked potentials in evaluation of motor function during clipping of anterior circulation aneurysms. World Neurosurg. 2014, 82, e739-e745. [CrossRef] [PubMed]

270. Yang, T.F.; Chen, H.H.; Liang, M.L.; Chen, C.; Chiu, J.W.; Wang, J.C.; Lai, C.J.; Liao, K.K.; Chan, R.C. Intraoperative brain mapping to identify corticospinal projections during resective epilepsy surgery in children with congenital hemiparesis. Child's Nerv. Syst. 2014, 30, 1559-1564. [CrossRef] [PubMed]

271. Landazuri, P.; Eccher, M. Simultaneous direct cortical motor evoked potential monitoring and subcortical mapping for motor pathway preservation during brain tumor surgery: Is it useful? J. Clin. Neurophysiol. 2013, 30, 623-625. [CrossRef] [PubMed]

272. Rajapakse, T.; Kirton, A. Non-invasive brain stimulation in children: Applications and future directions. Transl. Neurosci. 2013, 4, 217-233. [CrossRef]

273. Yamashita, S.; Sasaki, O.; Suzuki, K.; Takao, T.; Nakamura, K.; Koike, T. Transcranial motor evoked potentials monitoring for cerebral aneurysm surgery. No Shinkei Geka. Neurol. Surg. 2013, 41, 15-24.

274. Bacigaluppi, S.; Fontanella, M.; Manninen, P.; Ducati, A.; Tredici, G.; Gentili, F. Monitoring techniques for prevention of procedure-related ischemic damage in aneurysm surgery. World Neurosurg. 2012, 78, 276-288. [CrossRef] [PubMed]

275. De Witt Hamer, P.C.; Robles, S.G.; Zwinderman, A.H.; Duffau, H.; Berger, M.S. Impact of intraoperative stimulation brain mapping on glioma surgery outcome: A meta-analysis. J. Clin. Oncol. 2012, 30, 2559-2565. [CrossRef] [PubMed]

276. Emerson, R.G.; Adams, D.C. Intraoperative Monitoring by Evoked Potential Techniques. In Aminoff's Electrodiagnosis in Clinical Neurology; Elsevier: Amsterdam, The Netherlands, 2012; pp. 651-670; ISBN 978-14-5570-308-1.

277. Hotson, G.; Fifer, M.S.; Acharya, S.; Anderson, W.S.; Thakor, N.V.; Crone, N.E. Electrocorticographic decoding of ipsilateral reach in the setting of contralateral arm weakness from a cortical lesion. Annu. Int. Conf. IEEE. Eng. Med. Biol. Soc. 2012, 2012, 4104-4107. [CrossRef] [PubMed]

278. Ito, Z.; Imagama, S.; Sakai, Y.; Katayama, Y.; Wakao, N.; Ando, K.; Hirano, K.; Tauchi, R.; Muramoto, A.; El Zahlawy, H.; et al. A new criterion for the alarm point for compound muscle action potentials. J. Neurosurg. Spine. 2012, 17, 348-356. [CrossRef] [PubMed]

279. Guo, L.; Gelb, A.W. False negatives, muscle relaxants, and motor-evoked potentials. J. Neurosurg. Anesthesiol. 2011, $23,64$. [CrossRef] [PubMed]

280. Li, F.; Deshaies, E.M.; Allott, G.; Canute, G.; Gorji, R. Direct cortical stimulation but not transcranial electrical stimulation motor evoked potentials detect brain ischemia during brain tumor resection. Am. J. Electroneurodiagnostic. Technol. 2011, 51, 191-197. [CrossRef]

281. Deiner, S. Highlights of anesthetic considerations for intraoperative neuromonitoring. Semin. Cardiothorac. Vasc. Anesth. 2010, 14, 51-53. [CrossRef]

282. Pabon, B.; Vargas, S.; Franco, A.; Arias, J.F. Intraoperative neurophysiological monitoring and provocative test during endovascular treatment of avms. Neuroradiol. J. 2010, 23, 333.

283. Lefaucheur, J.P.; de Andrade, D.C. Intraoperative neurophysiologic mapping of the central cortical region for epidural electrode placement in the treatment of neuropathic pain by motor cortex stimulation. Brain Stimul. 2009, 2, 138-148. [CrossRef] [PubMed]

284. Sun, W.; Fu, W.; Wang, D.; Wang, Y. Ipsilateral responses of motor evoked potential correlated with the motor functional outcomes after cortical resection. Int. J. Psychophysiol. 2009, 73, 377-382. [CrossRef] [PubMed]

285. Duffau, H. Intraoperative neurophysiology during surgery for cerebral tumor. In Handbook of Clinical Neurophysiology; Elsevier: Amsterdam, The Netherlands, 2008; pp. 491-507; ISBN 978-04-4451-824-8.

286. Duffau, H. New insights into functional mapping in cerebral tumor surgery. In New Insights into Functional Mapping in Cerebral Tumor Surgery, 1st ed.; Nova Science Publishers Inc.: New York, NY, USA, 2008; pp. 1-95; ISBN 978-16-0692-136-4.

287. Takashima, K.; Takahashi, M.; Yubune, N.; Inaba, N.; Omoto, K.; Kawano, M.; Sakurabayashi, I.; Ishikawa, M.; Kusaka, G.; Shinoda, S. Evoked potential monitoring in an operation of neurosurgery. Rinsho Byori 2008, 56, 475-485. [PubMed]

288. Duffau, H. Contribution of cortical and subcortical electrostimulation in brain glioma surgery: Methodological and functional considerations. Neurophysiol. Clin. 2007, 37, 373-382. [CrossRef]

289. Tharin, S.; Golby, A. Functional brain mapping and its applications to neurosurgery. Neurosurgery 2007, 60, 185-201; discussion 201-202. [CrossRef] [PubMed]

290. Duffau, H. New concepts in surgery of WHO grade II gliomas: Functional brain mapping, connectionism and plasticity-A review. J. Neurooncol. 2006, 79, 77-115. [CrossRef] [PubMed]

291. Schramm, J.; Neuloh, G. Brain surgery and endangared motor function: What MEP monitoring adds to mapping techniques. Riv. Med. 2006, 12, 67.

292. Shinoura, N.; Suzuki, Y.; Yamada, R.; Kodama, T.; Takahashi, M.; Yagi, K. Restored activation of primary motor area from motor reorganization and improved motor function after brain tumor resection. AJNR Am. J. Neuroradiol. 2006, 27, 1275-1282. [PubMed]

293. Kuzniecky, R.I.; Jackson, G.D. Extra-temporal lobe epilepsy. In Magnetic Resonance in Epilepsy; Elsevier: Amsterdam, The Netherlands, 2005; pp. 177-196; ISBN 978-01-2431-152-7. 
294. Binder, D.K.; Lyon, R.; Manley, G.T. Transcranial motor evoked potential recording in a case of Kernohan's notch syndrome: Case report. Neurosurgery 2004, 54, 999-1002; discussion 1002-1003. [CrossRef] [PubMed]

295. Hashiguchi, K.; Morioka, T.; Fukui, K.; Kawamura, T.; Shono, T.; Sakaki, T. Postoperative transient hemiplegia after resection of the medial frontal tumor involving the supplementary motor area: Report of two cases. No Shinkei Geka. Neurol. Surg. 2004, 32, 947-953.

296. Kondo, R.; Saito, S.; Kuroki, A.; Sato, S.; Katakura, K.; Kayama, T. Significance and usefulness of corticospinal motor evoked potential monitoring for lesions adjacent to primary motor cortex. No To Shinkei 2004, 56, 496-502. [PubMed]

297. Neuloh, G.; Schramm, J. Motor evoked potential monitoring for the surgery of brain tumours and vascular malformations. Adv. Tech. Stand. Neurosurg. 2004, 29, 171-228. [CrossRef] [PubMed]

298. Di Lazzaro, V.; Oliviero, A.; Profice, P.; Ferrara, L.; Saturno, E.; Pilato, F.; Tonali, P. The diagnostic value of motor evoked potentials. Clin. Neurophysiol. 1999, 110, 1297-1307. [CrossRef]

299. Calancie, B.; Harris, W.; Broton, J.G.; Alexeeva, N.; Green, B.A. "Threshold-level" multipulse transcranial electrical stimulation of motor cortex for intraoperative monitoring of spinal motor tracts: Description of method and comparison to somatosensory evoked potential monitoring. J. Neurosurg. 1998, 88, 457-470. [CrossRef]

300. Reinhardt, H.F.; Trippel, M.; Westermann, B.; Horstmann, G.A.; Gratzl, O. Computer assisted brain surgery for small lesions in the central sensorimotor region. Acta. Neurochir. 1996, 138, 200-205. [CrossRef] [PubMed]

301. Newlon, P.G.; Greenberg, R.P. Evoked potentials in severe head injury. J. Trauma. 1984, 24, 61-66. [CrossRef] [PubMed] 